\title{
FULL-SCALE EXPERIMENTS TO INVESTIGATE THE USE OF A WATER CURTAIN OVER OPENINGS TO PREVENT FIRE SPREAD TO ADJACENT PROPERTIES
}

\author{
A thesis submitted to \\ the Faculty of Graduate and Postdoctoral Affairs \\ in Partial Fulfillment of the requirements for the degree \\ Master of Applied Science
}

By

\author{
Matt Turco \\ BEng. Civil \\ Department of Civil and Environmental Engineering \\ Carleton University \\ Ottawa-Carleton Institute of Civil and Environmental Engineering \\ June 2015 \\ C2015 Matt Turco
}




\section{ABSTRACT}

This thesis presents the results of several full-scale experiments to study heat radiation attenuation and shielding using sprinklers to create a water curtain between a compartment fire and a target wall. This work builds on the idea that water absorbs and scatters heat radiation and applies it as a shielding mechanism, which can be used to protect personnel and property exposed to an opening during a compartment fire. The purpose of the study is to determine how effective the water curtain created using sprinkler heads will be at attenuating the heat flux from flames exiting a compartment fire, shielding the target wall and preventing fire spread. The results show how the water spray reduces heat flux to the target wall and it allows decreasing the distance of a building from the property line. Heat fluxes along the target wall are compared to heat fluxes required for the piloted ignition of wood products. The effects of fire size, sprinkler system flow rate, and separation distance to the target wall are discussed.

The test room was $4 \mathrm{~m} \times 3 \mathrm{~m} \times 3 \mathrm{~m}$ high with an opening of $2 \mathrm{~m} \times 1.5 \mathrm{~m}$ high. The front wall of the room extended to $3 \mathrm{~m}$ above the roof of the room. To create the water curtain three sprinkler heads were used at a spacing of $2 \mathrm{~m}$ apart outside of the compartment just above the opening. The sprinklers were centred in the middle of the compartment opening. Five heat flux meters and five thermocouples were placed vertically along the centre of the target wall and three heat flux meters and three thermocouples were placed vertically along the centre of the extension wall. The fire used propane as the fuel, which ensured that a constant heat release rate was produced and maintained during the tests. Sprinkler flow rates were monitored using a flow meter and a pressure gauge located near the pump.

Tests were initially run with no sprinkler flow to determine fire heat fluxes on the target and extension walls. These heat fluxes are used as a baseline to determine the effectiveness of the water curtain in attenuating the heat fluxes. Tests were run until the heat flux readings along the target wall reached steady state. 
From the tests performed it can be seen that the presence of the water curtain results in a considerable decrease in the heat fluxes on the target wall and the compartment extension wall. The target wall never experienced a heat flux greater than $12.5 \mathrm{~kW} / \mathrm{m}^{2}$. This value was only exceeded when the target wall was close enough to be hit with the water spray from the sprinklers. While this heat flux is greater than that required for piloted ignition of wood products, ignition is unlikely to occur as the wall will be wet and there should be no sparks getting through the water curtain. 


\section{ACKNOWLEDGEMENTS}

First, I would like to thank my supervisor, Professor George Hadjisophocleous for his guidance and encouragement throughout my time in the Fire Safety Engineering program. I would also like to thank Ba Lamthien for all the work he put into helping me prepare and conduct my experiments for this research at the Carleton University Fire Research Lab in Carleton Place. In addition, I would like to thank both Carleton University and the National Research Council of Canada for making available the research facilities and to their staff for their assistance throughout the process of conducting this research.

I would like to thank Paul Lhotsky of Civelec Consultants for providing me with funding and materials necessary to complete this study, and for his assistance in helping conduct this research. The financial support of NSERC is also appreciated.

Lastly a big thank you to my family and friends who have supported me throughout my studies and put up with my stories of success and failures of burning rooms. 


\section{Table of Contents}

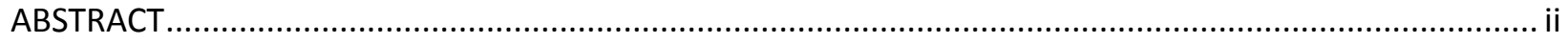

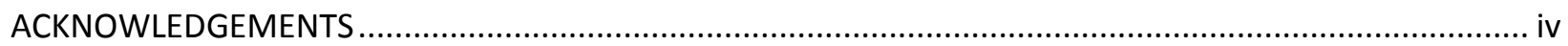

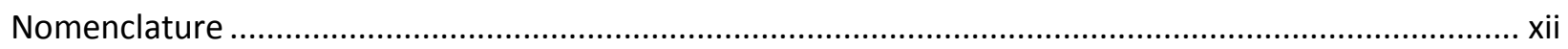

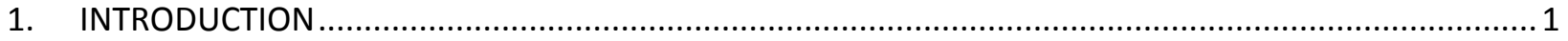

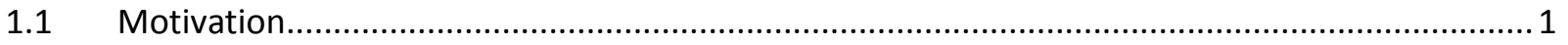

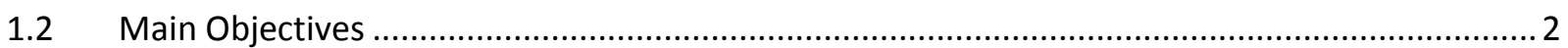

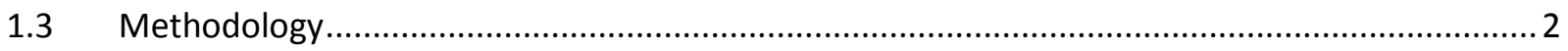

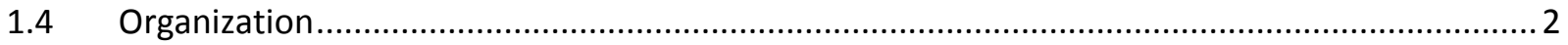

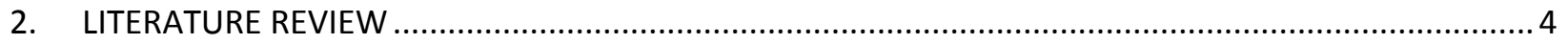

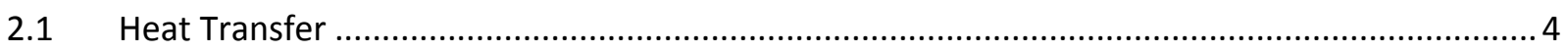

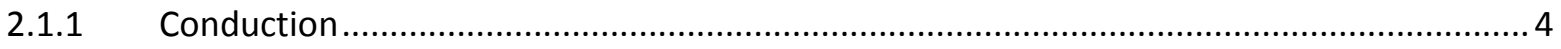

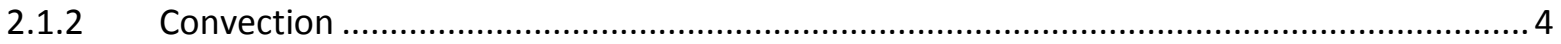

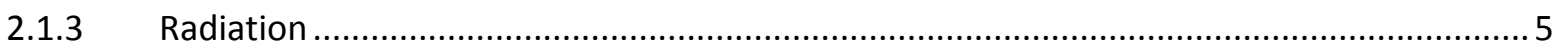

2.1.4 Configuration Factor .......................................................................................

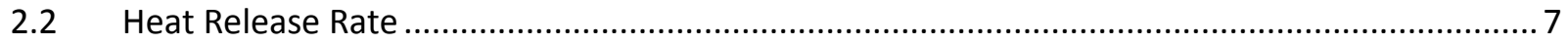

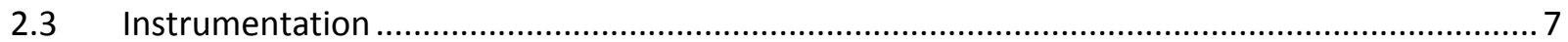

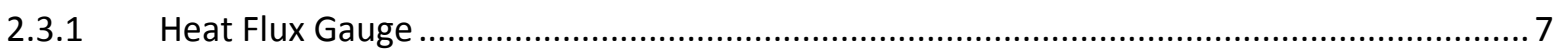

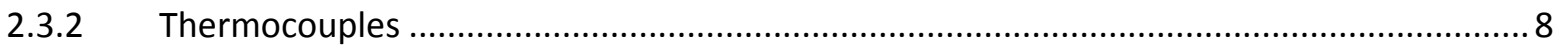

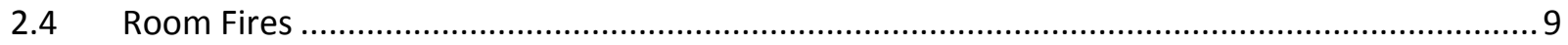

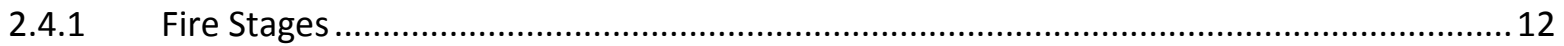

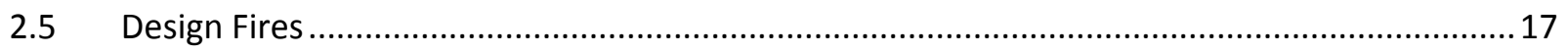

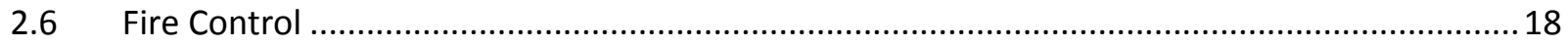

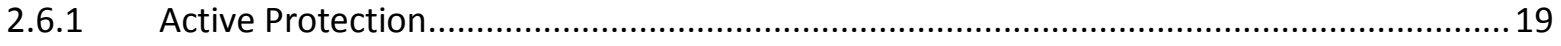

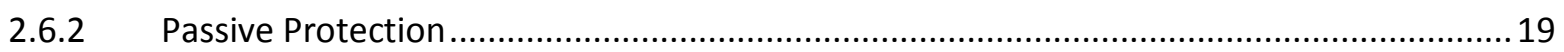

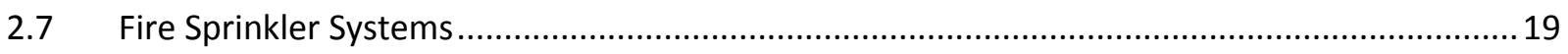

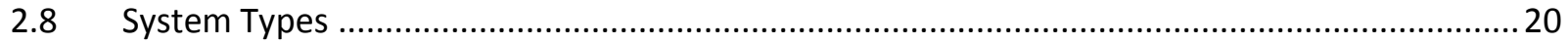

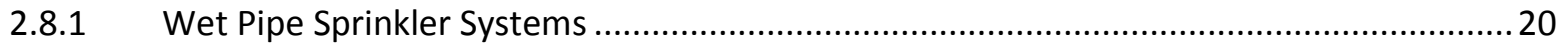

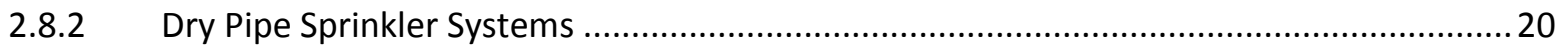

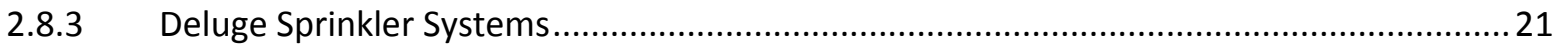

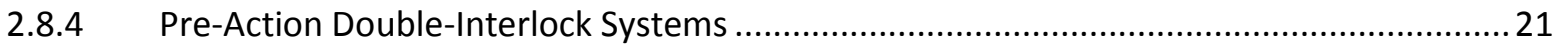

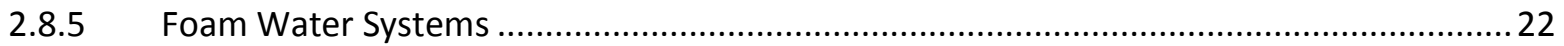




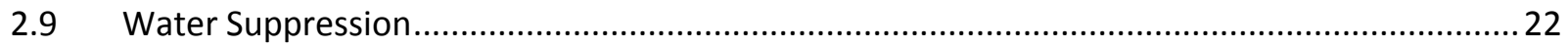

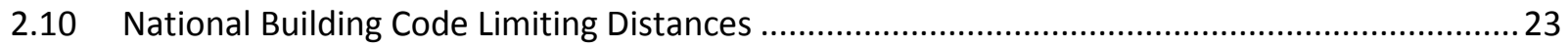

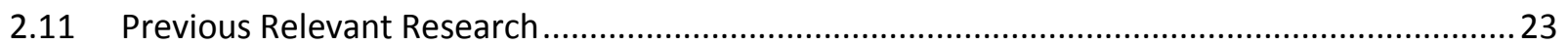

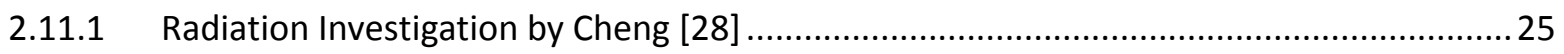

2.11.2 Water Mist Suppression by Kermida [29] ....................................................................... 30

2.11.3 Thermal and Smoke Blockage by Water Curtains Chow [35] .......................................... 34

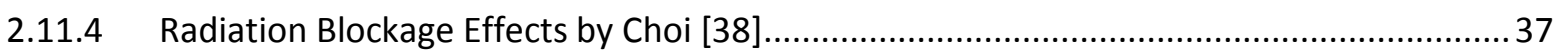

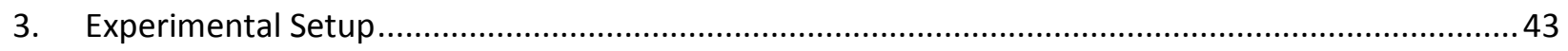

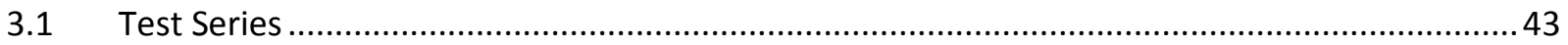

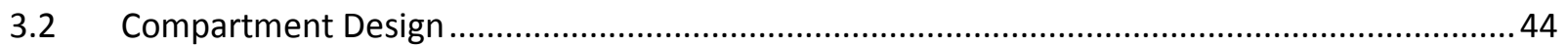

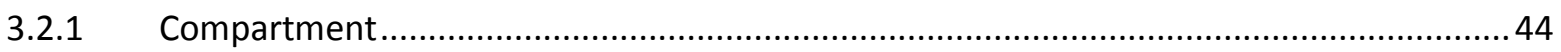

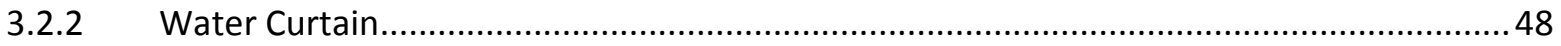

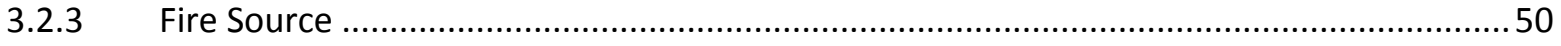

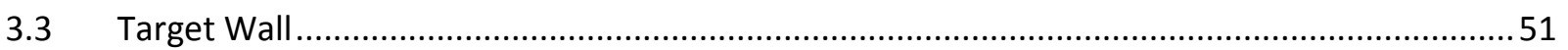

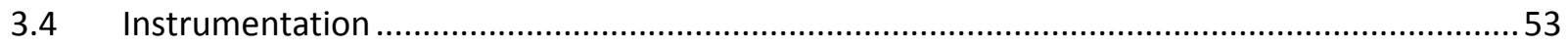

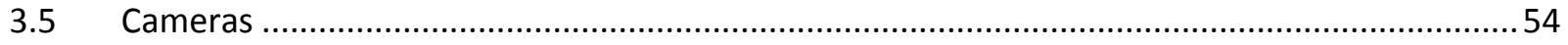

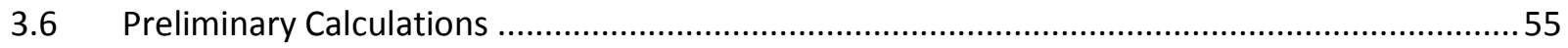

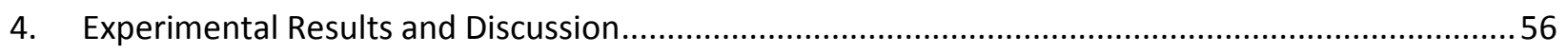

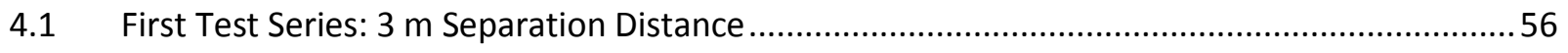

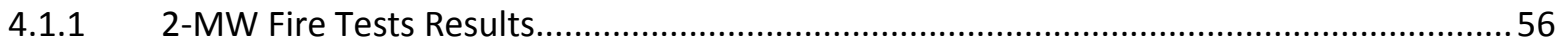

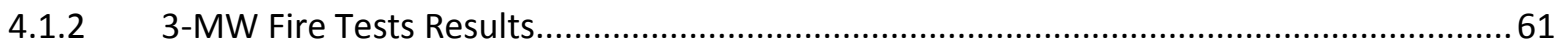

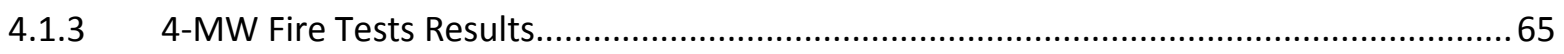

4.2 Second Test Series: 4 m Separation Distance .......................................................................69

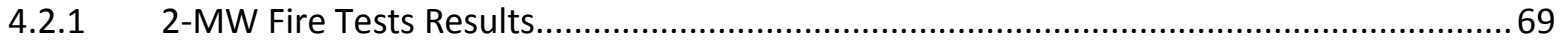

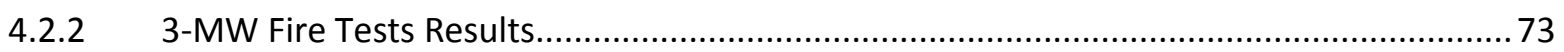

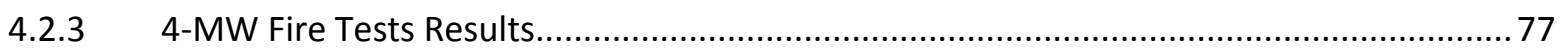

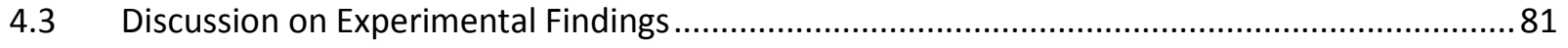

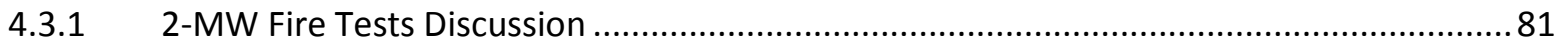

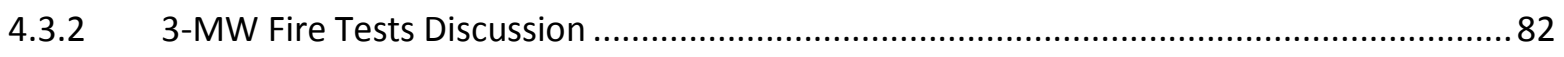

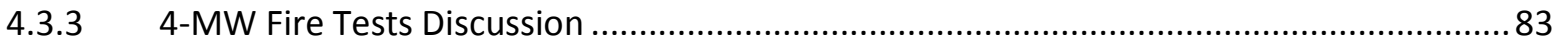

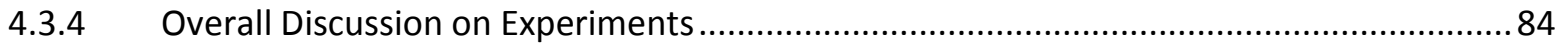

4.3.5 Comparison with National Building Code of Canada .................................................... 85 


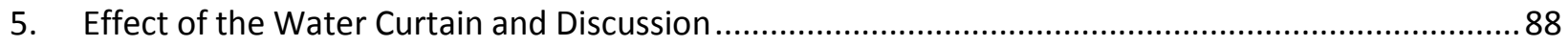

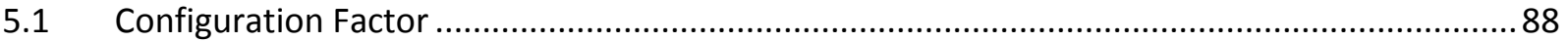

5.2 Compartment Temperature

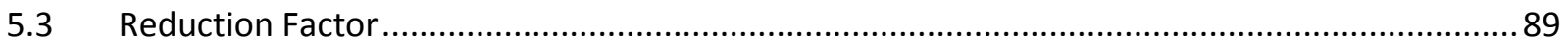

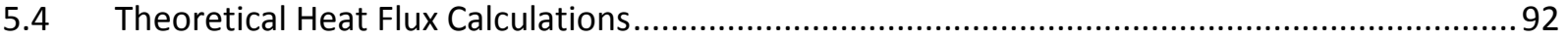

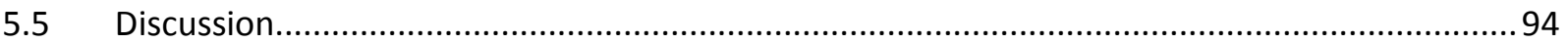

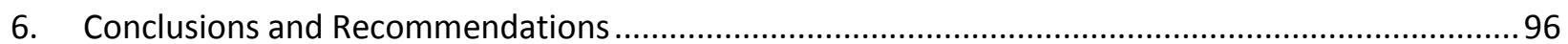

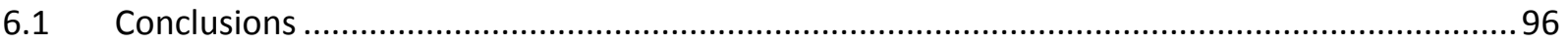

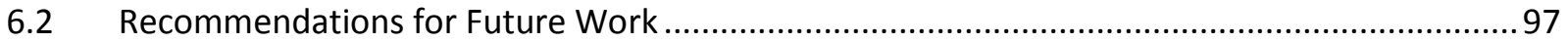

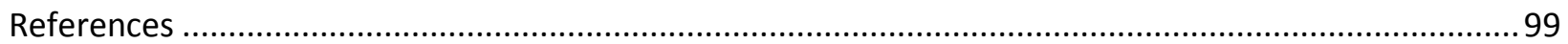

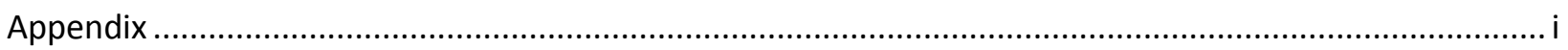

Appendix A …

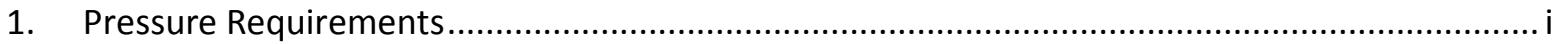

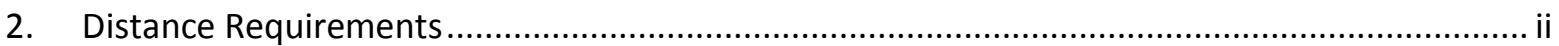




\section{List of Figures}

Figure 2.1 - Components of a radiation source used to determine the total configuration factor

Figure 2.2 - Individual component used to determine the configuration factor for the individual component..... 6

Figure 2.3 - Gardon gauge used at the Carleton University Fire Research Lab..................................... 8

Figure 2.4 - Typical K-Type Thermocouple used at the Carleton University Research Lab........................ 9

Figure 2.5 - The effect of an enclosure on the mass loss rate during combustion [5]........................... 10

Figure 2.6 - Stages of fire development in room without suppression based on temperature [11] .........11

Figure 2.7 - Stages of fire development in room without suppression based on heat release rate [12] ..11

Figure 2.8 - Fire growth following the incubation period [15] ........................................................ 12

Figure 2.9 - Fire Growth Rates based on Heat Release Rate [15] ....................................................... 14

Figure 2.10 - Vent flows for well mixed room with uniform temperature where $T_{g}>T_{a}[5] \ldots \ldots \ldots \ldots \ldots \ldots . . .15$

Figure 2.11 - Example of a simple design fire curve [5] ................................................................... 18

Figure 2.12 - Experimental results illustrating the temperature effects [28] ......................................26

Figure 2.13 - Experimental results illustrating the influence of radiation heat flux [28]........................29

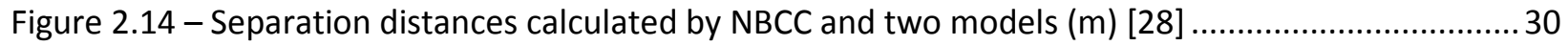

Figure 2.15 - A schematic representation of the radiant attenuation through water mist, due to absorption and scattering by the droplets [29]

Figure 2.16 - Experimental and predicted radiation flux at the end of the flame region, for the $53 \mathrm{~kW}$

flame, before and after application of the spray [29]

Figure 2.17 - Experimental and predicted radiation flux at the end of the flame region, for the $26.5 \mathrm{~kW}$

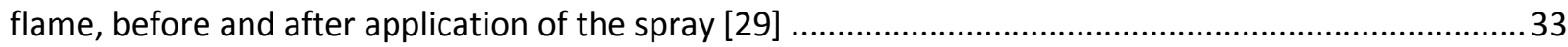

Figure 2.18 - Experimental setup of radiation attenuation of pool fires [35] ........................................ 35

Figure 2.19 - Summary of the results of the three nozzles [35] ......................................................... 35

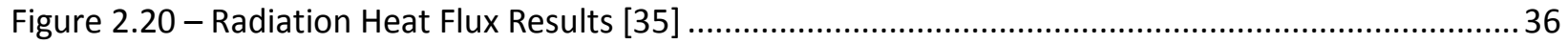

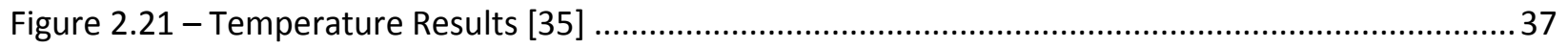

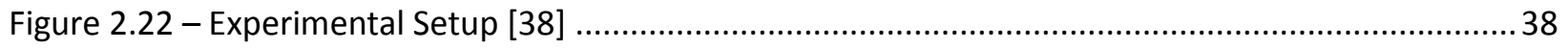

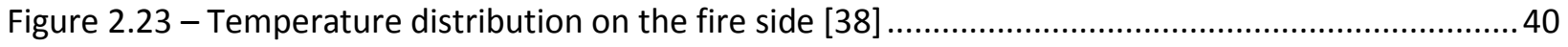

Figure 2.24 - Temperature distribution on the protected side [38] …................................................40

Figure 2.25 - Maximum temperature (T7) at fire side under different operating conditions [38] ............41

Figure 2.26 - Maximum temperature (T7') at protected side under different operating conditions [38] 41 
Figure 2.27 - Heat flux at protected side under different operating conditions [38] ............................ 42

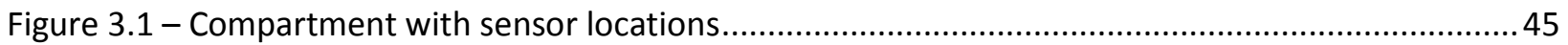

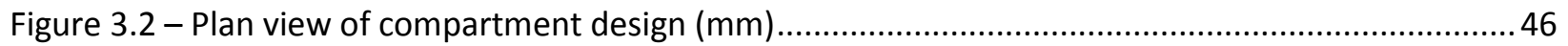

Figure 3.3 - Front View of the compartment with sensor locations $(\mathrm{mm})$......................................... 47

Figure 3.4 - Section of insulation that was damaged during testing................................................... 48

Figure 3.5 - Sprinkler pump, flowmeter, and controls ..................................................................... 50

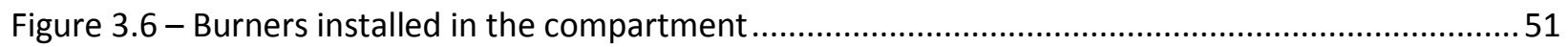

Figure 3.7 - Propane burners installed in the compartment and control valves at the rear ...................51

Figure 3.8 - Built target wall with sensor locations ........................................................................... 52

Figure 3.9 - Front View of the designed target wall with sensor locations ............................................53

Figure 4.1 - Target wall heat flux results for the 2-MW fire at a separation distance of $3 \mathrm{~m} . . . \ldots \ldots \ldots \ldots \ldots . . . . . .58$

Figure 4.2 - Façade wall heat flux results for the 2-MW fire at a separation distance of $3 \mathrm{~m}$..................58

Figure 4.3 - Target wall temperature results for the 2-MW fire at a separation distance of $3 \mathrm{~m} \mathrm{.............60}$

Figure 4.4 - Facade wall temperature results for the 2-MW fire at a separation distance of $3 \mathrm{~m}$...........60

Figure 4.5 - Target wall heat flux results for the 3-MW fire at a separation distance of $3 \mathrm{~m} . . . \ldots \ldots \ldots \ldots \ldots . . . . . .62$

Figure 4.6 - Façade wall heat flux results for the 3-MW fire at a separation distance of $3 \mathrm{~m} . . . \ldots \ldots \ldots . . . . . . . .62$

Figure 4.7 - Target wall temperature results for the 3-MW fire at a separation distance of $3 \mathrm{~m}$............64

Figure 4.8 - Façade wall temperature results for the 3-MW fire at a separation distance of $3 \mathrm{~m}$............64

Figure 4.9 - Target wall heat flux results for the 4-MW fire at a separation distance of $3 \mathrm{~m} \ldots \ldots \ldots \ldots \ldots \ldots . . . . .66$

Figure 4.10 - Façade wall heat flux results for the 4-MW fire at a separation distance of $3 \mathrm{~m} . . . \ldots \ldots \ldots \ldots . . . .66$

Figure 4.11 - Target wall temperature results for the 4-MW fire at a separation distance of $3 \mathrm{~m}$..........68

Figure 4.12 - Façade wall temperature results for the 4-MW fire at a separation distance of $3 \mathrm{~m}$..........68

Figure 4.13 - Target wall heat flux results for the 2-MW fire at a separation distance of $4 \mathrm{~m}$.................. 70

Figure 4.14 - Façade wall heat flux results for the 2-MW fire at a separation distance of $4 \mathrm{~m} . . . . . . . . . . . . . . .71$

Figure 4.15 - Target wall temperature results for the 2-MW fire at a separation distance of $4 \mathrm{~m} \ldots \ldots \ldots . . .72$

Figure 4.16 - Façade wall temperature results for the 2-MW fire at a separation distance of $4 \mathrm{~m}$.......... 73

Figure 4.17 - Target wall heat flux results for the 3-MW fire at a separation distance of $4 \mathrm{~m}$................. 74

Figure 4.18 - Façade wall heat flux results for the 3-MW fire at a separation distance of $4 \mathrm{~m} . . . \ldots \ldots \ldots \ldots . . . . .75$

Figure 4.19 - Target wall temperature results for the 3-MW fire at a separation distance of $4 \mathrm{~m}$........... 76

Figure 4.20 - Façade wall temperature results for the 3-MW fire at a separation distance of $4 \mathrm{~m}$...........77

Figure 4.21 - Target wall heat flux results for the 4-MW fire at a separation distance of $4 \mathrm{~m}$.................. 78

Figure 4.22 - Façade wall heat flux results for the 4-MW fire at a separation distance of $4 \mathrm{~m} . . . \ldots \ldots \ldots \ldots . . . . .79$ 
Figure 4.23 - Target wall temperature results for the 4-MW fire at a separation distance of $4 \mathrm{~m}$........... 80

Figure 4.24 - Façade wall temperature results for the 4-MW fire at a separation distance of $4 \mathrm{~m}$........... 81

Figure 5.1 - Calculated and experimental heat flux differences with critical heat flux displayed .............93 


\section{List of Tables}

Table 2.1 - Fire Growth Rates based on Heat Release Rate [2] 13

Table 4.1- Heat flux $\left(\mathrm{kW} / \mathrm{m}^{2}\right)$ results for the 2-MW fire tests at a separation distance of $3 \mathrm{~m}$. .57

Table 4.2 - Temperature $\left({ }^{\circ} \mathrm{C}\right)$ results for the 2-MW fire tests at a separation distance of $3 \mathrm{~m}$ 59

Table 4.3 - Heat flux $\left(\mathrm{kW} / \mathrm{m}^{2}\right)$ results for the 3-MW fire at a separation distance of $3 \mathrm{~m}$. 61

Table $4.4-$ Temperature $\left({ }^{\circ} \mathrm{C}\right)$ results for the 3-MW fire at a separation distance of $3 \mathrm{~m}$ .63

Table 4.5 - Heat flux $\left(\mathrm{kW} / \mathrm{m}^{2}\right)$ results for the 4-MW fire at a separation distance of $3 \mathrm{~m}$. .65

Table 4.6 - Temperature $\left({ }^{\circ} \mathrm{C}\right)$ results for the 4-MW fire at a separation distance of $3 \mathrm{~m}$ 67

Table 4.7 - Heat flux $\left(\mathrm{kW} / \mathrm{m}^{2}\right)$ results for the 2-MW fire at a separation distance of $4 \mathrm{~m}$. .70

Table $4.8-$ Temperature $\left({ }^{\circ} \mathrm{C}\right)$ results for the 2-MW fire at a separation distance of $4 \mathrm{~m}$ .72

Table 4.9 - Heat flux $\left(\mathrm{kW} / \mathrm{m}^{2}\right)$ results for the 3-MW fire at a separation distance of $4 \mathrm{~m}$. 74

Table 4.10 - Temperature $\left({ }^{\circ} \mathrm{C}\right)$ results for the 3-MW fire at a separation distance of $4 \mathrm{~m}$ .76

Table 4.11 - Heat flux $\left(\mathrm{kW} / \mathrm{m}^{2}\right)$ results for the 4-MW fire at a separation distance of $4 \mathrm{~m}$. 78

Table 4.12 - Temperature $\left({ }^{\circ} \mathrm{C}\right)$ results for the 4-MW fire at a separation distance of $4 \mathrm{~m}$ 80

Table 5.1 - Average calculated compartment temperatures based on the baseline test results .89

Table 5.2 - Calculated theoretical and experimental reduction factors at sensors within the configuration factor

Table 5.3 - Calculated theoretical and experimental heat fluxes at sensors with the configuration factor

for each fire size and flow rate .94 


\section{Nomenclature}

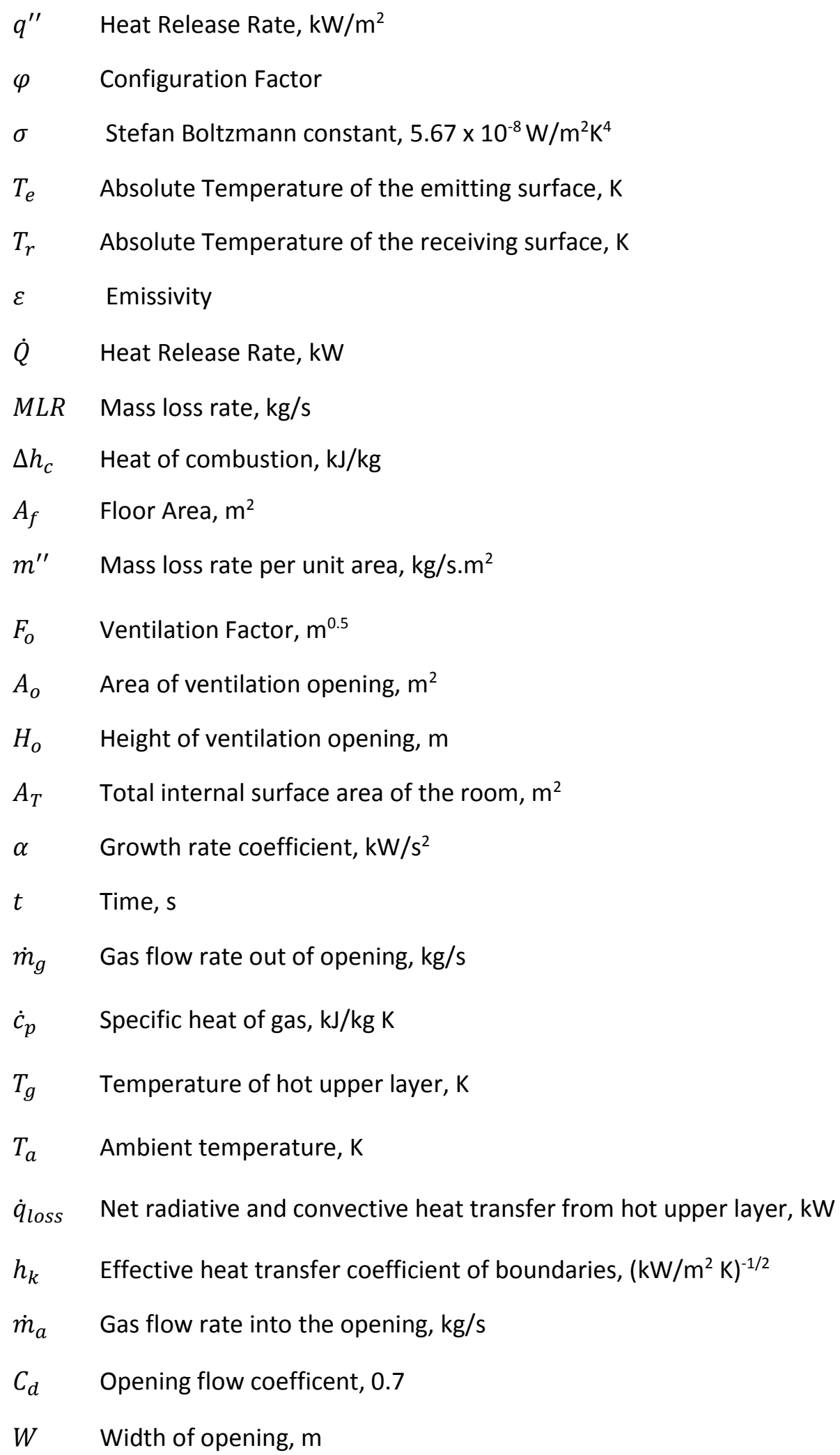


$\rho_{a} \quad$ Density of air, $\mathrm{kg} / \mathrm{m}^{3}$

$\rho_{g} \quad$ Density of gas exiting the opening, $\mathrm{kg} / \mathrm{m}^{3}$

$g$ Acceleration due to gravity, $\mathrm{m} / \mathrm{s}^{2}$

$h_{l} \quad$ Height of the neutral plane, $\mathrm{m}$

$\dot{m}_{b} \quad$ Burning rate, $\mathrm{kg} / \mathrm{s}$

$H_{N} \quad$ Height of opening, $\mathrm{m}$

$\dot{Q}_{F O} \quad$ Heat Release Rate required for flashover, kW

$\dot{Q}_{\text {peak }}$ Peak Heat Release Rate, kW

$T_{g, \max }$ Maximum Temperature, $\mathrm{K}$

$q^{\prime \prime}{ }_{r} \quad$ Experimental Reduced Heat Flux, $\mathrm{kW} / \mathrm{m}^{2}$

$f_{t} \quad$ Theoretical Reduction Factor

$T_{e} \quad$ Average Compartment Temperature, $\mathrm{K}$

$T_{a} \quad$ Ambient Temperature, $\mathrm{K}$

$q^{\prime \prime}{ }_{\text {base }}$ Experimental Baseline Heat Flux, $\mathrm{kW} / \mathrm{m}^{2}$

$f_{e} \quad$ Experimental Reduction Factor

$q^{\prime \prime}{ }_{t} \quad$ Theoretical Reduced Heat Flux $\mathrm{kW} / \mathrm{m}^{2}$

\section{Appendix}

$P \quad$ Pressure, psi

$P_{L} \quad$ Pressure Loss due to friction, psi

Q Flow Rate, gpm

C Hazen-Williams roughness constant, 120

d Internal diameter, in

$L \quad$ Length of pipe, $\mathrm{ft}$ 


\section{INTRODUCTION}

\subsection{Motivation}

During a compartment fire, flames may exit out of the openings of the compartment causing radiation and convective heat fluxes to impinge on the surrounding areas. The flames and heat from the fire can then cause ignition of combustible material allowing the fire to spread to adjacent properties. When the temperatures of the combustible materials on the adjacent properties are raised high enough the fire will spread from the compartment through the opening to the adjacent property. This can cause a fire to spread quickly within an area endangering lives and property. When there is no wind to aid fire spread and the distance between properties is large enough that the flames exiting the compartment are not directly impinging on the adjacent property, the convective heat flux is lower in relation to the radiation heat flux due to the decreasing hot gas temperatures with increasing horizontal distance from the compartment opening. To minimize the probability of fire spread to adjacent properties, the National Building Code of Canada [1] has limitations on the distance between a building and its property line. As fire spread to adjacent properties depends on the radiation heat flux from the fire received by the adjacent property, a study of reducing fire spread between adjacent properties mitigating the radiation heat flux leaving the fire building and impinging on the adjacent property, is important.

To limit the severity of a fire, a designer may control the number and size of openings of a compartment reducing the amount of air available to be consumed by the fire. In some cases this is not feasible either due to sizing or client requirements. A fire protection often used in buildings is the installation of sprinkler systems. Sprinklers are very effective at suppressing a fire, minimising fire spread and managing to control the fire until firefighters can arrive to extinguish the fire. The most common use of sprinklers is within the compartment itself but there are other ways to utilize sprinklers. This thesis will look to utilize sprinklers such that they create a water curtain outside of a compartment opening in order 
to reduce radiation heat fluxes to an adjacent property due to flames leaving a compartment through an opening.

\subsection{Main Objectives}

The main objectives of the research presented in this thesis are to:

1. Determine the effectiveness of a water curtain at attenuating heat radiation leaving a compartment to prevent fire spread to adjacent properties

2. To compare the results to the $12.5 \mathrm{~kW} / \mathrm{m}^{2}$ heat flux that cause piloted ignition of wood.

3. To model the effect that the water curtain has on the radiation exiting the compartment in order to develop a simple mathematical model for radiation that accounts for the reduction caused by the water curtain.

\subsection{Methodology}

A series of 24 experiments were conducted at the Carleton University Fire Research Lab where a compartment with sprinklers above the opening and a movable target wall were constructed in order to study the effect a water curtain would have on the radiation exiting a compartment during a fire scenario. Data on the heat fluxes and temperatures was gathered using heat flux gauges and thermocouples installed at various locations along the target wall and above the compartment opening. This thesis discusses the results of the experiments and the potential implications for the use of this research.

\subsection{Organization}

This thesis is organized into 7 chapters;

- Chapter 1 gives an introduction to the research topic, objectives, and methodology.

- Chapter 2 provides a literature review of the theory used in this research.

- Chapter 3 presents the experimental setup and parameters for this research.

- Chapter 4 discusses the results of the experiments conducted. 
- Chapter 5 presents the radiation attenuation effect of the water curtain.

- Chapter 6 discusses the conclusions that can be made from this research and potential future topics of study. 


\section{LITERATURE REVIEW}

This chapter contains a summary of the literature referenced in this thesis.

\subsection{Heat Transfer}

Heat transfer is the transfer of thermal energy due to temperature difference. As a fire causes an increase of temperature, heat is transferred from the fire area to surrounding areas. This energy can be transferred in three possible modes:

\subsubsection{Conduction}

Conduction heat transfer occurs in solid materials and will always move from a region of high temperature to a region of low temperature within the material. This method of heat transfer is dependent on the material properties such as; density, specific heat, and thermal conductivity [2]. Materials with large thermal conductivity make good thermal conductors while materials with small thermal conductivity make good thermal insulators.

\subsubsection{Convection}

Convective heat transfer occurs due to the movement of a fluid [2]. Fluid motion that arises naturally due to temperature gradients generating buoyant-driven flows is referred to as free convection. Forced convection is the result of external forces acting on the system. When discussing free convection it is important to distinguish the boundary conditions as either; bounded or unbounded. The rate of heat transfer is dependent on the heat transfer coefficient and the difference in temperature between mediums. The heat transfer coefficient is dependent of the geometry and orientation of the surface and fluid properties including the flow parameters. Convective heat transfer is the main method of heat transfer at relatively low temperature fires. 


\subsubsection{Radiation}

Radiation heat transfer occurs due to the transfer of energy by electromagnetic waves [2]. The radiation heat flux is affected by many factors such as the flames exiting the compartment, compartment size, and opening size. Radiation is the main method of heat transfer generated by large fires and as such will be the focus of this research.

The reduction of the heat flux, that is the focus of this study, will be that required for the piloted ignition of wood products, $12.5 \mathrm{~kW} / \mathrm{m}^{2}$. In a performance based design fire spread to adjacent properties can be controlled by limiting distances for adjacent properties such that the radiation transferred from one building to adjacent properties does not exceed $12.5 \mathrm{~kW} / \mathrm{m}^{2}$. Equation 2.1 is used to calculate the radiation impinging on a receiving surface from a radiation source.

$$
\begin{aligned}
& q^{\prime \prime}=\varphi \varepsilon \sigma\left(T_{e}^{4}-T_{r}^{4}\right) \\
& \varphi=\text { Configuration Factor } \\
& \sigma=\text { Stefan Boltzmann constant, } 5.67 \times 10^{-8} \mathrm{~W} / \mathrm{m}^{2} \mathrm{~K}^{4} \\
& T_{e}=\text { Absolute Temperature of the emitting surface, } \mathrm{K} \\
& T_{r}=\text { Absolute Temperature of the receiving surface, } \mathrm{K} \\
& \varepsilon=\text { emissivity, } \varepsilon=\left(\frac{1}{\varepsilon_{e}}+\frac{1}{\varepsilon_{r}}-1\right)^{-1}
\end{aligned}
$$

\subsubsection{Configuration Factor}

A configuration factor is used in order to calculate the radiation intensity at a point distant away from the radiation source [2]. The radiation impinging on a surface is affected by the dimensions of the radiating surface and the distance from the radiation source to the affected surface. In order to calculate the configuration factor for any location, the radiating source is broken up into sections as shown in Figure 2.1. Each section is then given an individual configuration factor, shown in Figure 2.2, to be calculated using Equation 2.2. The dimensions of the individual components to be input into this equation are 
calculated using Equations 2.3 and 2.4. The resulting configuration factor is the sum of configurations factors for each component. Equation 2.5 is used to determine the total configuration factor that is used in Equation 2.1.

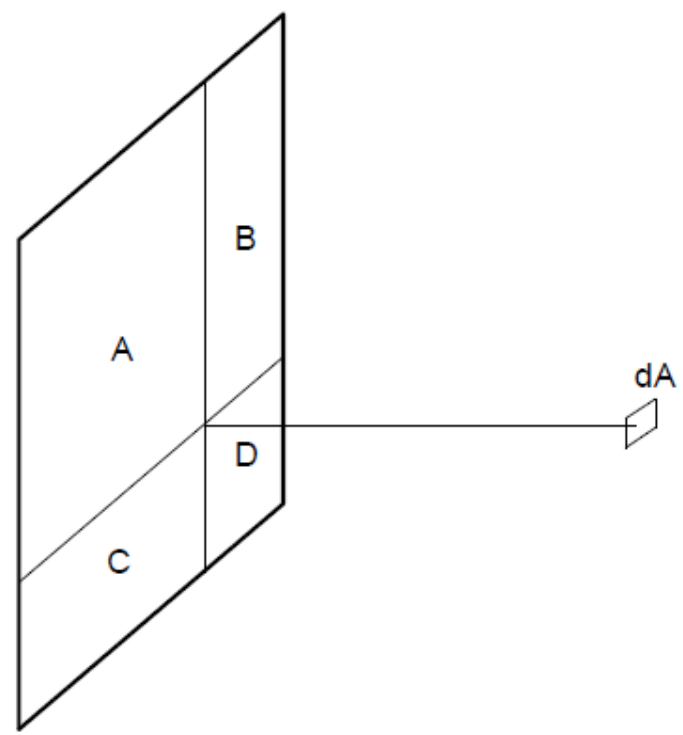

Figure 2.1 - Components of a radiation source used to determine the total configuration factor

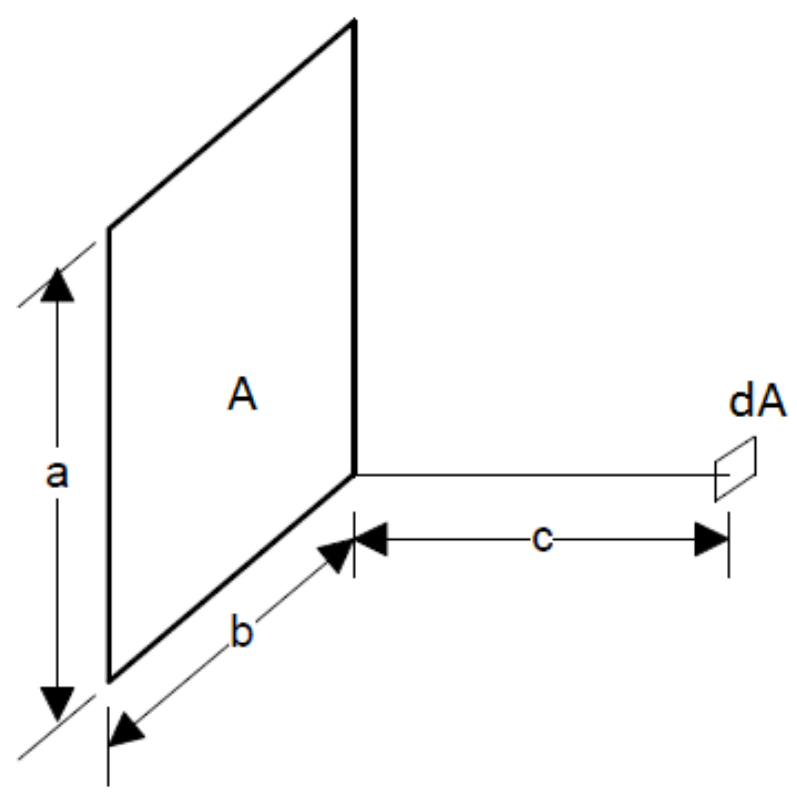

Figure 2.2 - Individual component used to determine the configuration factor for the individual component

$\varphi=\frac{1}{2 \pi}\left\{\frac{X}{\sqrt{1+X^{2}}} \tan ^{-1}\left[\frac{Y}{\sqrt{1+X^{2}}}\right]+\frac{Y}{\sqrt{1+Y^{2}}} \tan ^{-1}\left[\frac{X}{\sqrt{1+Y^{2}}}\right]\right\}$ 


$$
\begin{gathered}
X=\frac{a}{c} ; \quad Y=\frac{b}{c} \\
\varphi_{T}=\varphi_{A}+\varphi_{B}+\varphi_{C}+\varphi_{D}
\end{gathered}
$$

\subsection{Heat Release Rate}

The heat release rate (HRR) is commonly used to determine the amount of energy release during a fire event. It has been described as the single most important variable in determining a fire hazard [3]. It is the rate at which heat is generated during a combustion reaction, typically expressed in Watts (W) [4]. During a fire it is said to control the environmental consequences to a considerable extent [5]. The $\operatorname{HRR}(\dot{Q})$ can be calculated using the mass loss rate, Equation 2.6:

$$
\begin{aligned}
& \dot{Q}=M L R \Delta h_{c} \\
& M L R=\text { mass loss rate, } \mathrm{kg} / \mathrm{s} \\
& \Delta h_{c}=\text { heat of combustion, } \mathrm{kJ} / \mathrm{kg}
\end{aligned}
$$

This is often expressed in terms of horizontal burning area which becomes Equation 2.7:

$$
\begin{aligned}
& \dot{Q}=A_{f} m^{\prime \prime} \Delta h_{c} \\
& A_{f}=\text { Floor Area, } \mathrm{m}^{2} \\
& m^{\prime \prime}=\text { mass loss rate per unit area, } \mathrm{kg} / \mathrm{s} \cdot \mathrm{m}^{2}
\end{aligned}
$$

\subsection{Instrumentation}

\subsubsection{Heat Flux Gauge}

Heat flux gauges measure the heat flux being transferred to a surface via radiation. The gauges use a transducer to generate an electric signals that are proportional to a heat flux rate based on the heat applied to the sensor. They can be used to measure the different forms of heat transfer. They can come in different forms such as; circular-foil gauges, thin-film gauges, and Schmidt-Boelter gauges. The Gardon 
gauge contains a thermocouple sensor with a black coating on a thermopile sensor that absorbs the radiation heat flux [6]. Heat travels through the sensor to the housing and from the housing to the cooling water. The thermopile sensor generates a voltage output that is proportional to the heat flux. The measured heat flux is in watts per meter squared $\left(\mathrm{W} / \mathrm{m}^{2}\right)$.

The Gardon, Figure 2.3, and Schmidt-Boelter gauges are typically used to study radiation heat flux from fire and flames. Gardon gauges can only measure heat flux perpendicular to the gauge while Schmidt-Boelter gauges can measure heat flux both perpendicular and parallel to the gauge [7]. Gardon gauges are typically used for high intensity radiation. They are water cooled and do not require power to operate. Schmidt-Boelter gauges have the same outward appearance as a Gardon gauge, but employ different sensor technology. The Schmidt-Boelter has a plated constantan wire wrapped around an insulating chip [7]. The gauges are different in that Gardon gauges are manufactured to withstand extremely high heat fluxes, while Schmidt-Boelter gauges have a lower response time.

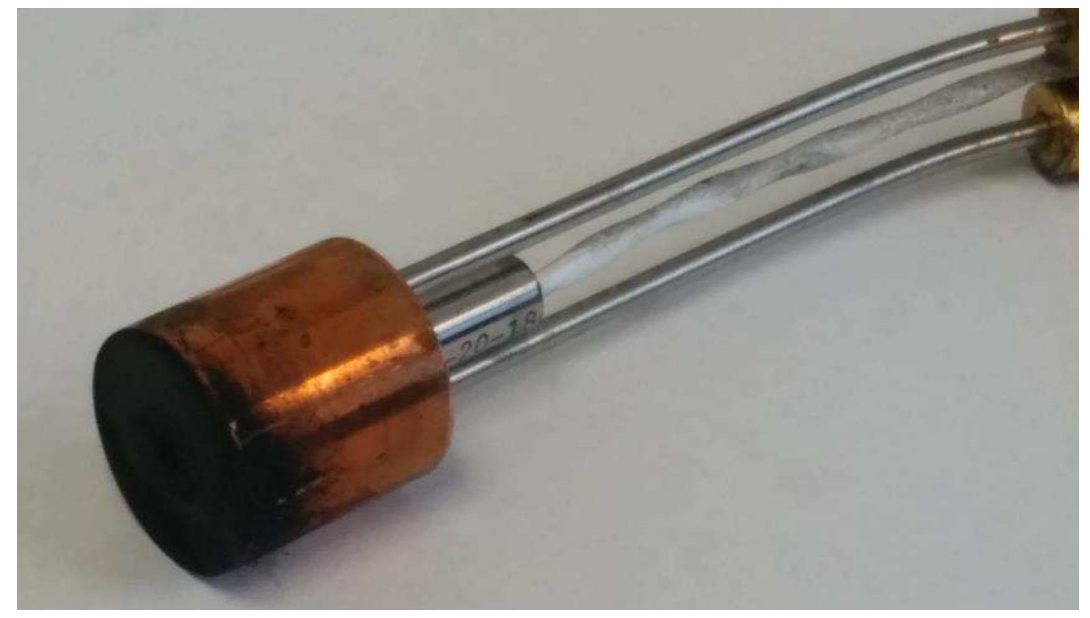

Figure 2.3 - Gardon gauge used at the Carleton University Fire Research Lab

\subsubsection{Thermocouples}

Thermocouples, Figure 2.4, measure the temperature of a given medium by taking advantage of a phenomenon known as the Seebeck effect [8]. When a wire has different temperatures at each end of the wire an electrical potential is created, known as the Seebeck coefficient. When two wires with 
different Seebeck coefficients are joined together, the temperature can be determined based on the voltage running through the circuit. This effect works best when the Seebeck coefficients are large and in opposing directions (positive and negative) [8].

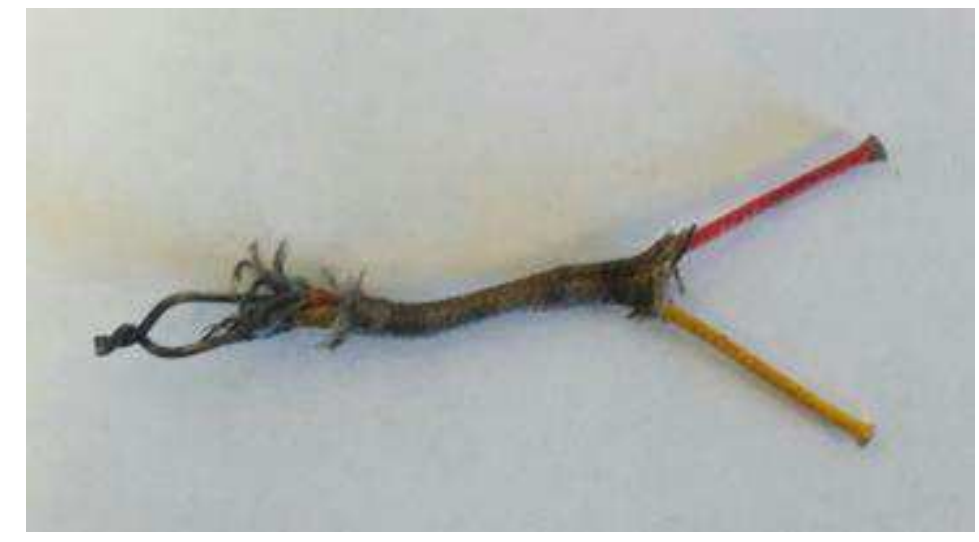

Figure 2.4 - Typical K-Type Thermocouple used at the Carleton University Research Lab

\subsection{Room Fires}

A room fire, also known as a compartment fire, can occur in any confined space that controls the ultimate air supply and thermal environment of the fire [9]. These factors influence energy released, spread and growth of the fire, as well as its maximum burning rate and duration, making the phenomena different from that of an open fire.

In a room fire the hot gases collect at the ceiling, developing a hot gas layer and heating the interior surfaces of the room. These cause heat to be radiated back to the fuel augmenting the combustion process by increasing the burning rate as seen in Figure 2.5. Openings in a room can limit the oxygen supply which can reduce the rate of fuel burnt and energy released resulting in a decrease in the burning rate. Equation 2.8 provides the ventilation factor, showing how the area of an opening is proportional to the burning rate within a compartment $[5,10]$. 


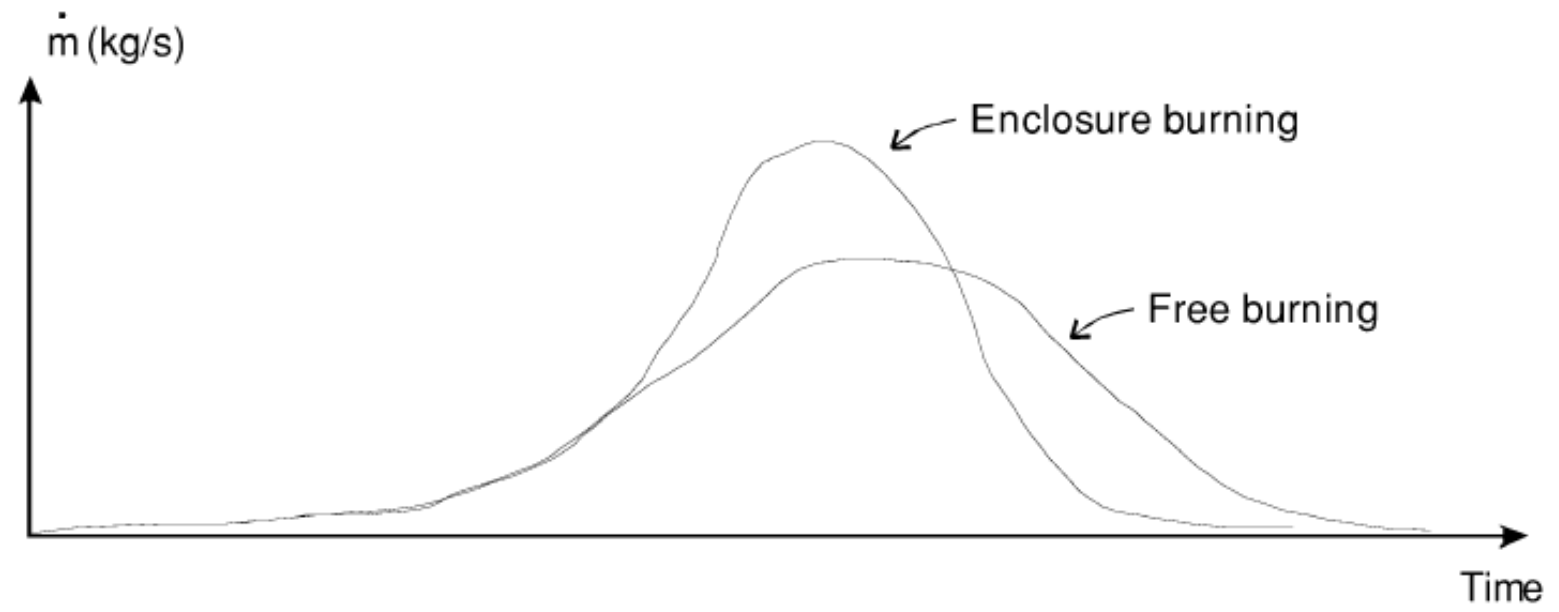

Figure 2.5 - The effect of an enclosure on the mass loss rate during combustion [5]

$$
F_{o}=\frac{A_{o} \sqrt{H_{o}}}{A_{T}}
$$

$A_{o}=$ Area of ventilation opening, $\mathrm{m}^{2}$

$H_{o}=$ Height of ventilation opening, $\mathrm{m}$

$A_{T}=$ Total internal surface area of the room, $\mathrm{m}^{2}$

Room fires typically consist of two main stages, pre-flashover fire and post-flashover fire [5]. The pre-flashover stage involves the growth stage of the fire, and is the time period when fire safety designers focus on occupant safety $[5,10]$. The post-flashover stage is when fire safety designers focus on structural stability, fire fighter safety, and measures to protect property [5]. Walton and Thomas [11] provide a more detailed description of a fire based on temperature. A fire is described in five stages Ignition, Growth, Flashover, Fully Developed, and Decay, shown in Figure 2.6. Figure 2.7 shows the development of a fire based on the heat release rate which follows a similar pattern to that of the temperature figure. 


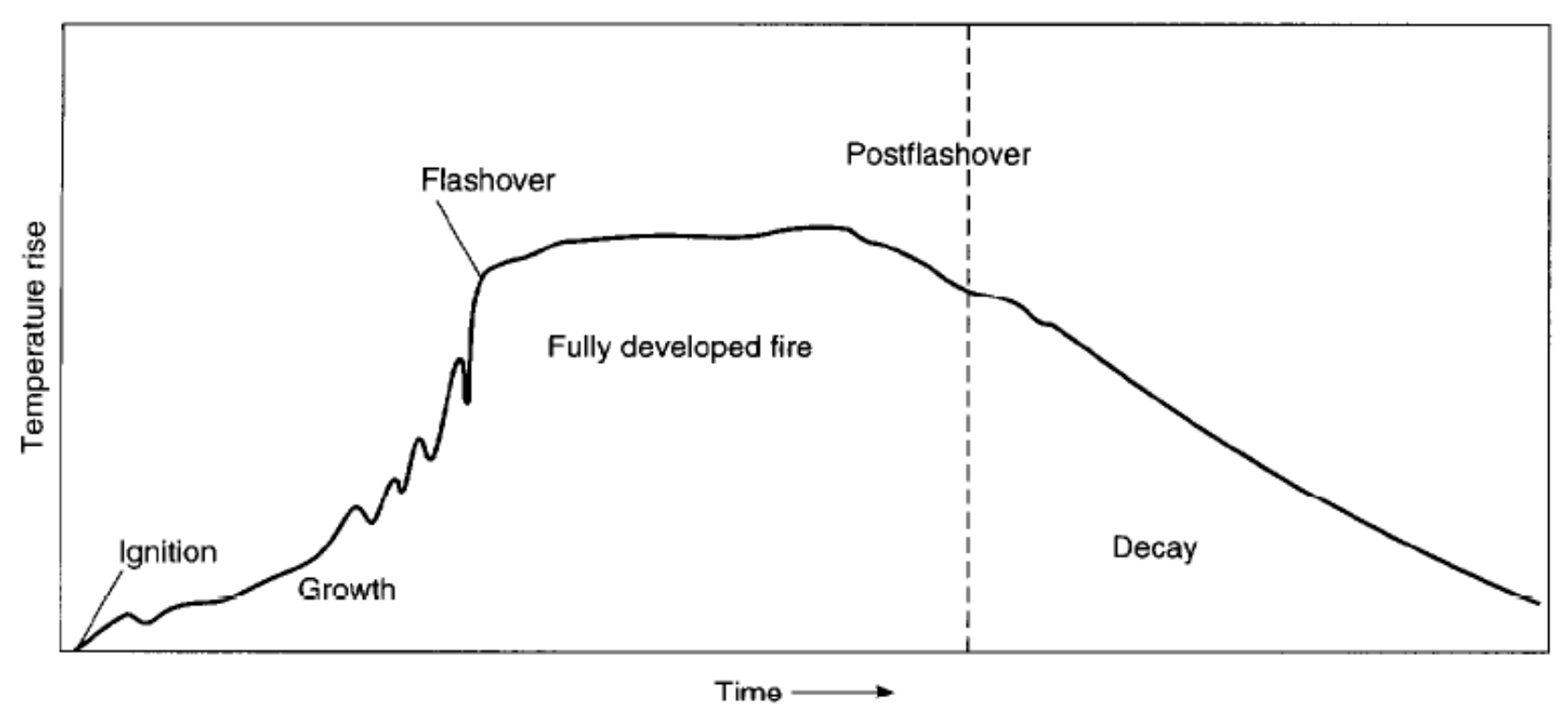

Figure 2.6 - Stages of fire development in room without suppression based on temperature [11]

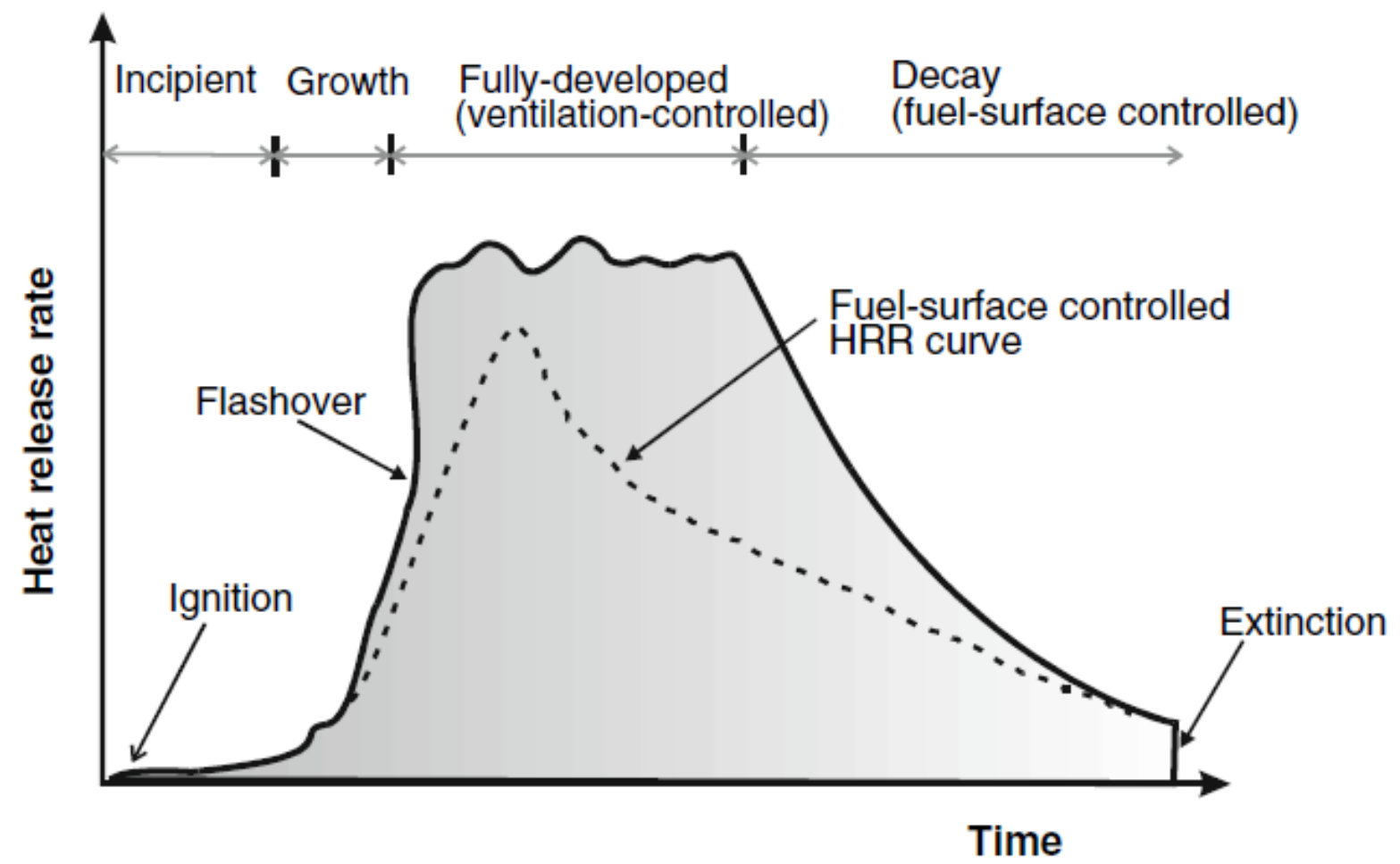

Figure 2.7 - Stages of fire development in room without suppression based on heat release rate [12] 


\subsubsection{Fire Stages}

\subsubsection{Pre-Flashover}

\subsection{Ignition}

The combustion process is initiated by an exothermic reaction that is caused by the ignition of combustible materials. This can be through piloted ignition (spark, flame or other pilot source) or by spontaneous combustion (heat causes unprompted ignition of a combustible material) [5].

\subsection{Growth}

After ignition a fire undergoes an incubation period, shown in Figure 2.8, during which the fire grows very slowly until the confinement starts to affect the fire development. It is difficult to quantify this period as various factors can influence the fire during this time such as the strength of the ignition source, location of burning, and properties of initial burning material [2].

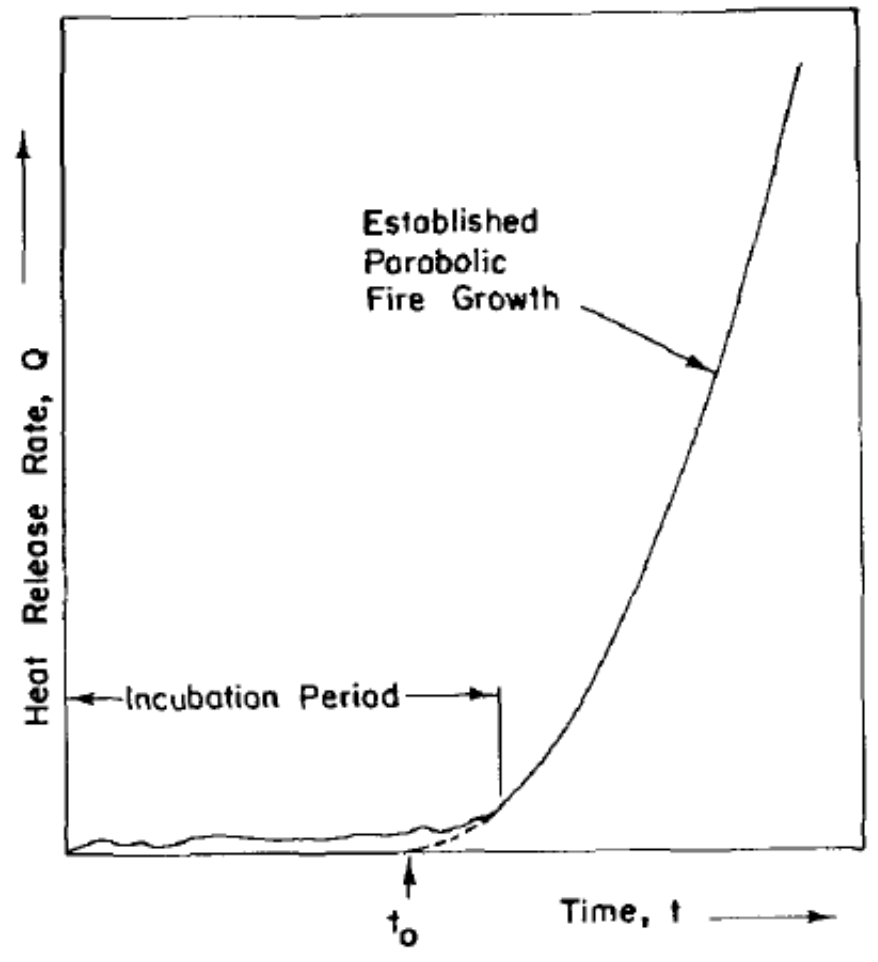

Figure 2.8 - Fire growth following the incubation period [15] 
A fuel controlled fire is when there is enough fuel and ventilation allowing the fire to develop into full room involvement. The fire growth in this stage can be categorized by the t-squared growth rate [13]. A simple equation used for the design of t-squared fires where the incubation period is ignored is presented in Equation 2.9

$$
\begin{aligned}
& \qquad \dot{Q}=\alpha t^{2} \\
& \alpha=\text { growth rate coefficient, } \mathrm{kW} / \mathrm{s}^{2} \\
& t=\text { time, s }
\end{aligned}
$$

The NFPA $[5,14]$ presents recommended categories of fire growth in design fires, corresponding to the time it takes to reach $1055 \mathrm{~kW}$, shown in Table 2.1 and Figure 2.9

Table 2.1 - Fire Growth Rates based on Heat Release Rate [2]

\begin{tabular}{lcc}
\hline Fire Growth Rate & Time required to reach $1055 \mathrm{~kW}(\mathrm{~s})$ & Value of $\alpha\left(10^{-3} \mathrm{MW} / \mathrm{s}^{2}\right)$ \\
\hline Slow & 600 & 0.00293 \\
Medium & 300 & 0.0117 \\
Fast & 150 & 0.0466 \\
& & 0.1874 \\
Ultrafast & 75 & \\
\hline
\end{tabular}




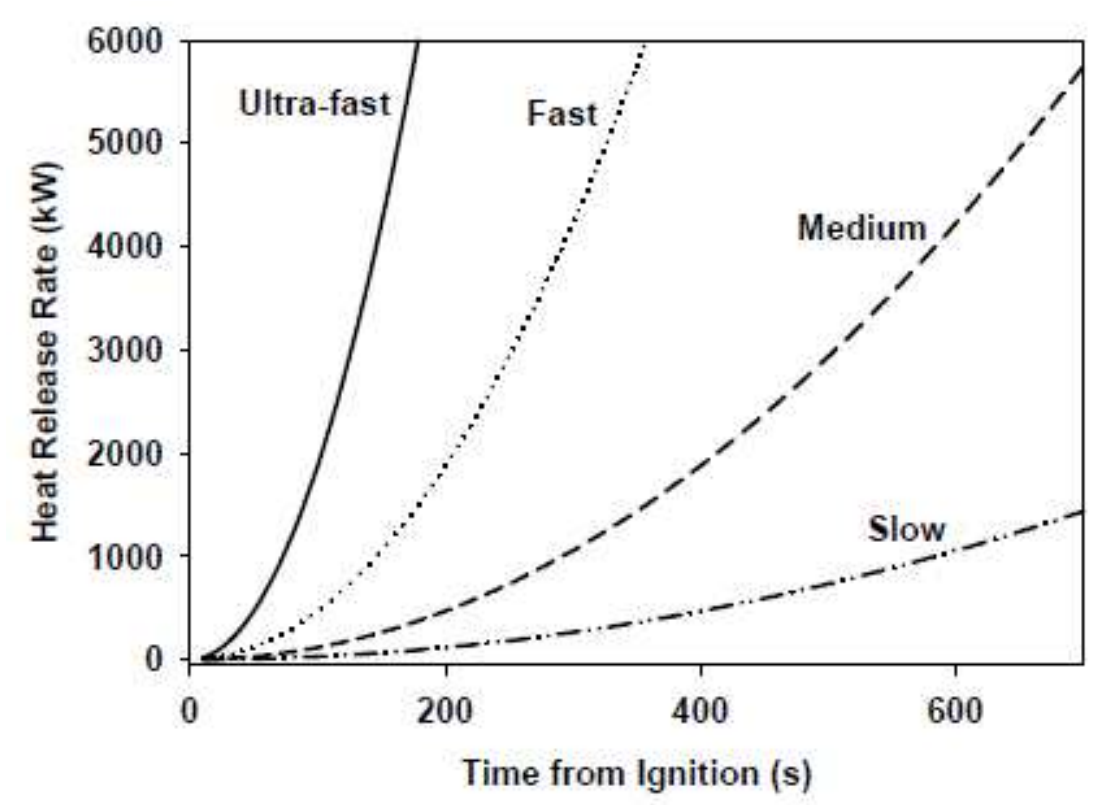

Figure 2.9 - Fire Growth Rates based on Heat Release Rate [15]

\subsubsection{Flashover and Post-Flashover}

\subsection{Flashover}

Flashover is defined as the transition to a fully developed fire, at which point all available combustibles within the room become involved in the fire. This is defined as the critical heat flux, which at the floor level is equal to $20 \mathrm{~kW} / \mathrm{m}^{2}[10,16]$, ceiling temperatures of $500-600^{\circ} \mathrm{C}[10,11]$, or the observation of flames projecting from the openings of the compartment [17]. Flashover can only occur in an enclosed space as open spaces do not allow for the formation of a hot upper layer.

The rapid rise in energy release and temperature at flashover make the area untenable and focus shifts from occupant safety to structural integrity and firefighter safety. Temperature within the compartment is of most concern [12]. In order to predict the conditions in the room where the heat release rate of the fire is assumed to be delivered to the upper layer, a simple energy balance is used given in Equation 2.10 [18].

$$
\dot{Q}=\dot{m}_{g} \dot{c}_{p}\left(T_{g}-T_{a}\right)+\dot{q}_{\text {loss }}
$$


$\dot{m}_{g}=$ gas flow rate out of opening, $\mathrm{kg} / \mathrm{s}$

$\dot{c}_{p}=$ specific heat of gas, $\mathrm{kJ} / \mathrm{kg} \mathrm{K}$

$T_{g}=$ temperature of hot upper layer, $\mathrm{K}$

$T_{a}=$ ambient temperature, $\mathrm{K}$

$\dot{q}_{\text {loss }}=h_{k} A_{t}\left(T_{g}-T_{\infty}\right)$

$=$ net radiative and convective heat transfer from hot upper layer, $\mathrm{kW}$

$h_{k}=$ effective heat transfer coefficient of boundaries, $\left(\mathrm{kW} / \mathrm{m}^{2} \mathrm{~K}\right)^{-1 / 2}$

Using vent flow analysis the mass flow rates into and out of the compartment can be calculated.

By using the mixed well case, shown in Figure 2.10, and the burning rate in the room, Equation 2.12 and Equation 2.13 can be determined [5].

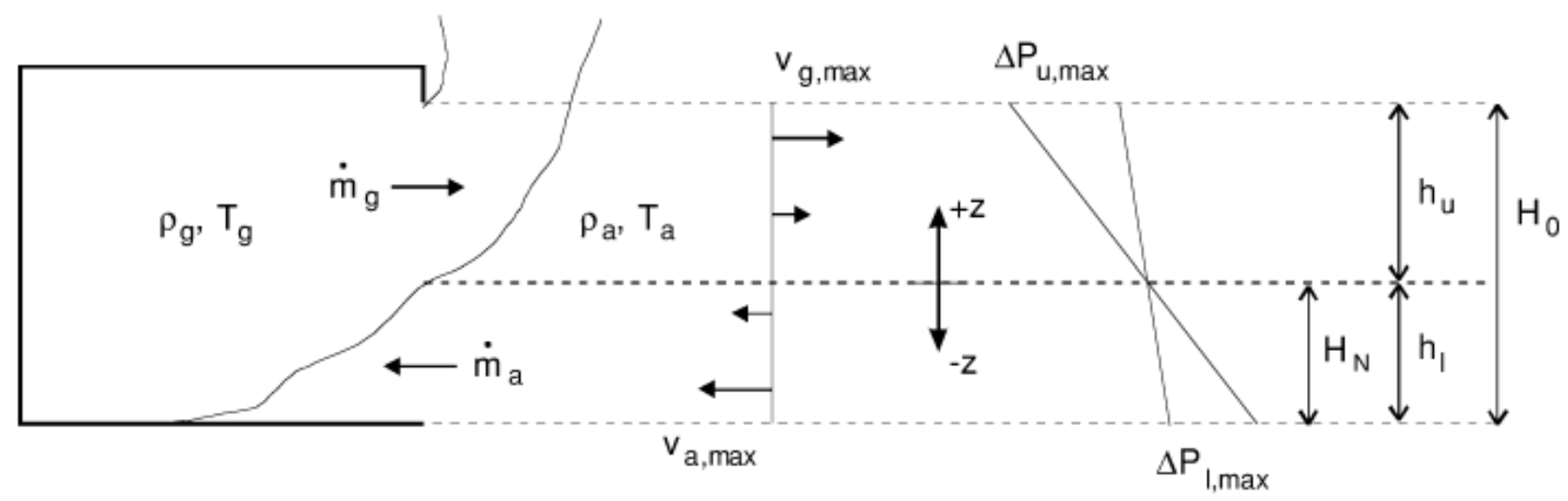

Figure 2.10 - Vent flows for well mixed room with uniform temperature where $T_{g}>T_{a}[5]$

$$
\dot{m}_{a}=\frac{2}{3} C_{d} W \rho_{a} \sqrt{\frac{2\left(\rho_{a}-\rho_{g}\right) g}{\rho_{a}}} h_{l}^{3 / 2}
$$

$\dot{m}_{a}=$ gas flow rate into the opening, $\mathrm{kg} / \mathrm{s}$

$C_{d}=0.7$ = opening flow coefficent

$W=$ width of opening, $\mathrm{m}$

$\rho_{a}=$ density of air, $\mathrm{kg} / \mathrm{m}^{3}$

$\rho_{g}=$ density of gas exiting the opening, $\mathrm{kg} / \mathrm{m}^{3}$

$g=$ acceleration due to gravity, $\mathrm{m} / \mathrm{s}^{2}$ 


$$
\begin{gathered}
h_{l}=\text { height of the neutral plane, } \mathrm{m} \\
\dot{m}_{g}=\dot{m}_{a}+\dot{m}_{b}=\frac{2}{3} C_{d} W \rho_{a} \sqrt{\frac{2\left(\rho_{a}-\rho_{g}\right) g}{\rho_{a}}} h_{u}^{3 / 2} \\
\dot{m}_{b}=\text { burning rate, } \mathrm{kg} / \mathrm{s} \\
H_{N}=h_{l}+h_{u}=\text { height of opening, } \mathrm{m}
\end{gathered}
$$

Equation 2.12 can be solved by iteration to come up with Equation 2.13, if the burning rate is known in order to determine the neutral plane. From this the flow rates and temperatures can be determined.

McCaffrey, Quintiere and Harkleroad developed an expression to predict the minimum heat release rate required for flashover, Equation 2.14, which assumes a conservative temperature increase of $500^{\circ} \mathrm{C}$ [18]. This method replaces $\dot{m}_{g}$ with $\sqrt{g} \rho_{g} A_{O} \sqrt{H_{O}}$. Thomas developed a similar expression, given by Equation 2.15 [11].

$$
\begin{aligned}
& \dot{Q}_{F O}=610\left(h_{k} A_{T} A_{O} \sqrt{H_{O}}\right)^{1 / 2} \\
& \dot{Q}_{F O}=7.8 A_{T}+378 A_{O} \sqrt{H_{O}}
\end{aligned}
$$

\subsection{Post-Flashover}

After flashover the heat release rate is the greatest and often more fuel is pyrolyzed than can be combusted within the room. This means that the fire is fully developed and controlled by the amount of air entering the room, known as ventilation controlled. Equation 2.16 shows the mass flow rate of air given by Drysdale [2]. The peak heat release rate, Equation 2.17, is calculated using the assumption that the amount of energy released when air is consumed is $3 \mathrm{MJ} / \mathrm{kg}$.

$$
\dot{m}_{a}=0.5 A_{O} \sqrt{H_{O}}
$$




$$
\dot{Q}_{\text {peak }}=1.5 A_{O} \sqrt{H_{O}}
$$

During the fully developed fire stage, the main concern is for structural integrity and the most important measures are of temperature and duration. In order to estimate the maximum temperature an empirical method was provided by Law, Equation 2.18 [11].

$$
\begin{aligned}
& T_{g, \max }=6000 \frac{\left(1-e^{-0.1 \Omega}\right)}{\sqrt{\Omega}} \\
& \Omega=\frac{A_{T}-A_{V}}{A_{V} \sqrt{H_{V}}}
\end{aligned}
$$

\subsection{Decay}

Once the fuel is consumed the heat release rate begins to decrease, this is known as the decay phase. This causes the temperature within the compartment to reduce and the fire changes back from a ventilation controlled fire to a fuel controlled fire.

\subsection{Design Fires}

The main objectives in fire safety design of buildings are to ensure occupant safety and structural integrity of the building. In order to meet these objectives fire protection engineers utilize design fires, to have a comparable performance under fire conditions, to determine the performance of the building during a fire. These fires are most often similar to that of compartment fires and typically focus on the post-flashover phase when the temperatures are highest and considered to be uniform within the compartment.

Engineers use the information available on buildings and fuels, and engineering judgement to determine the appropriate fire to use for design as there is no exact methodology available to determine 
the design fire to be used in compartment fires [5]. Design fires are usually expressed in terms of heat release rate vs. time and have three phases: Growth, Steady burning and Decay. To model the growth and decay phases of the design fire, the t-squared fires, discussed in Section 2.4.1.1.2, are commonly used and adjusted to fit the design fire. The fully developed phase is based on $Q_{\max }$ which is calculated using the Equation 2.17. The steady burning phase is based on the maximum heat release. The max heat release is based on the size of the ventilation opening and the duration is based on the fire load. For given fire loads, the duration will be shorter for higher fire loads with high temperatures while the duration will be shorter for low intensity fires. An example design fire is presented in Figure 2.1.

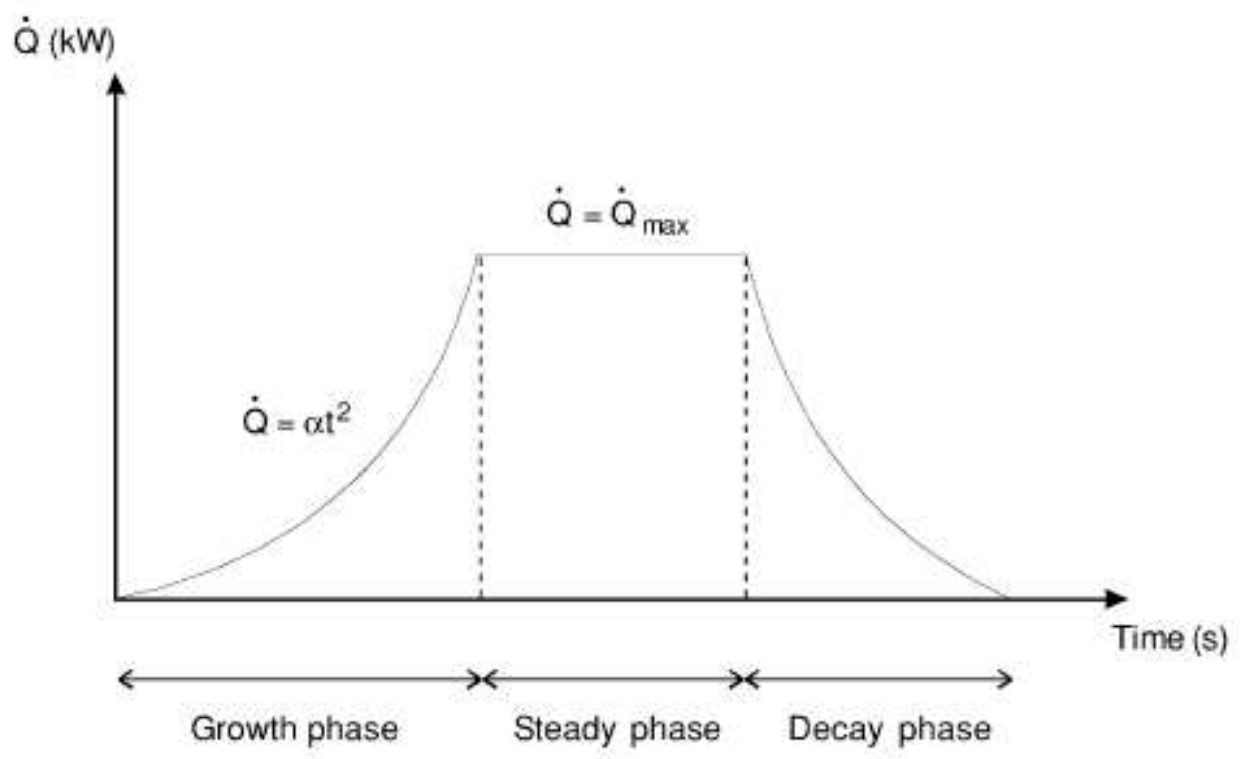

Figure 2.11 - Example of a simple design fire curve [5]

\subsection{Fire Control}

In order to control a fire the use of either active or passive protective systems are used. It is necessary to ensure facilities have proper detection and notification systems, travel paths for occupants and fire fighters, barriers to control the spread of fire and smoke, and structures which will withstand the fire long enough to ensure safe egress of occupants [10]. 


\subsubsection{Active Protection}

Active protection refers to controlling the fire by actions taken by a person or an automatic device. One of the most used form of active fire protection is the automatic sprinklers which spray water over an area under the activated sprinkler head [10]. The use of fans and other devices to remove smoke from an area or to pressurize stairwells is another form of active protection [10].

\subsubsection{Passive Protection}

Passive protection refers to controlling the fire by systems built into the structure that do not require operation by occupants or automatic operation. Passive protection includes using building materials that do not contribute to rapid flame spread. During the fully-developed phase passive protection is provided by materials which have sufficient fire resistance to prevent both flame spread and structural collapse [10].

\subsection{Fire Sprinkler Systems}

One fire safety technology is the automatic fire sprinklers because they have been shown to have a very high probability for controlling and extinguishing any fire [10]. The piping system is connected to a water supply system which generates enough pressure at the required flowrate to control the fire once the sprinklers are activated. The system must activate early in order to be useful as these systems are designed to control fires of a certain size [10]. The building code determines what buildings are equipped with automatic sprinklers.

Water is a good extinguishing agent for most fires. Sprinklers are best utilized during the initial flame growth period when the fire is easiest to control. A properly designed sprinkler system will be activated by heat from the fire and begin suppression, controlling the fire within a few minutes of activation, resulting in significantly less damage [19]. 
During the incubation fire stage, heat output is relatively low and thus does not cause sprinkler operation [20]. The thermal linkage is the component that controls water release. Each linkage applies pressure to a pipe cap which acts as a plug preventing water from flowing until the temperature around the sprinkler reaches the design activation temperature. As the fire grows the thermal linkage elements on the sprinklers become exposed to elevated temperatures and release the sprinkler seal. Once the seal is released, water beings to discharge onto the fire starting the suppression action. In most situations less than five sprinklers are needed to control the fire. In fast growing fire scenarios, however, such as a flammable liquid spill, up to 50 sprinklers may be required [20].

\subsection{System Types}

There are five basic types of sprinkler systems: wet pipe, dry pipe, deluge, pre-action doubleinterlock, and foam. Choosing the appropriate system depends on a variety of conditions such as potential fire severity, anticipated fire growth rates, content water sensitivity, ambient conditions, and desired response [19].

\subsubsection{Wet Pipe Sprinkler Systems}

Wet pipe sprinkler systems are the most common as they are the most reliable due to their simplicity. Wet pipe systems are filled with water that is released after the activation of the sprinklers. They operate using the automatic sprinklers and a water supply provides water under pressure to the system. These systems are simple and reliable, have low installation and maintenance costs, are easy to modify, and have short term down time after a fire [19]. The main disadvantage to this type of system is that they are not suitable for application in below freezing environments.

\subsubsection{Dry Pipe Sprinkler Systems}

Dry pipe sprinkler system are often installed in unheated buildings, and outdoor systems attached to buildings. These are the second most common system type. Dry pipe systems have a release valve that 
allows water into the system after the alarm has been triggered. NFPA standards state that dry pipe systems can be installed if the range of ambient temperatures reaches above $40^{\circ} \mathrm{F}$ [20]. The main advantage of this system is that is can be installed in environments where freezing may be an issue [19]. Disadvantages of dry pipe systems include, increased complexity, higher installation and maintenance costs, lower design flexibility, increased response time, and increased corrosion potential [19]. The system is filled with pressurized air or nitrogen holding the dry pipe valve in a closed position. The valve is located in a heated area and prevents water from entering the pipe until a sprinkler activates causing the air to escape and releasing the valve. Water then begins to flow into the system to the sprinklers controlling the fire. NFPA 13 standard states that the time it takes water to reach the hydraulically remote sprinkler from the time that sprinkler is activated is limited to a maximum of 60 seconds [20].

\subsubsection{Deluge Sprinkler Systems}

"Deluge" sprinkler systems have all sprinklers connected to the water piping system open, in that the thermal linkage element is removed. Water is not present in the piping until the system operates. Due to the sprinkler orifices being open, the piping is kept at atmospheric pressure. To prevent the water from entering into the piping a deluge valve is used in the water supply connection, which is a mechanically latched valve [19]. It is a non-resetting valve, and stays open once tripped. The deluge valve is usually controlled by a solenoid valve activated by a fire alarm system. The initiation device signals the fire alarm panel, which in turn energizes the solenoid valve and causes the deluge valve to open. The system can also be activated manually. Manual activation is usually by a manual valve that bypasses the solenoid valve and causes the deluge valve to open.

\subsubsection{Pre-Action Double-Interlock Systems}

Pre-action double-interlock sprinkler systems are specialized for use in locations to protect against accidental discharge, such as in museums and data centres. Pre-action systems are a combination of wet 
and dry systems. The pre-action system employs the basic concept of a dry pipe system in that water is not normally contained within the pipes. The difference is that water is held from piping by a pre-action (deluge) valve [19]. Typically, the valve is controlled by an independent fire detection system. Two separate events must occur to initiate discharge of the system. First, the detection system must identify a developing fire and then open the pre-action valve. This allows water to flow into system piping, which effectively creates a wet pipe sprinkler system. Second, individual sprinkler heads must release to permit water flow onto the fire [19]. The double interlock system has two conditions for water to enter the system: low air pressure and fire detection. Pre-action system is used to have faster water delivery prefill the system before opening the sprinklers. Disadvantages of this system include; higher installation and maintenance costs, modification difficulties, and potential decreased reliability [19].

\subsubsection{Foam Water Systems}

A foam water fire sprinkler system is a special system that discharges a mixture of water and low expansion foam concentrate, resulting in a foam spray. These systems are usually used with special hazards occupancies associated with unusual fire, such as flammable liquids.

\subsection{Water Suppression}

The ability of water droplets to suppress fires is due to the following four methods; gas phase cooling, oxygen dilution, fuel bed cooling due, and radiation attenuation [21]. Water droplets prevent heat from rising up into the hot gas layer and reradiating heat back to the fire. They also reduce the concentration of oxygen available for the combustion reaction. In order to cool the fuel the water droplets penetrate the fire plume to reach the fuel bed. Finally, the water droplets absorb and scatter heat radiation leaving the fire. It has been shown that the oxygen dilution effect is the dominant mechanism in suppressing large fires [21]. Water mist can also be used as a radiative shield in fire suppression in order to protect adjacent material from secondary ignition [22]. 


\subsection{National Building Code Limiting Distances}

The National Building Code of Canada [1] defines the limiting distance as the distance from an exposing building face to a property line, the centre line of a street, lane or public thoroughfare, or to an imaginary line between two buildings or fire compartments on the same property, measured at right angles to the exposing building face [1]. The unprotected openings in an exposing building face are determined by the available limiting distance. The National Building Code of Canada states;

1) Except as permitted by Articles 3.2.3.10. to 3.2.3.12., the area of unprotected openings in an exposing building face for the applicable limiting distance shall be not more than the value determined in accordance with;

A) Table 3.2.3.1.B. or Table 3.2.3.1.C. for an exposing building face conforming to Article 3.2.3.2. of a building or fire compartment which is not sprinklered, or

B) Table 3.2.3.1.D. or Table 3.2.3.1.E. for an exposing building face conforming to Article 3.2.3.2. of a sprinklered fire compartment that is part of a building which is sprinklered in accordance with Section 3.2

2) The area of the unprotected openings in an exposing building face shall be the aggregate area of unprotected openings expressed as a percentage of the area of the exposing building face in Table 3.2.3.1.B., Table 3.2.3.1.C., Table 3.2.3.1.D., or Table 3.2.3.1.E.

\subsection{Previous Relevant Research}

Several studies with conflicting results have been completed on the topic of heat radiation leaving a compartment during a fire [23 - 25]. The experimental results of the St. Lawrence burns [23] showed that radiation from flames coming out of a window was a major contributor to the total radiation, but Law $[24,25]$ stated that the contribution of flames exiting a window was not significant to the radiation heat flux and could be ignored. For single room fires, Lin [26] found that the temperatures and heat fluxes were 
higher when the window and door to the room were open. For two room fires, Lin [26] found that, when the upper door was closed the plume from the lower room entered the upper room with available air, when the upper door open the air was entrained into the lower room and flames could not enter the upper room. Based on the experimental results of Chen and Francis [27], it was estimated that about 19\% of radiation was from the external flames. Cheng [28] investigated the effects flames exiting compartments on heat radiation based on these previous works [23-27].

Kermida [29] modelled the effects of a water mist. A method was developed by Coppalle et al. [30] to take into account both the absorption and scattering effect of the droplets that could be easily incorporated into any general computing program such as FDS. Parent et al. [31] found the vertical position of a spray had little effect on attenuation but lateral position could significantly affect the attenuation. The average transmissivity decreases as the water flow rate increases but does not fall below a minimum level reached at a pressure of 4 bar was stated by Parent et al. [31]. Modelling of water droplets was stated to be inefficient by Hostikka and McGratten [32] due to the computational limitations, only small sample sizes could be accurately tracked leading to inaccuracies. Yang et al. [33] developed a two-flux model that described scattering and absorption in a water mist using Mie Theory, while gas phase absorption was modelled using an exponential wide-band model. Attenuation could increase with an increase in flow rate through a given water curtain was predicted by Boulet et al. [34]. Chow [35] studied the effect of a water curtain created using deluge system separating a fire room from an adjoining room. Grant et al. [36] studied water spray fire suppression to determine the optimum rate of agent application was dependent on the fire scenario, compartment size, opening size, and type of fuel. Water mist fire suppression systems studied by Grant et al. [36] found that their effectiveness was highly dependent on droplet size. Buchlin [37] found that increased nozzles increased the attenuation and that if the nozzles impinging on a wall increases attenuation due to the creation of a falling water film being continuously refreshed. Radiation blockage effects were studied by Choi [38] in a similar setup to Chow's experiments 
[35]. Simulations performed by Wen et al. [39] found that factors such as flow rate, droplet size, and wind conditions effect suppression. Wen et al. [39] found that water curtains created using a deluge system could effectively protect personal and property. The optimum droplet size of $2 \mu \mathrm{m}$ was discovered by Ravigururajan [40] but larger droplets could produce the same effect with larger quantities of water.

The main mechanisms involved are radiation absorption and scattering by water droplets [2934]. Studies have investigated the ability of water curtains as a shield to protect property [33, 34, 36, and 37]. This research is being undertaken to determine if the use of a water curtain over an opening can be utilized to add another factor of safety to limit the distance of adjacent properties.

\subsubsection{Radiation Investigation by Cheng [28]}

In order to study the amount of radiation heat flux emitted from the flames projecting out of a window (unprotected opening), an experimental investigation was conducted at the full scale fire research lab of the National Research Council of Canada. Experiments were conducted in a room with one window that could be adjusted such that the width could change while maintaining the same height. The other parameters of the experiments included fuel type, and separation distance between the external wall of the fire building and a target wall. For each window configuration, four experiments were conducted using three separation distance and two fuels.

The compartment dimensions were 5.95 by 4.40 by $2.75 \mathrm{~m}$ high. The three windows used were 2.55 by $1.45 \mathrm{~m}$ high, 1.45 by $1.45 \mathrm{~m}$ high, and 1.10 by $1.45 \mathrm{~m}$ high. The target wall was placed at separation distances of $2.2 \mathrm{~m}, 3.0 \mathrm{~m}, 3.5 \mathrm{~m}$, and $4.0 \mathrm{~m}$. The experiments used between eight to ten radiometers and 21 to 25 thermocouples to measure the radiation heat flux and temperature, respectively. Most of the radiometers and thermocouples were placed on a vertical line opposite the vertical center line of the window of the fire compartment in order to find the position of maximum radiation heat flux and surface temperature on the target wall. 
During the propane tests the control valves were opened fully and sustained for 10 minutes in order to assume the maximum propane flow rate had the same value for every experiment, however the actual propane flow rate was not measured. Figure 2.12 shows the temperature results for the fire experiments.

\begin{tabular}{|c|c|c|c|c|c|c|c|}
\hline No. & Fuel & $\begin{array}{l}\text { Window }(\mathrm{W} \times \mathrm{H}) \\
(\mathrm{m})\end{array}$ & $\begin{array}{l}\text { Separation } \\
\text { distance } \\
(\mathrm{m})\end{array}$ & $\begin{array}{l}\text { Flame height } \\
\text { above window } \\
\text { ( } \mathrm{m} \text { ) }\end{array}$ & $\begin{array}{l}\text { Maximum room } \\
\text { temperature } \\
\left(C^{\circ}\right)\end{array}$ & $\begin{array}{l}\text { Maximum flame } \\
\text { temperature at window } \\
\left(\mathrm{C}^{\circ}\right)\end{array}$ & $\begin{array}{l}\text { Flame temperature at } \\
50 \mathrm{~cm} \text { above window } \\
\left(\mathrm{C}^{\circ}\right)\end{array}$ \\
\hline 1 & Propane & $2.55 \times 1.45$ & 3 & 1.5 & 1210 & 1021 & NA \\
\hline 2 & Propane & $2.55 \times 1.45$ & 3.5 & 1.5 & 1215 & 1047 & NA \\
\hline 3 & Propane & $2.55 \times 1.45$ & 4 & 1.5 & 1205 & 1073 & 810 \\
\hline 4 & Propane & $1.45 \times 1.45$ & 3 & 3 & 957 & 993 & 991 \\
\hline 5 & Propane & $1.45 \times 1.45$ & 3.5 & 3 & 918 & 985 & 921 \\
\hline 6 & Propane & $1.45 \times 1.45$ & 2.4 & 3 & 979 & 1022 & 970 \\
\hline 7 & Propane & $1.10 \times 1.45$ & 3.5 & 4 & 879 & 976 & 968 \\
\hline 8 & Propane & $1.10 \times 1.45$ & 3 & 4 & 873 & 1084 & 962 \\
\hline 9 & Propane & $1.10 \times 1.45$ & 4 & 4 & 875 & 1047 & 964 \\
\hline 10 & Wood cribs $2 " x 4 "$ & $1.10 \times 1.45$ & 3 & 3 & 958 & 942 & 884 \\
\hline 11 & Wood cribs $2 " x 4^{\prime \prime}$ & $1.45 \times 1.45$ & 3 & 2.5 & 1083 & 1010 & 846 \\
\hline 12 & Wood cribs 2"x2" & $2.50 \times 1.45$ & 3 & 3.2 & 1050 & 1079 & 956 \\
\hline
\end{tabular}

Figure 2.12 - Experimental results illustrating the temperature effects [28]

From the propane experiments the impact of the window size could be summarized as follows:

a. Room temperature decreases as the window size decreases;

b. External flame height increases as the window width decreases;

c. In the test with a window of 2.55 by $1.45 \mathrm{~m}$ high, the flame temperature at the window was lower than the room temperature; in the tests with the window of 1.45 by $1.45 \mathrm{~m}$ high and 1.10 by 1.45 $\mathrm{m}$ high, the flame temperature at the window was higher than the room temperature. This is due to the increased combustion taking place outside the room as unburned propane escaped through the window; 
d. In the test with a window of 2.55 by $1.45 \mathrm{~m}$ high, the flame temperature above the window dropped quickly with height; in the tests with the window of 1.45 by $1.45 \mathrm{~m}$ high and 1.10 by 1.45 $\mathrm{m}$ high, the flame temperature above the window did not change much with height until reaching approximately $2 \mathrm{~m}$ below the flame tip. This is due to the same reason mentioned above in c.

The results show that the window size has a great impact on all compartment fire characteristics. The larger the window, the higher the compartment temperature, burning rate, and flame temperature at the window. The flame height however decreases as the window width increases. The experimental results correlated well with theoretical calculations.

To study the effect of separation distance, the results from three propane experiments with a window size of 1.45 by $1.45 \mathrm{~m}$ high were used to show that:

a. The closer the separation distance, the higher the maximum temperature and radiation heat flux on the target wall;

b. The positions of maximum temperature and radiation heat flux are above the height of the soffit of the window;

c. There is a local maximum temperature and radiation heat flux above the center height of the window;

d. The separation distance has little effect on the shape of the radiation distribution curve on the target wall.

To study the impact of window size on radiation heat flux the results of three propane experiments with different window sizes but the same separation distance of $3 \mathrm{~m}$ were used to show that: 
a. For the 2.55 by $1.45 \mathrm{~m}$ high window, the points with maximum temperature and heat flux are located just above the center of the window and within the boundary of the window; External flames above the window have little influence on radiation distribution on the target wall due to the radiation from external flames being much smaller than that from the window radiator;

b. For the 1.45 by $1.45 \mathrm{~m}$ high and 1.10 by $1.45 \mathrm{~m}$ high window, the points with maximum temperature and heat flux are located above the soffit of the window. The smaller the window width, the higher the location of the maximum temperature and heat flux; External flames above the window had a greater influence on radiation distribution on the target wall;

c. For the experiment with the 1.45 by $1.45 \mathrm{~m}$ high window, the maximum temperature and radiation heat flux are smaller than the two experiments with the larger and smaller window sizes.

The ratio of the height to width of a window has a significant impact on the radiation distribution on a target wall. The location of the maximum heat flux on the target wall goes up as the ratio of the height to width of the window increases. It can be concluded that for a window with its width much larger than its height, the radiation on the target wall is mainly from the window and for a window with its width much smaller than its height, the radiation on the target wall is mainly from the external flame above the window. It can be considered that the radiation on the target wall comes from two radiators: the window radiator and the external flame out of the soffit of the window. The results illustrating radiation heat fluxes effect are summarized in Figure 2.13. 


\begin{tabular}{|c|c|c|c|c|c|c|c|}
\hline Test & Fuel & $\begin{array}{l}\text { Window } \\
(\mathrm{W} \times \mathrm{H}) \\
(\mathrm{m})\end{array}$ & $\begin{array}{l}\text { Separation } \\
\text { distance } \\
\text { (m) }\end{array}$ & $\begin{array}{l}\text { Heat flux at the point opposite } \\
\text { center of window } \dot{q}_{c w}^{+} \\
\qquad\left(\mathrm{kW} / \mathrm{m}^{2}\right)\end{array}$ & $\begin{array}{l}\text { Maximum heat } \\
\text { flux } \dot{q}_{\max }^{\circ} \\
\left(\mathrm{kW} / \mathrm{m}^{2}\right)\end{array}$ & $\frac{\dot{q}_{\max }^{n}}{\dot{q}_{c w}}$ & $\begin{array}{c}\text { Position of } \\
\text { maximum heat flux }\end{array}$ \\
\hline 1 & Propane & $2.55 \times 1.45$ & 3 & 23.99 & 26.71 & 1.11 & Within window \\
\hline 2 & Propane & $2.55 \times 1.45$ & 3.5 & 18.70 & 20.23 & 1.08 & Within window \\
\hline 3 & Propane & $2.55 \times 1.45$ & 4 & 15.97 & 17.31 & 1.08 & Within window \\
\hline 4 & Propane & $1.45 \times 1.45$ & 3 & 15.24 & 18.22 & 1.20 & above window \\
\hline 5 & Propane & $1.45 \times 1.45$ & 3.5 & 10.46 & 12.67 & 1.21 & above window \\
\hline 6 & Propane & $1.45 \times 1.45$ & 2.4 & 22.02 & 28.75 & 1.31 & above window \\
\hline 7 & Propane & $1.10 \times 1.45$ & 3.5 & 14.84 & 26.46 & 1.78 & above window \\
\hline 8 & Propane & $1.10 \times 1.45$ & 3 & 18.65 & 25.62 & 1.37 & above window \\
\hline 9 & Propane & $1.10 \times 1.45$ & 4 & 11.50 & 15.93 & 1.39 & above window \\
\hline 10 & Wood cribs 2"x 4" & $1.10 \times 1.45$ & 3 & 11.82 & 13.65 & 1.15 & above window \\
\hline 11 & Wood cribs $2 " \times 4^{n}$ & $1.45 \times 1.45$ & 3 & 17.49 & 19.45 & 1.11 & Within window \\
\hline 12 & Wood cribs 2"x2" & $2.55 \times 1.45$ & 3 & 28.79 & 31.47 & 1.09 & Within window \\
\hline
\end{tabular}

Figure 2.13 - Experimental results illustrating the influence of radiation heat flux [28]

The separation distances required by NBCC 2005 are very different from those computed by the two models of fire spread between buildings, shown in Figure 2.14. For the case with smaller ratio of aggregate opening area to the exposing building face area, the required separation distance between buildings is less than that calculated by the two models of fire spread between buildings. This may be caused by the fact that National Building Code of Canada [1] only considers the ratio of aggregate opening area to the exposing building face area, not the size of an individual opening. For the case with larger ratio of aggregate opening area to the exposing building face area, the required separation distance between buildings is much larger than that calculated by the two models of fire spread between buildings. The main problem of the National Building Code of Canada [1] requirements is that it is based on the ratio of the aggregate opening area to the exposing building face area, not the sizes of the openings or their distribution on the external wall. 


\begin{tabular}{|c|c|c|c|c|c|c|}
\hline & & $<5 \mathrm{~min}$ & $5-6 \mathrm{~min}$ & $6-10 \mathrm{~min}$ & $10-11 \mathrm{~min}$ & $>11 \mathrm{~min}$ \\
\hline NBCC & Residential & $2.4-3$ & 8 & 12 & 12 & 16 \\
\hline \multirow{3}{*}{$\begin{array}{c}\text { Configuration } \\
\text { factor (Severity) }\end{array}$} & $\begin{array}{c}\text { Normal } \\
\left(\mathrm{F}_{\text {erit }}=0.07\right)\end{array}$ & 5.27 & 6.18 & 6.97 & 7.57 & 8.75 \\
\cline { 2 - 7 } & $\begin{array}{c}\text { Hazardous } \\
\left(\mathrm{F}_{\text {ert }}-0.035\right)\end{array}$ & 7.99 & 9.38 & 10.61 & 11.60 & 13.56 \\
\hline \multirow{3}{*}{$\begin{array}{c}\text { Radiation } \\
\text { (Emissivity of } \\
\text { external flame) }\end{array}$} & 0.252 (Law) & 6.20 & 7.29 & 8.20 & 8.92 & 10.33 \\
\cline { 2 - 7 } & 0.394 (Beyreis) & 6.56 & 7.74 & 8.74 & 9.53 & 11.07 \\
\cline { 2 - 7 } & 0.519 or 0.820 & 6.96 & 8.20 & 9.23 & 10.08 & 11.69 \\
\cline { 2 - 7 } & 0 (Experiment) & 5.46 & 6.32 & 7.09 & 7.64 & 8.82 \\
\hline
\end{tabular}

Figure 2.14 - Separation distances calculated by NBCC and two models (m) [28]

\subsubsection{Water Mist Suppression by Kermida [29]}

The study by Kermida [29] states that water mist suppresses fire growth through four key mechanisms: gas phase cooling, oxygen dilution, fuel surface cooling and radiation attenuation. Water mist can also be used as a radiative shield, for the protection of adjacent material from possible ignition, by absorbing and scattering radiation shown in Figure 2.15. A rising concern for the optimal design of water mist suppression systems is the lack of dependable, comprehensive models for the prediction of thermal radiation attenuation. 


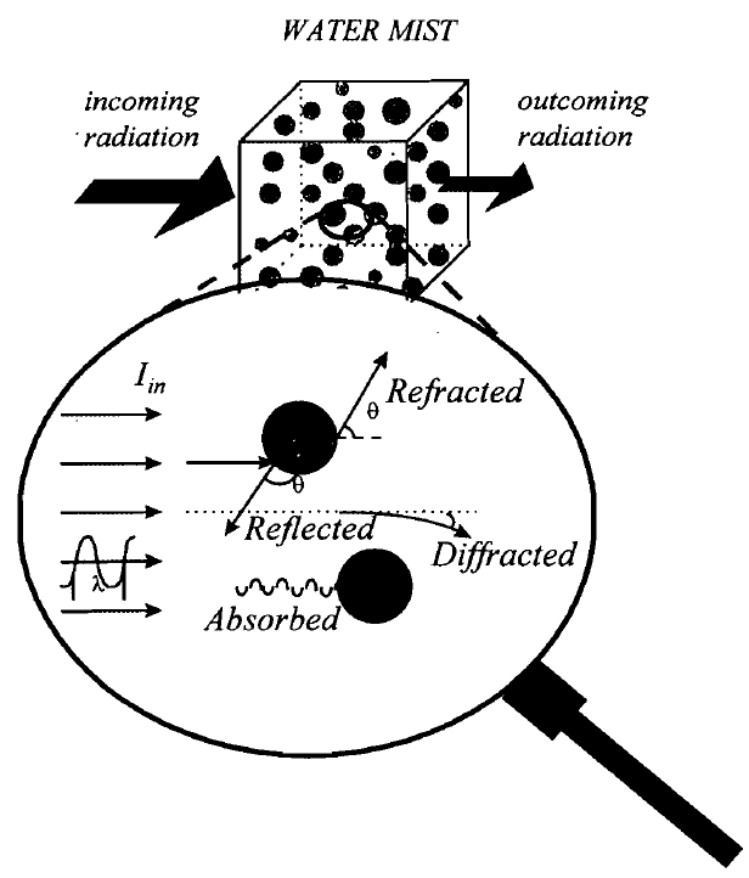

Figure 2.15 - A schematic representation of the radiant attenuation through water mist, due to absorption and scattering by the droplets [29]

The radiation model used in this study is the six-flux model to cover simple two-phase flows. In the six-flux model, the spatial discretization of a solid angle is such that the radiation fluxes are accounted for along the positive and negative coordinate directions.

Regarding droplet evaporation the following assumptions are made:

i) The droplet remains spherical.

ii) Droplet density is independent of temperature.

iii) Droplet temperature is uniform.

iv) The water vapor immediately above the surface of the droplet is in thermal equilibrium with the droplet. Therefore, the droplet and its vapor have the same temperature.

The case simulated draws from an experiment conducted by Downie et al. [41], to investigate the interaction of a fine water spray with a buoyant diffusion flame. The experiments were performed in a 2 $\times 2 \times 2 \mathrm{~m}$ enclosure. A natural gas burner was located at the center of the chamber floor at a distance of 
$1.87 \mathrm{~m}$ below the downward hollow cone nozzle. An extraction hood was located $10 \mathrm{~cm}$ above the chamber, and a $13 \mathrm{~cm}$ high opening along the bottom of each wall allowed air to be drawn into the fire. The burner was located $5 \mathrm{~cm}$ above the test chamber floor and it was 25 by $25 \mathrm{~cm}$. Centerline plume temperatures were measured using six thermocouples located between $0.15 \mathrm{~m}$ and $1.4 \mathrm{~m}$ above the burner. A radiometer was used to measure flame radiation from a distance of $50 \mathrm{~cm}$ from the center of the burner. For each flame tested, the radiometer was placed at a height equal to the transition between the continuous and intermittent flame regions, defined by McCaffrey [42]. The total heat releases from the three buoyant methane diffusion flames tested were $26.5,40.0$ and $53.0 \mathrm{~kW}$. The nozzle flow rate was $0.013 \mathrm{~kg} / \mathrm{s}$, the mean droplet diameter was between 250 and $270 \mu \mathrm{m}$ and the initial injection velocity was $15 \mathrm{~m} / \mathrm{s}$.

The experimental data reported by Downie et al. [41] and the calculated results obtained with and without radiation are shown in Figure 2.16 and 2.17. A comparison between experimental and predicted variation of the radiation flux at the location of the radiometer for the case of the $53 \mathrm{~kW}$ is shown Figure 2.16, and for the $26 \mathrm{~kW}$ case is Figure 2.17, flames has shown good agreement, demonstrating that the model is predicting the correct trends. Before the application of the mist, mean radiation intensity is steady. After application, there is an initial relatively rapid decrease in the radiation heat flux, followed by a slow rate of decrease. Fluxes can therefore be directly compared and the effect of the water particle cloud is observed. 


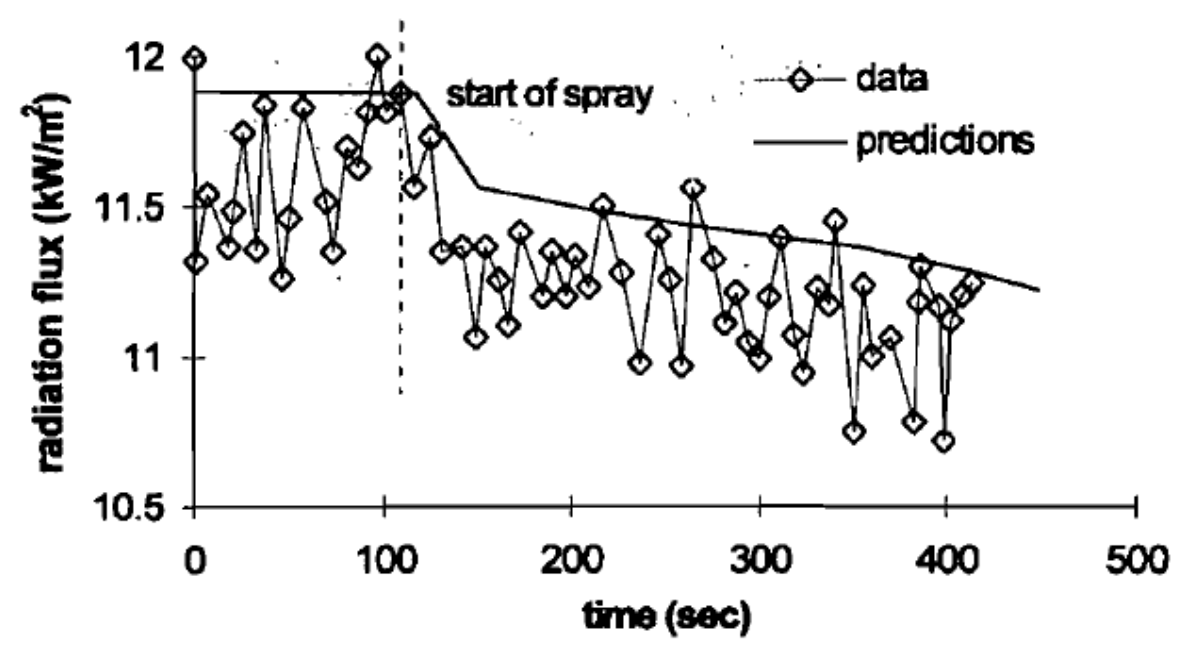

Figure 2.16 - Experimental and predicted radiation flux at the end of the flame region, for the $53 \mathrm{~kW}$ flame, before and after application of the spray [29]

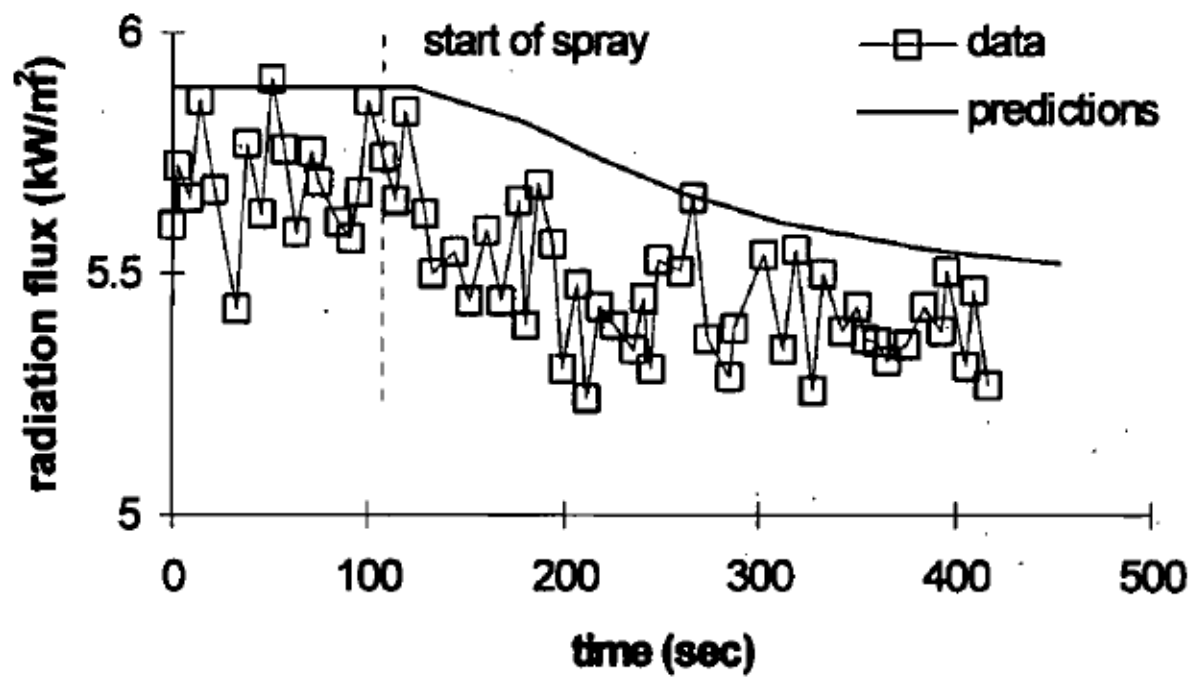

Figure 2.17 - Experimental and predicted radiation flux at the end of the flame region, for the $\mathbf{2 6 . 5} \mathrm{kW}$ flame, before and after application of the spray [29]

A two-phase radiation model has been developed to meet the needs of numerical computations of two-phase systems composed of a fine, real water spray, using an Euler-Lagrange technique. The model has been developed to assist with the design of water mist suppression systems, by evaluating the effect of water mist on thermal radiation. The model possesses two distinguishing features: (a) it calculates the optical properties of the non-uniform water droplet cloud in the infrared and (b) it establishes compatibility between the Eulerian and the Lagrangian modeling approaches. The model accomplishes 
these, therefore, avoiding the tedious and time-consuming calculations normally required to describe the complex variation of the water droplets optical properties with radiation wavelength.

The model has been validated through comparisons with experimental measurements. The agreement obtained between the numerical predictions and the experiments is adequate and has shown that the model describes the water mist/radiation interaction with sufficient accuracy. An important outcome from this numerical test was the quantification of the energy sinks distribution, which is difficult to obtain through experiments, showing that half of the droplet enthalpy gain is coming from radiation absorption. This shows that in the development of comprehensive water mist/fire interaction models, radiative heat transfer in the particulate phase cannot be overlooked.

\subsubsection{Thermal and Smoke Blockage by Water Curtains Chow [35]}

Due to limited experimental data being available, it is not certain whether drencher systems would be effective at blocking heat and smoke during a fire. Water spray patterns from three different drencher nozzles were studied.

Experiments were carried out in a fire chamber with two symmetric chambers $4.0 \times 2.9 \times 2.6 \mathrm{~m}$ high with an opening of $2.2 \times 1.83 \mathrm{~m}$ high between them as shown in Figure 2.18. A two-room structure was constructed with a room for burning pool fires and another room that is protected with a water curtain separating them. Thermal radiation heat fluxes on the protected side without discharging water curtain were measured initially followed by the radiation attenuation by a discharging water curtain from the three selected nozzles. A $165 \mathrm{~kW}$ pool fire of 0.6 m diameter was set up by burning 4 liters of propanol in the fire side room. Radiative heat fluxes and temperatures were measured by a heat flux transducer and K-type thermocouple trees in the protected room. The chemical heat of combustion of propanol was $31.8 \mathrm{~kJ} / \mathrm{g}$. The burning durations were about $420 \mathrm{sec}$ and varied as shown in the results, Figure 2.19. 


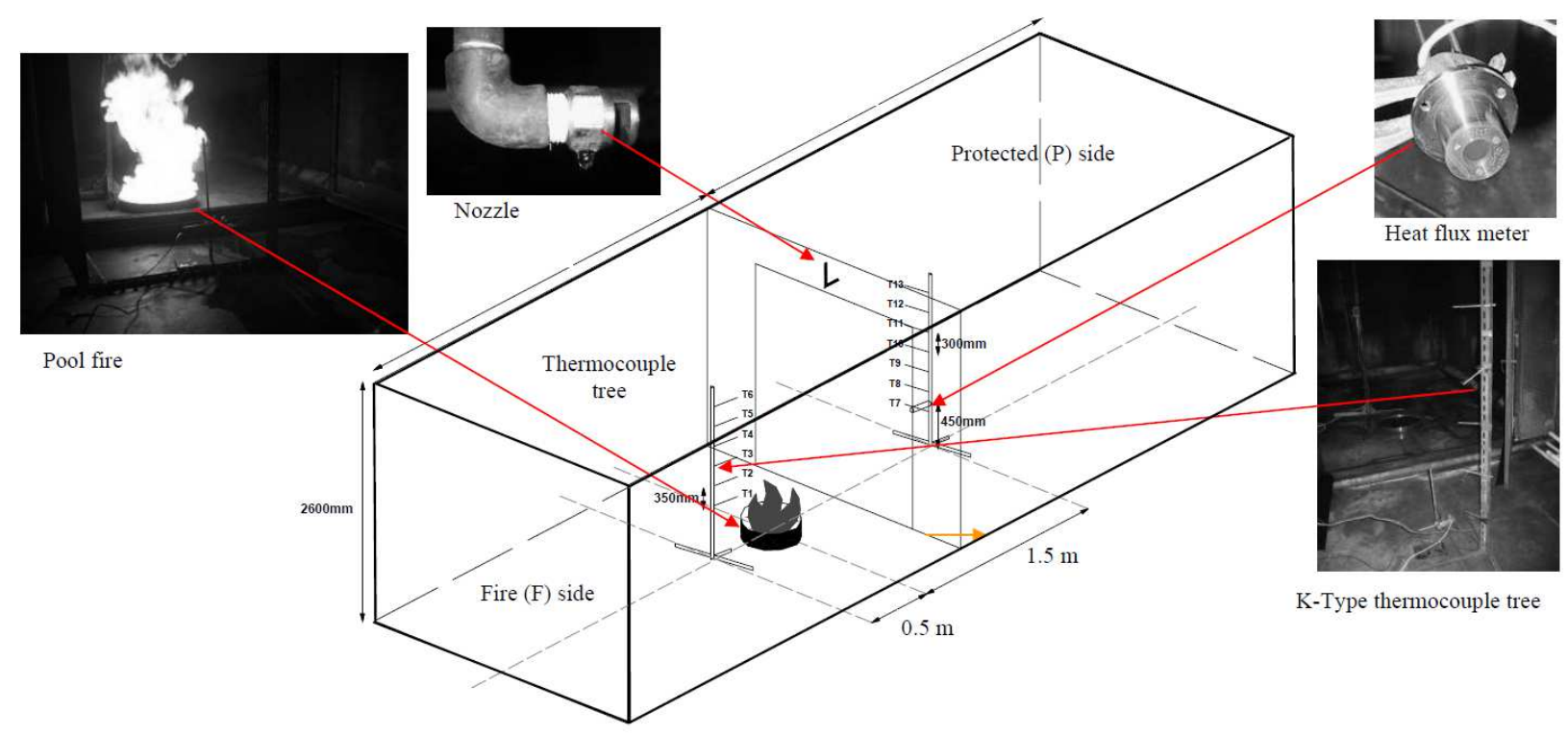

Figure 2.18 - Experimental setup of radiation attenuation of pool fires [35]

\begin{tabular}{|c|c|c|c|c|c|c|c|c|c|c|}
\hline $\begin{array}{l}\text { Nozzle } \\
\text { number }\end{array}$ & $\begin{array}{l}\text { Orifice } \\
\text { size } \\
(\mathrm{mm})\end{array}$ & $\begin{array}{c}\mathrm{K}- \\
\text { Factor }\end{array}$ & $\begin{array}{l}\text { Pump } \\
\text { pressure } \\
\text { (bar) }\end{array}$ & $\begin{array}{l}\text { Operating } \\
\text { pressure } \\
\text { (bars) }\end{array}$ & $\begin{array}{c}\text { Flow rate } \\
(\mathrm{L} / \mathrm{s})\end{array}$ & $\begin{array}{l}\text { Porosity } \\
\beta(\%)\end{array}$ & $\begin{array}{c}\text { Fire } \\
\text { duration } \\
\text { (s) }\end{array}$ & $\begin{array}{c}\text { Average } \\
\text { radiation } \\
\text { attenuation }(\%)\end{array}$ & $\begin{array}{l}\text { Temperature } \\
\text { dropped in } \\
\text { P-side }\left({ }^{\circ} \mathrm{C}\right)\end{array}$ & $\begin{array}{c}\text { Time required for } \\
\text { temperature to fall } \\
\text { below } 50^{\circ} \mathrm{C}(\mathrm{s})\end{array}$ \\
\hline A & 8 & 40 & 12.30 & 5.0 & 1.49 & 28.6 & 846 & 72.7 & 58 & 56 \\
\hline B & 13 & 115 & 10.50 & 0.8 & 1.70 & 41.3 & 947 & 68.1 & 43 & 230 \\
\hline C & 5.2 & 16 & 11.80 & 9.7 & 0.83 & 23.2 & 722 & 75.6 & 65 & 12 \\
\hline
\end{tabular}

Figure 2.19 - Summary of the results of the three nozzles [35]

From photographs taken during testing of the water curtains it was discovered, through the use of computer software to determine porosity, that the discharge patterns were not continuous layers. Therefore, thermal radiation and smoke cannot be entirely blocked. It was found that the higher the porosity, the lower the radiation attenuation.

Attenuation of thermal radiation was studied using the measured radiation heat fluxes in the protected room as shown in Figure 2.20. Radiation heat fluxes reduced in the protected room after discharging water. During the experiments it was observed that smoke spread from the fire room through the water curtain to the protected room. This can be justified by comparing the temperature profiles in both the fire room and protected room at the highest point as shown in Figure 2.21. Temperatures at the protected side after discharging water curtain reduced due to the blocking of thermal radiation by the water curtain. Temperature values dropped are shown in Figure 2.19. Air temperatures in the protected 
room for nozzle $\mathrm{B}$ reduced by only $40^{\circ} \mathrm{C}$ while air temperature reductions of over $60^{\circ} \mathrm{C}$ were recorded for nozzles A and C. Although smoke was observed to spread from the fire room to the protected room, temperatures in the protected side were reduced. Therefore, a discharging water curtain is quite effective in keeping the protected compartment cool. The three nozzles chosen were run under different flow rates and pressures. The discharged curtains from nozzles $A$ and $C$ were observed to have a similar porosity, $\beta$, shown in Figure 2.19.

Although radiation attenuation of the water curtain depends on the porosity, there is cooling effect in the protected room due to the water curtain. Air temperature in the protected room can be kept cooler, even when the water curtain has a thermal radiation attenuation of only $70 \%$. However, smoke spread from the fire room, to the protected room cannot be prevented. Based on the above theory, it is difficult to conclude that installing a drencher system with the three tested nozzles is equivalent to installing standard fire resistant measures. The discharged water curtain is unable protect the opening in the same way a wall with adequate fire resistance can.

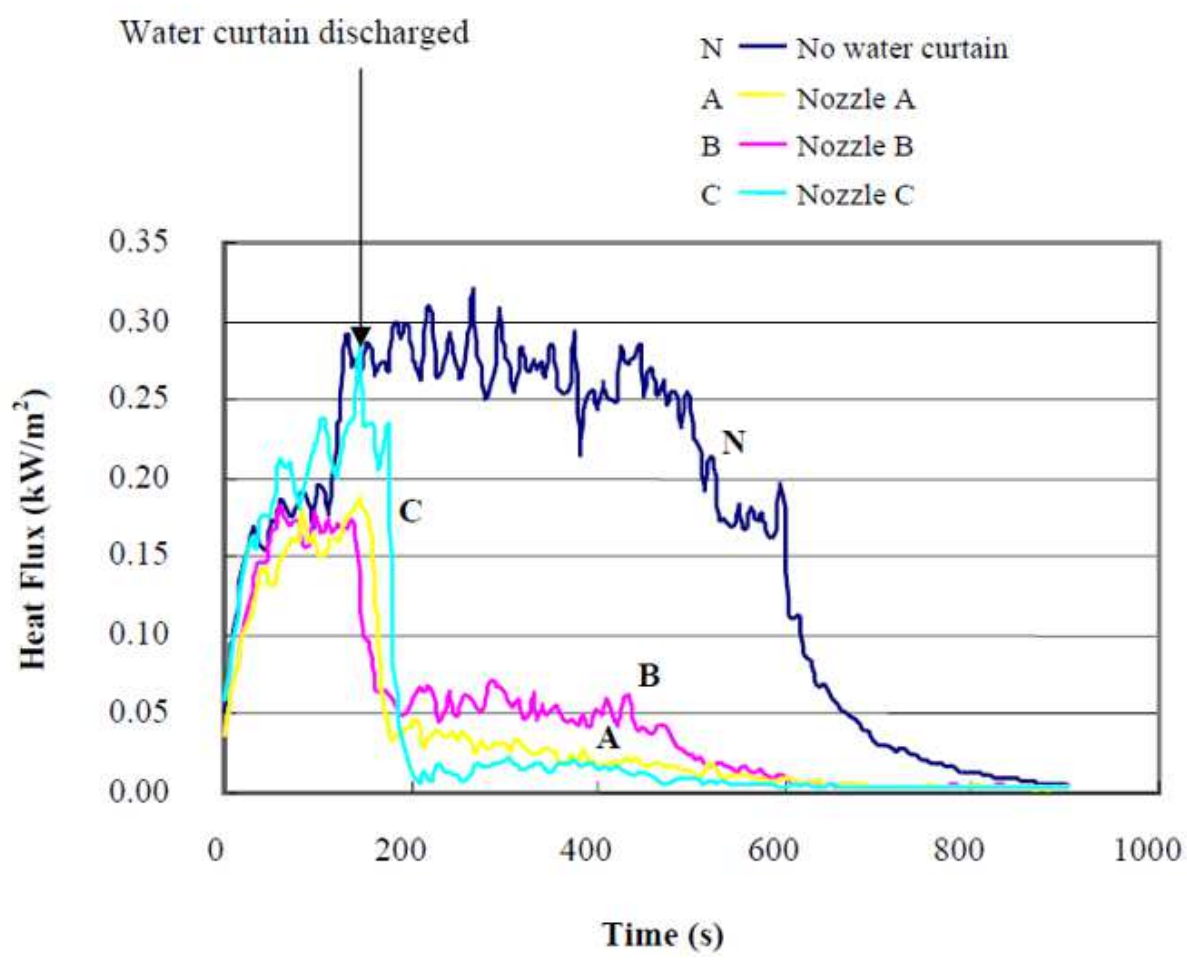

Figure 2.20 - Radiation Heat Flux Results [35] 


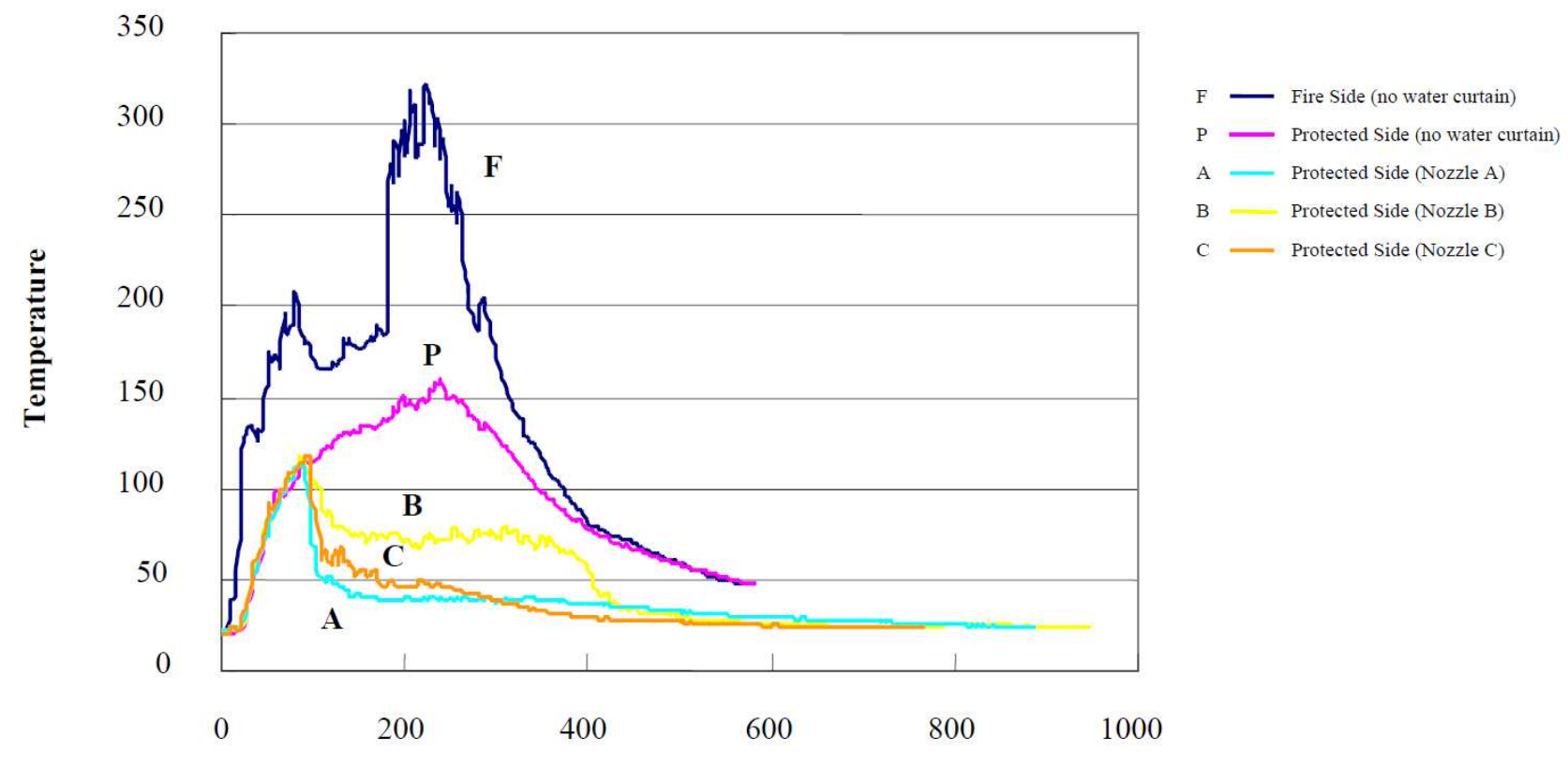

Time (s)

Figure 2.21 - Temperature Results [35]

\subsubsection{Radiation Blockage Effects by Choi [38]}

Experiments were conducted to examine whether radiative heat flux can be blocked by a water curtain under various operating conditions by measuring the temperature and heat flux distributions between two chambers. The experiments were conducted in a fire chamber at the Hong Kong Polytechnic University Department of Building Services Engineering laboratory. Two symmetric chambers 4.0 x 2.9 x $2.6 \mathrm{~m}$ high with a $2.25 \times 1.8 \mathrm{~m}$ high opening in between were constructed for the experiments, shown in Figure 2.22. The drencher head was installed above the opening centered at $2.25 \mathrm{~m}$ from the finished floor level. A Viking C-1 window sprinkler with orifice diameter of $16 \mathrm{~mm}$ was used. 


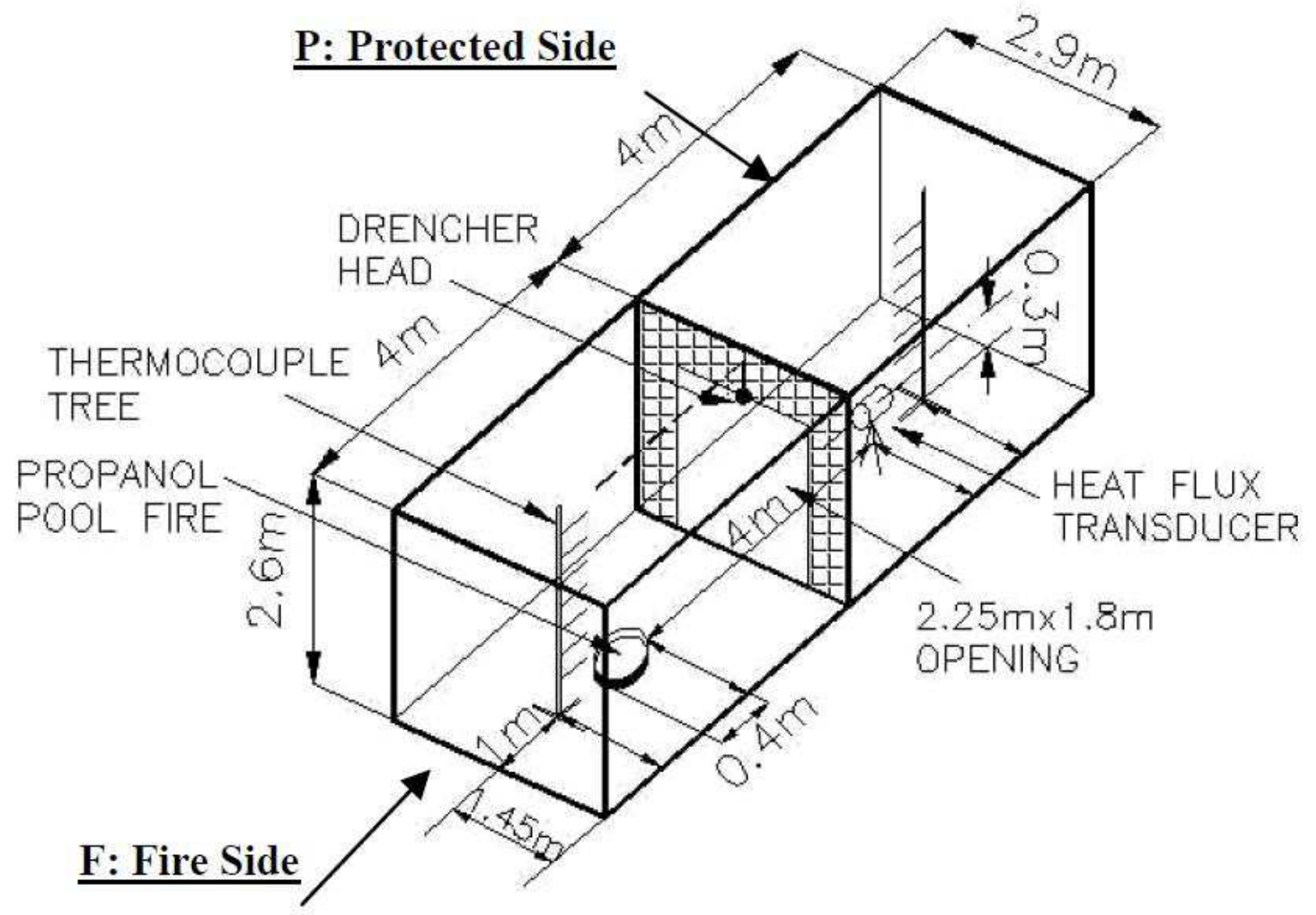

Figure 2.22 - Experimental Setup [38]

The two chambers were separated by a water curtain created by discharging the drencher system.

The chamber with the pool fire located at the center is referred to as the fire side and the other is referred to as the protected side. A $2000 \mathrm{ml}$ propanol pool fire with $0.4 \mathrm{~m}$ diameter was used during the experiments. The discharge pattern of the water curtain was observed from the photographs taken after activation of the drencher system.

To measure the temperature distribution thermocouple trees were placed on each side of the chamber. The thermocouples trees had seven K-type thermocouples spaced $0.3 \mathrm{~m}$ apart (T1 at the bottom and $\mathrm{T} 7$ at the top). 
To measure the thermal radiation effects, a Schmidt-Boelter sensor type heat flux transducer was used. For fire test purposes, the sensing element was mounted in a water-cooled body. It is also configured as radiometer such that the sensor window is used to eliminate convective currents in order for only the radiation heat flux to be measured and the spectrum transmitted by the sapphire window was nominal from 0.15 to $5.0 \mu \mathrm{m}$ which is suitable for measuring the $2 \mu \mathrm{m}$ wavelength emitted from the fire.

Based on the ASTM Standard E603 Room Fire Experiment, the heat flux transducer is suggested to be located at the room center floor level in order to protect the cooling and data lines from fire and physical damage. Therefore, it was placed at $0.3 \mathrm{~m}$ above the floor level at the center of protected room. The heat flux transducer had a calibration traceable to the National Institute of Standards and Technology. All data was read directly on an $\mathrm{H}-201$ heat flux meter and recorded by a Fluke187 multimeter at intervals of $5 \mathrm{~s}$.

Temperature results are shown in Figure 2.23 through Figure 2.27. Results on the effects of heat flux are shown in Figure 2.28. From the results it was found that the actuation of the drencher system caused both the temperatures and heat flux readings in the protected side to decrease. 


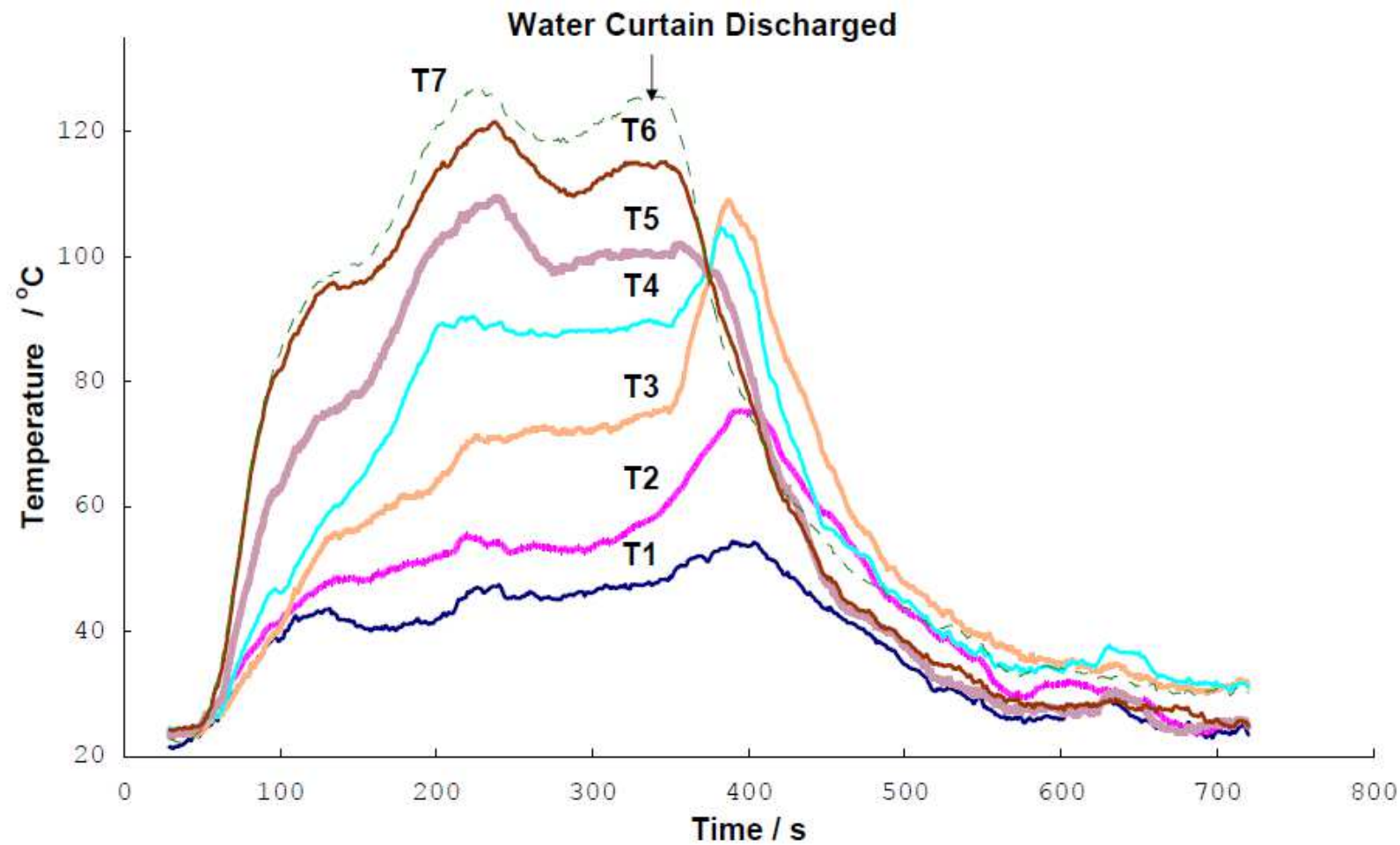

Figure 2.23 - Temperature distribution on the fire side [38]

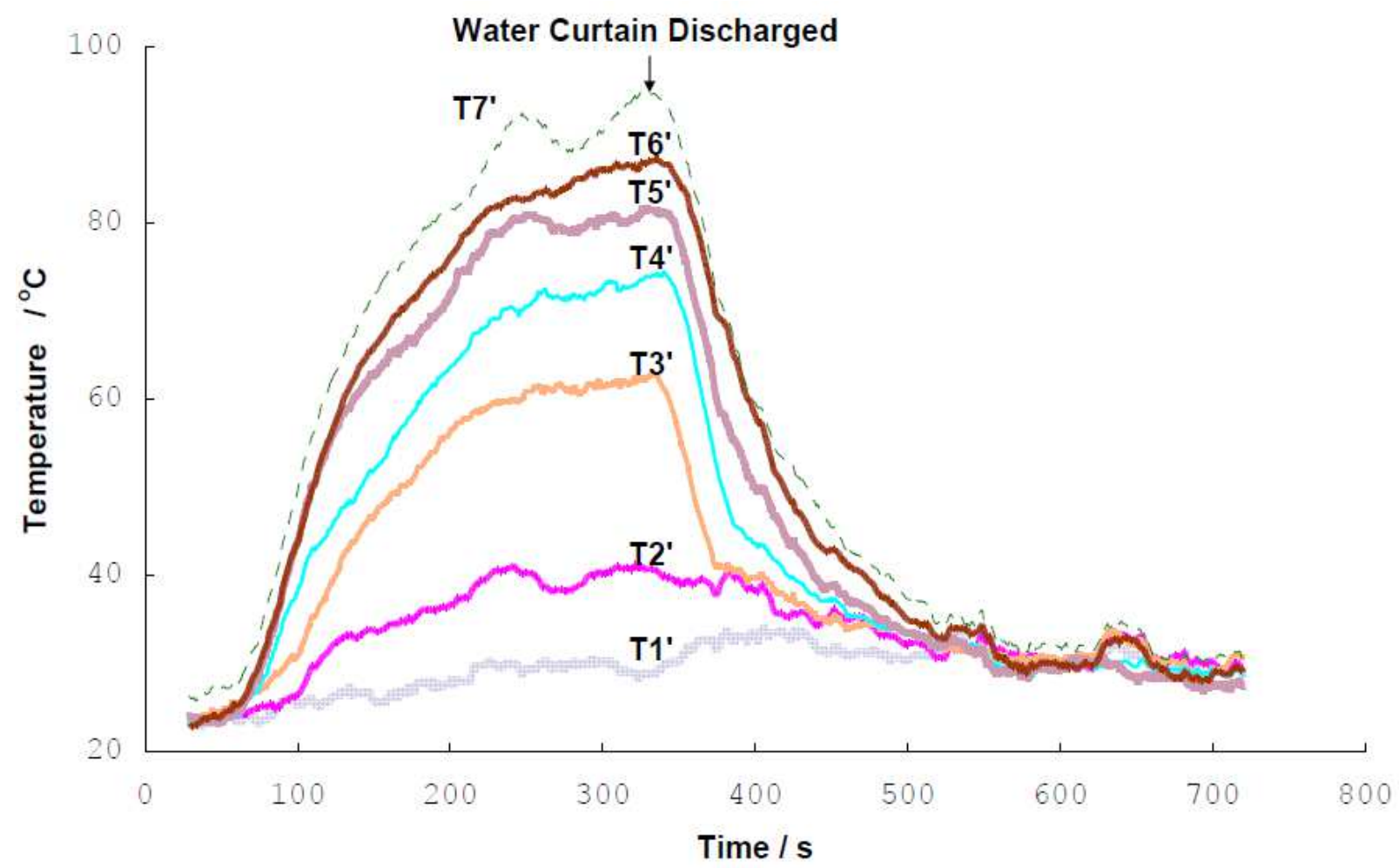

Figure 2.24 - Temperature distribution on the protected side [38] 


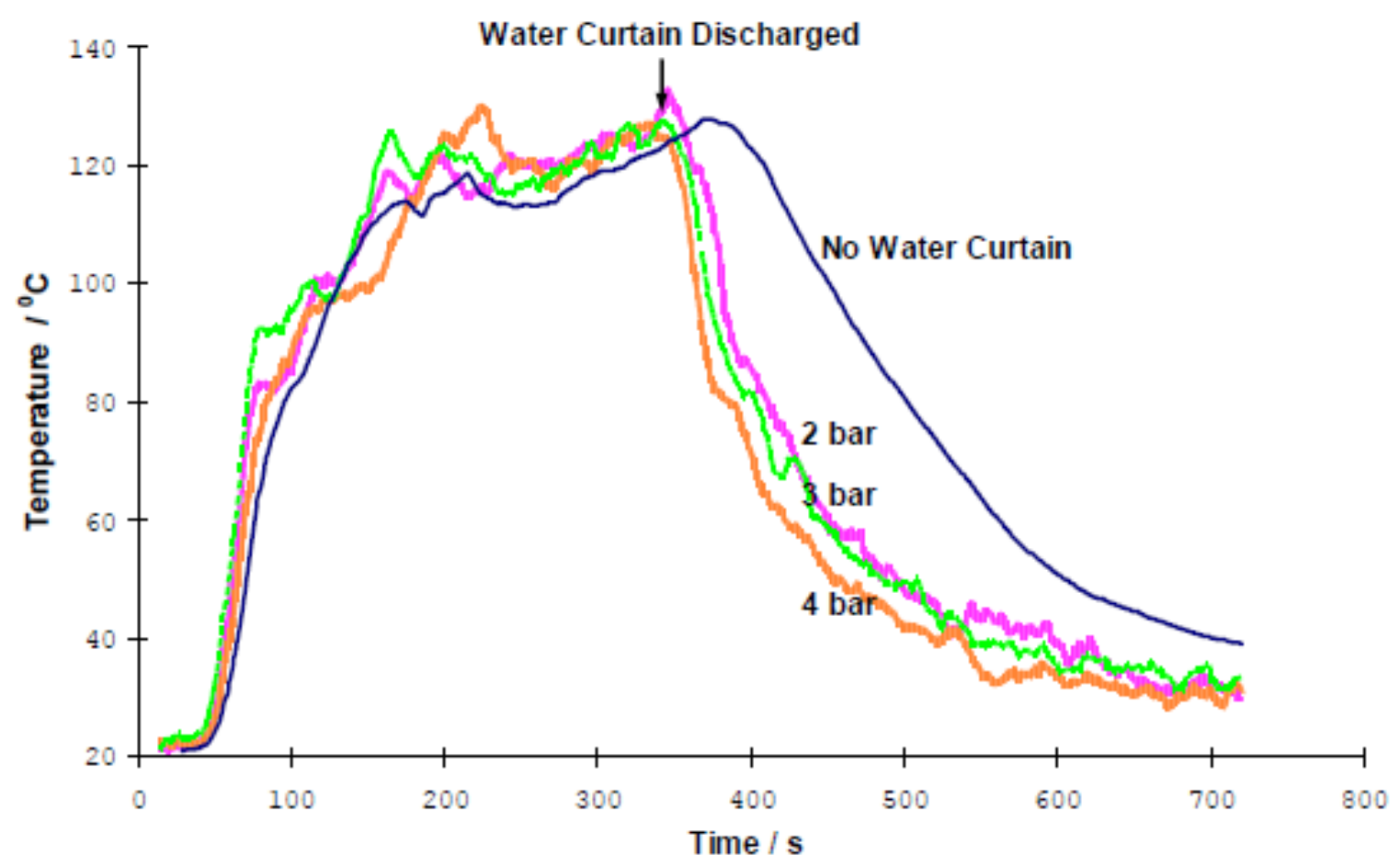

Figure 2.25 - Maximum temperature (T7) at fire side under different operating conditions [38]

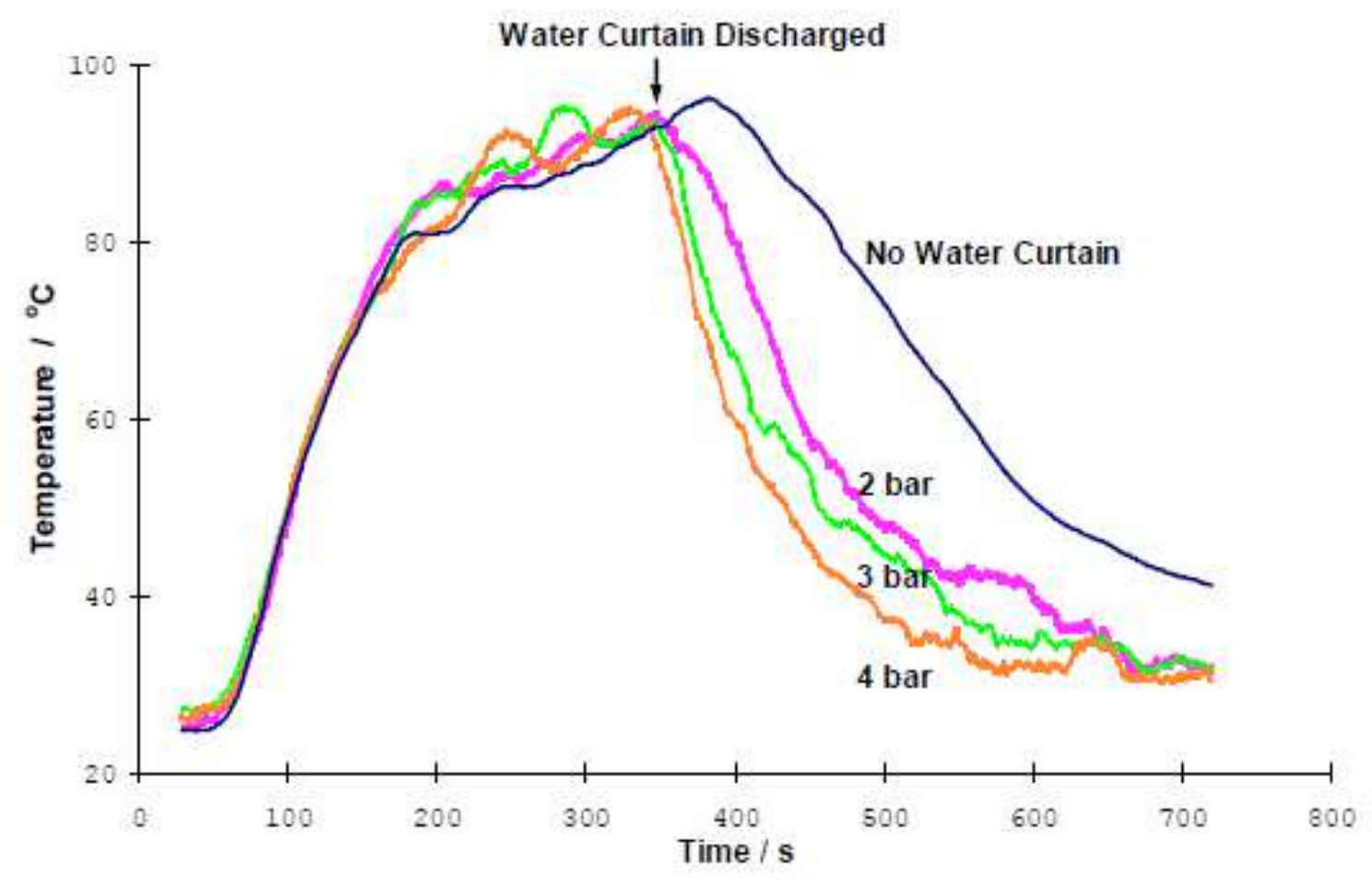

Figure 2.26 - Maximum temperature ( $\left.\mathrm{T7}^{\prime}\right)$ at protected side under different operating conditions [38] 


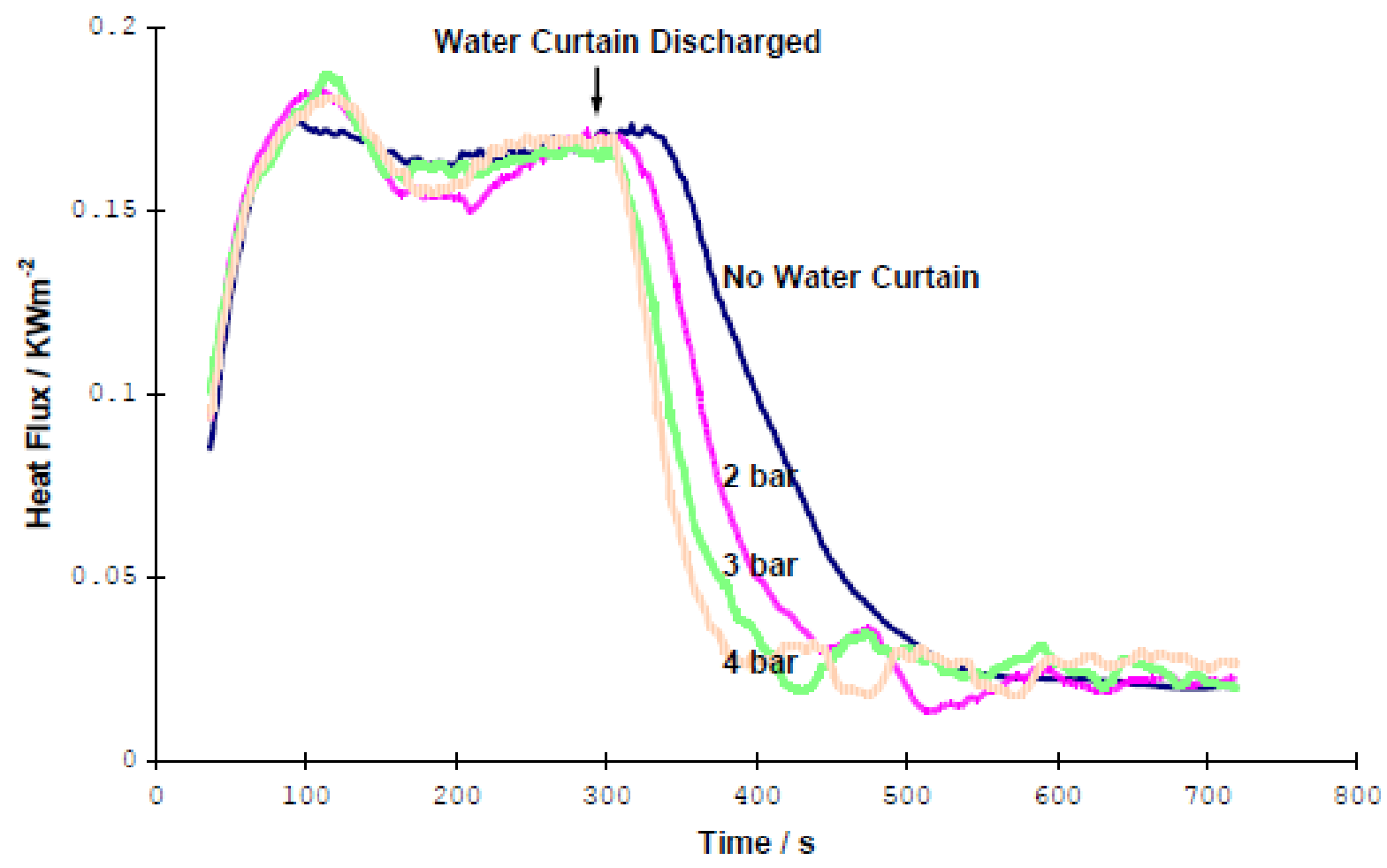

Figure 2.27 - Heat flux at protected side under different operating conditions [38] 


\section{Experimental Setup}

This research was conducted to determine if the use of a water curtain can be used in Canada as an effective measure to prevent fire spread during a compartment fire. Due to the limited research available on the issue of fire spread between adjacent properties during a compartment fire, a series of experiments to investigate the use of a water curtain over a compartment opening to prevent fire spread to adjacent properties was performed between May 2014 and May 2015 at Carleton University's Fire Research Lab. The tests utilized a small compartment with propane burners and a target wall which could be moved to a desired distance away from the compartment.

\subsection{Test Series}

A compartment was constructed for the purposes of testing the effect of heat radiation leaving a compartment opening and impinging on adjacent properties. A target wall was placed a set distance from the compartment across from the opening. The target wall was instrumented with heat flux gauges and thermocouples to measure radiation heat flux and temperatures from the compartment fire and flames leaving the compartment opening. For all of the experiments propane was used as the fuel. The experiments were conducted using propane diffusion burners along three pipelines evenly distributed along the floor of the compartment. The propane mass flow rate was manually controlled using valves located behind the compartment and measured using a portable propane flow rate meter. Three fire sizes, representing fires of increasing severity, and three sprinkler flow rates were used for these experiments. The sprinklers were controlled using a valve located on the water feed main.

The test series used fires of sizes; 2-MW, 3-MW, and 4-MW. Tests ran until steady state conditions were reached. Steady state was assumed to occur when the heat flux readings along the target wall stop fluctuating. Initial tests were run without the use of sprinklers in order to determine baseline heat flux readings on the target wall. This allowed for comparison with the effect of the sprinklers. Following the 
baseline tests the sprinklers were activated and ran at flow rates of $15 \mathrm{gpm}(56.85 \mathrm{~L} / \mathrm{min}), 20 \mathrm{gpm}$ (75.8 L/min), and $24 \mathrm{gpm}(90.96 \mathrm{~L} / \mathrm{min}$ ) per sprinkler (Note that flow is in US gallon per minute). The target wall was placed at distances of $3 \mathrm{~m}$, and $4 \mathrm{~m}$ away from the compartment. A series of tests with the target wall at $5 \mathrm{~m}$ was scheduled but it was determined that it was not needed following the tests with the target wall at $3 \mathrm{~m}$ and $4 \mathrm{~m}$.

The first set of tests was run at a distance of $3 \mathrm{~m}$ with each fire size and sprinkler flow rate was tested. Following these tests the ceiling insulation failed requiring repairs. The damage caused the continuation of the tests to be postponed until after the winter months due to issues with the water freezing. After the repairs were completed in the spring of 2015 the next set of tests at a distance of $4 \mathrm{~m}$ was run. It was determined after these tests that due to the low heat fluxes experienced on the target wall that further testing at a larger distance was not needed.

\subsection{Compartment Design}

\subsubsection{Compartment}

The compartment, Figure 3.1, was designed to ensure that the structure could endure repeated fire tests of varying size. The compartment was built upon a levelled wooden base using non-combustible steel studs as a framing material. The steel studs were standard 38 by $140 \mathrm{~mm}$ studs spaced $30 \mathrm{~cm}$ apart. The interior surfaces, floor, walls and ceiling, were made using half inch non-combustible Hardi Backer 500 cement boards. These were protected using $50 \mathrm{~mm}$ of Fibrefrax high temperature insulation. The floor was additionally lined with fire resistant bricks with extra bricks to support the propane burners. All joints were sealed using heat resistant caulking. The façade wall was built using the same steel studs, braced into the roof of the compartment. The front of the façade wall was lined with non-combustible cement board. Additional cement boards were installed on the front wall of the compartment 
surrounding the opening to help protect the frame of the structure from the flames exiting the compartment.

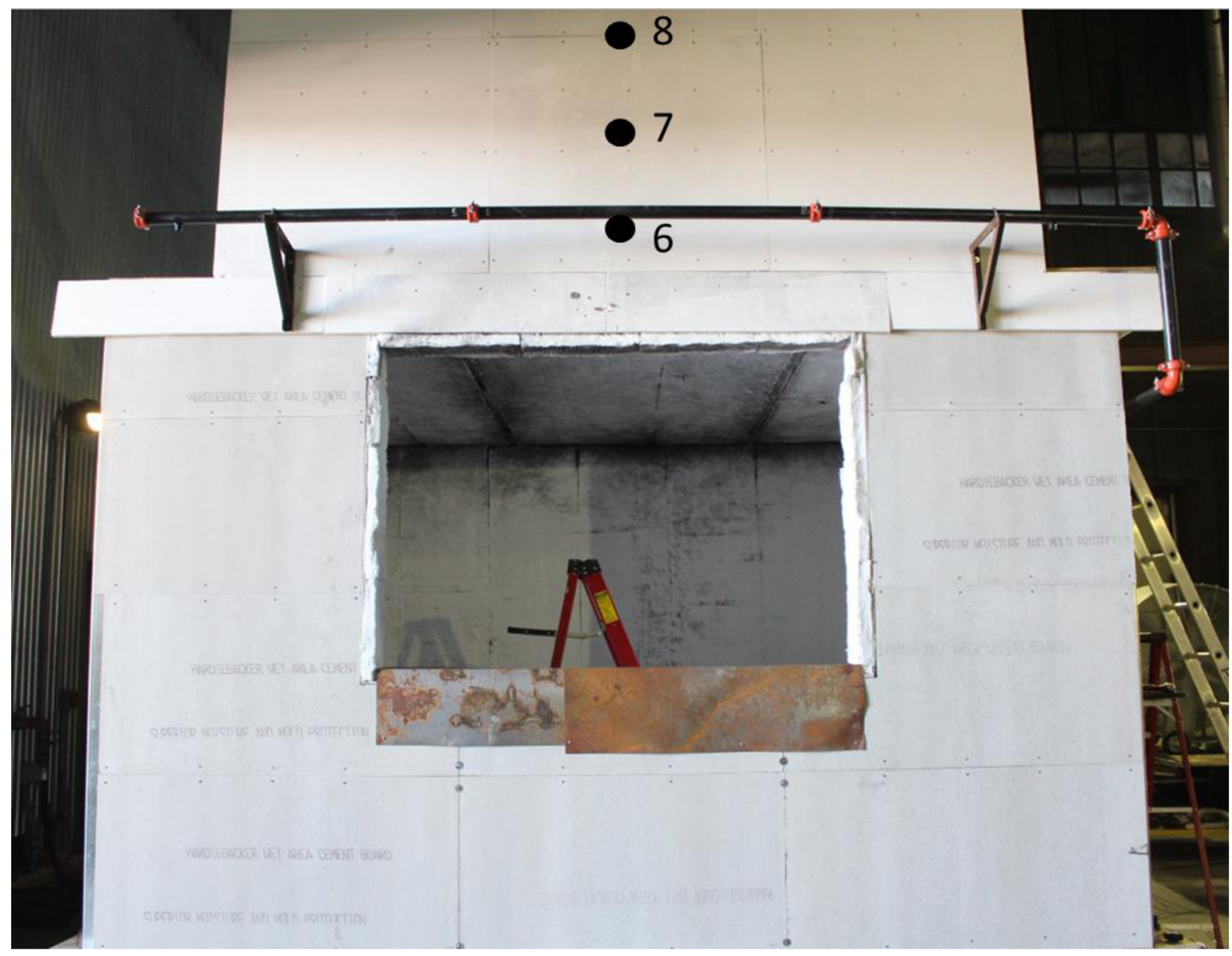

Figure 3.1 - Compartment with sensor locations

The compartment design, Figure 3.2 and 3.3, had interior dimensions of $4 \mathrm{~m} \times 3 \mathrm{~m} \times 3 \mathrm{~m}$ high. The opening of the compartment was fixed at $2 \mathrm{~m} \times 1.5 \mathrm{~m}$ high. The front façade wall extended $3 \mathrm{~m}$ above the roof of the compartment. The compartment was designed to have three sensor locations on the front façade wall above the compartment opening. Each sensor location contained a heat flux meter and a thermocouple. 


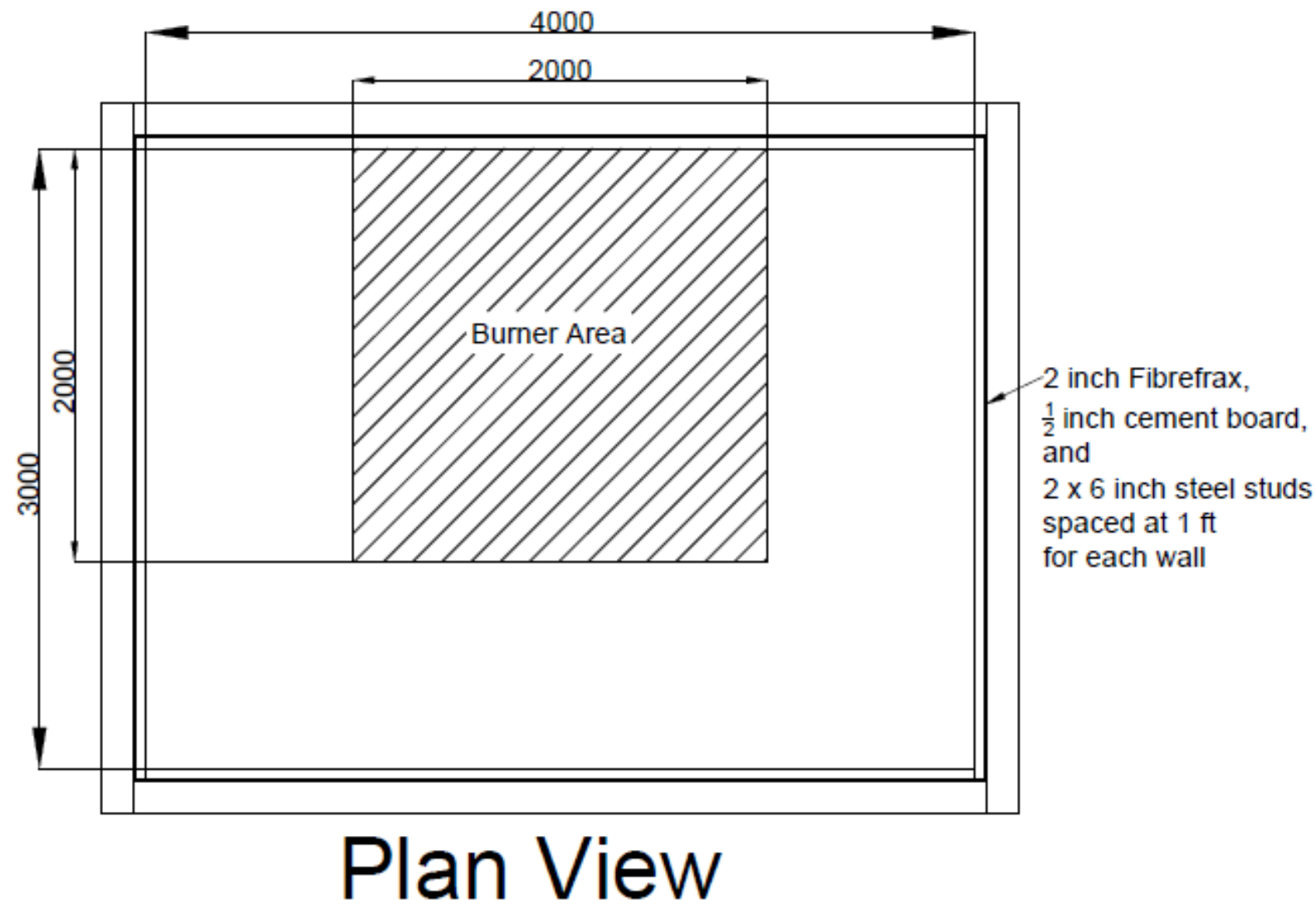

Figure 3.2 - Plan view of compartment design $(\mathrm{mm})$ 


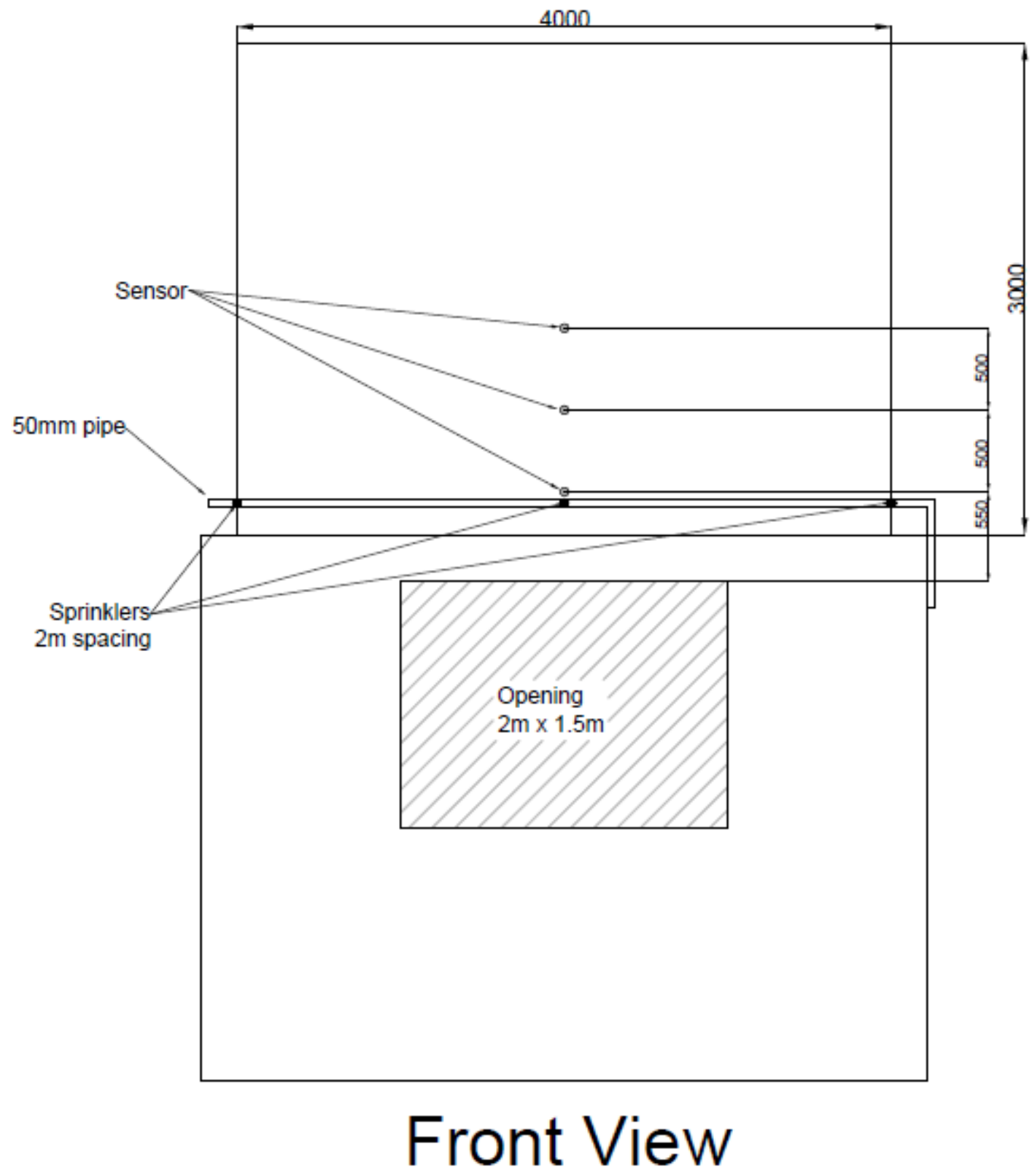

Figure 3.3 - Front View of the compartment with sensor locations ( $\mathrm{mm}$ )

The compartment walls were erected initially with cement boards and insulation added. Then the ceiling was built in three separate sections with cement boards and insulation added on. The individual ceiling pieces were then raised and placed into position. Finally the front façade wall was built, raised into position, and braced into the ceiling. 
After the initial set of tests at $3 \mathrm{~m}$, a segment of insulation along the ceiling failed, shown in Figure 3.4, allowing gas to escape into the ceiling joists. This was remedied by installing an additional cement board over the damaged section and applying a new layer of insulation.

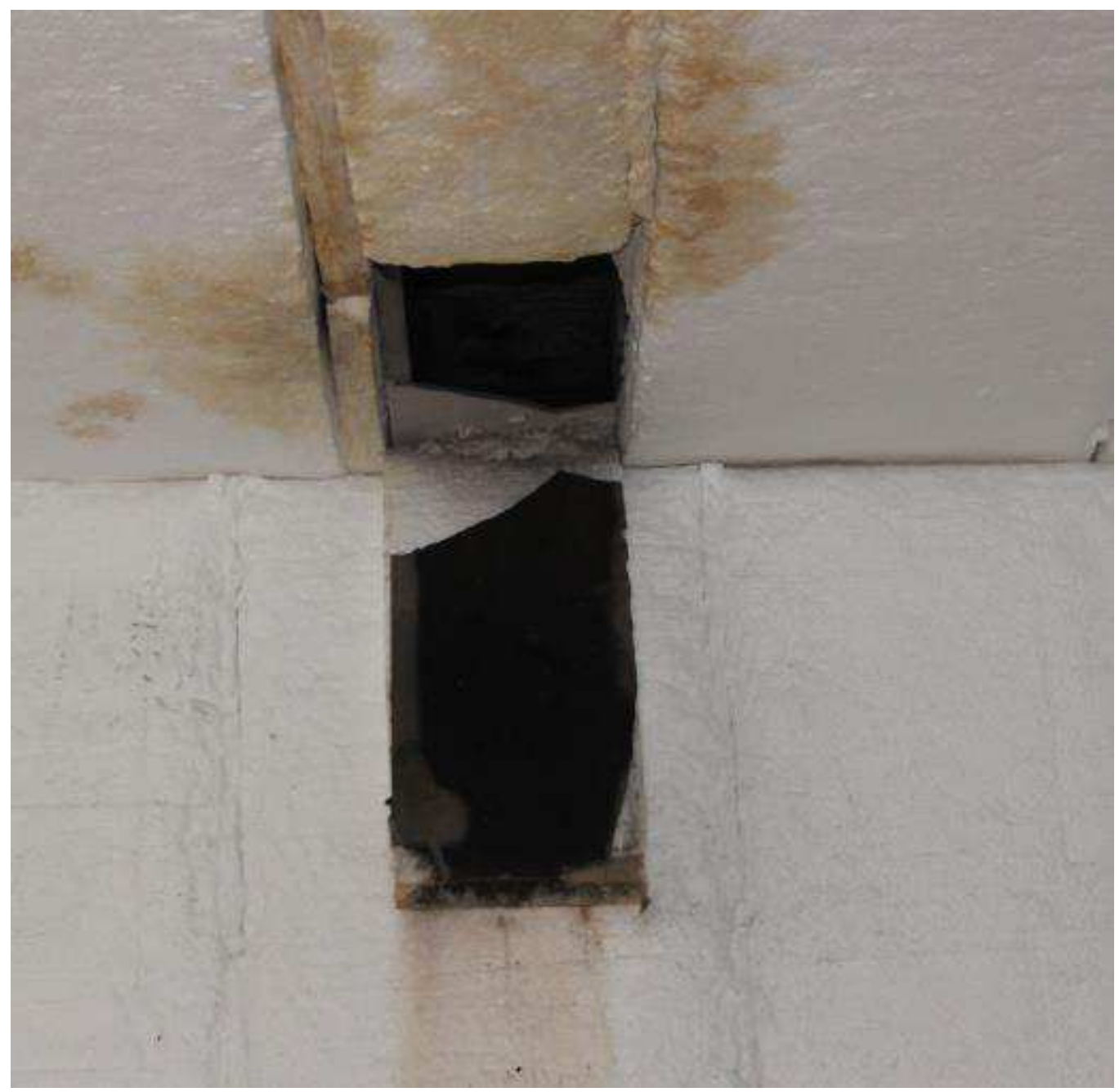

Figure 3.4 - Section of insulation that was damaged during testing

\subsubsection{Water Curtain}

To create the water curtain 3 pendent sprinkler heads were designed as shown in Figure 3.3, to be used outside of the compartment at a spacing of $2 \mathrm{~m}$ each. The sprinkler pipe was placed on brackets such that they were $460 \mathrm{~mm}$ above the opening and $305 \mathrm{~mm}$ away from the front of the compartment. The sprinklers were centred in the middle of the compartment opening in line with the sensors. The 
sprinklers were installed on a $50 \mathrm{~mm}$ steel pipe which ran from a reservoir to the front of the compartment. To feed water to the system, a $3 \mathrm{HP}$ Chemflo pump was used to pump water from a reservoir into the system. The reservoir was created using the drainage basin within the lab and sealing the outflow pipe. The water used during testing was recycled into the basin in order to conserve water usage. A filter was placed at the pump inlet to filter any debris that may have entered the basin during testing. To control the flow rates of the sprinklers, a flowmeter with a manual control valve was installed next to the pump. A pressure gauge was used to verify the correct pressure required for the system.

The pipeline was constructed in the atrium and then raised into place on top of the two brackets on the front of the compartment. The pump, flowmeter, and controls were built onto a wooden frame that could be moved to the desired location, shown in Figure 3.5. 


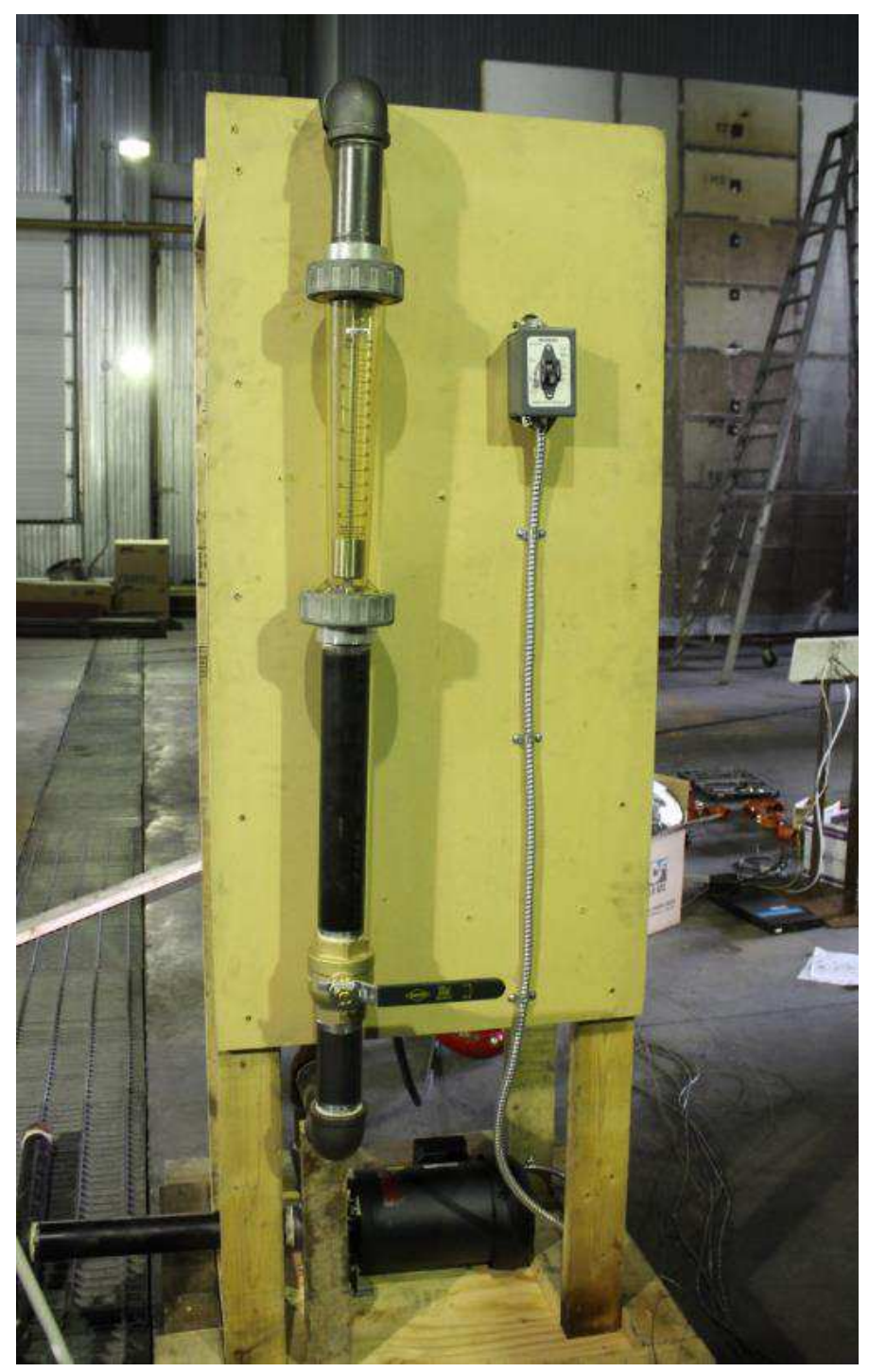

Figure 3.5 - Sprinkler pump, flowmeter, and controls

\subsubsection{Fire Source}

To create the fire, three propane burners, Figure 3.6, were placed in the centre of the compartment on top of fire bricks $0.06 \mathrm{~m}$ above the floor. The burners were constructed using heavy gauge steel tubing with a diameter of $50 \mathrm{~mm}$. Each burner consisted of two lines that could be manually controlled using valves placed along the pipe outside the rear of the compartment. The burners enter the compartment through openings at the rear of the compartment which were sealed after the burners were installed. The propane flow rate was controlled using the valves at the rear of the compartment, Figure 
3.7, and monitored using pressure gauges and a propane flow meter. This ensured that a constant fire heat release rate was produced and maintained during the tests.

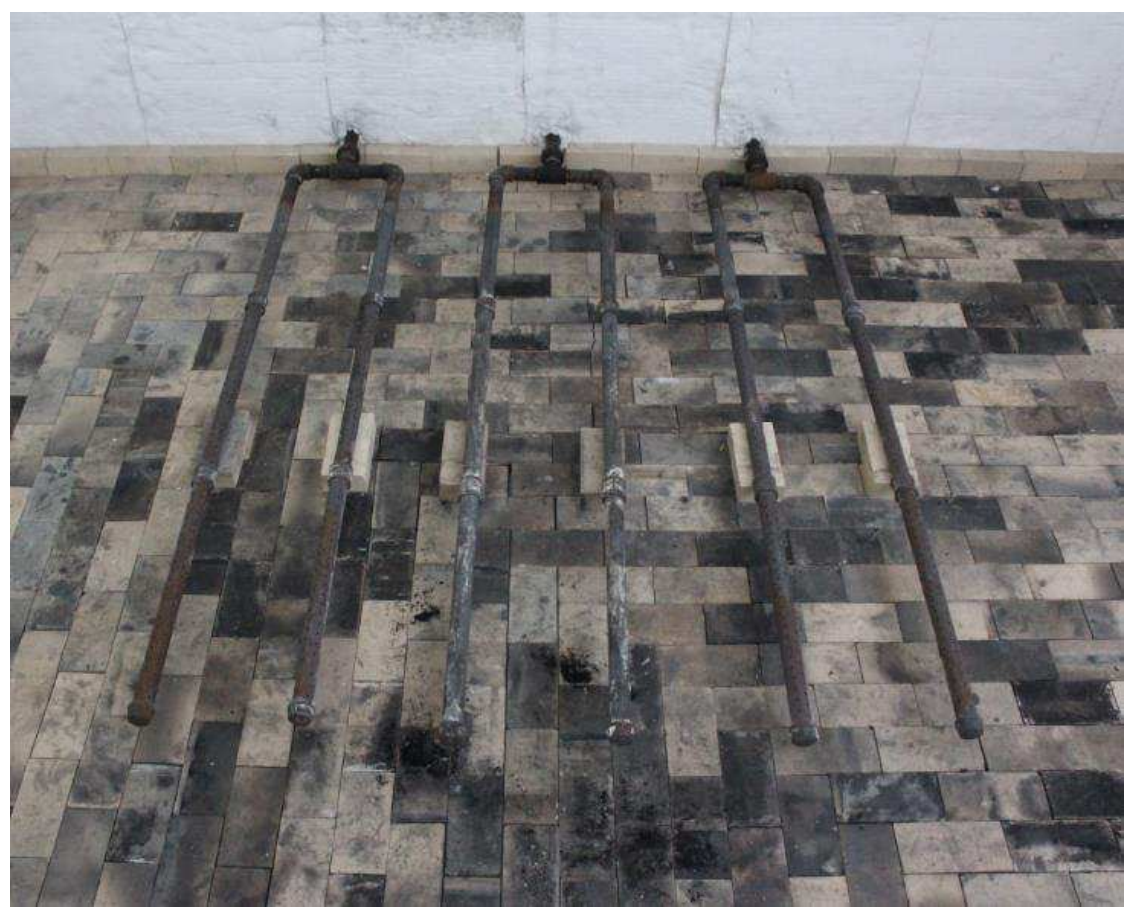

Figure 3.6 - Burners installed in the compartment

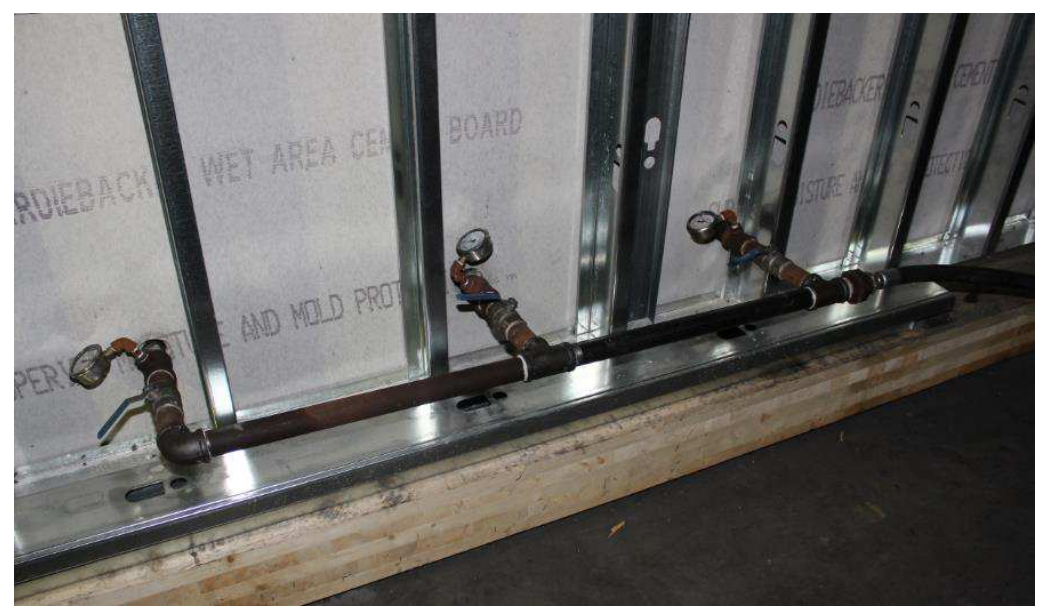

Figure 3.7 - Propane burners installed in the compartment and control valves at the rear

\subsection{Target Wall}

The target wall, Figure 3.8, was built using a wooden frame protected by non-combustible cement board on the front face. The target wall was built on rollers to allow for the wall to be movable. The wall is $4.9 \mathrm{~m}$ by $4.9 \mathrm{~m}$ and can be moved to the desired distance away from the compartment. The target wall 
was designed, Figure 3.9, to have five sensor locations. The sensors were placed along the same line as the sensors placed above the compartment, centred in the middle of the compartment opening. As with the sensors on the compartment, each sensor location contained a heat flux gauge and a thermocouple.

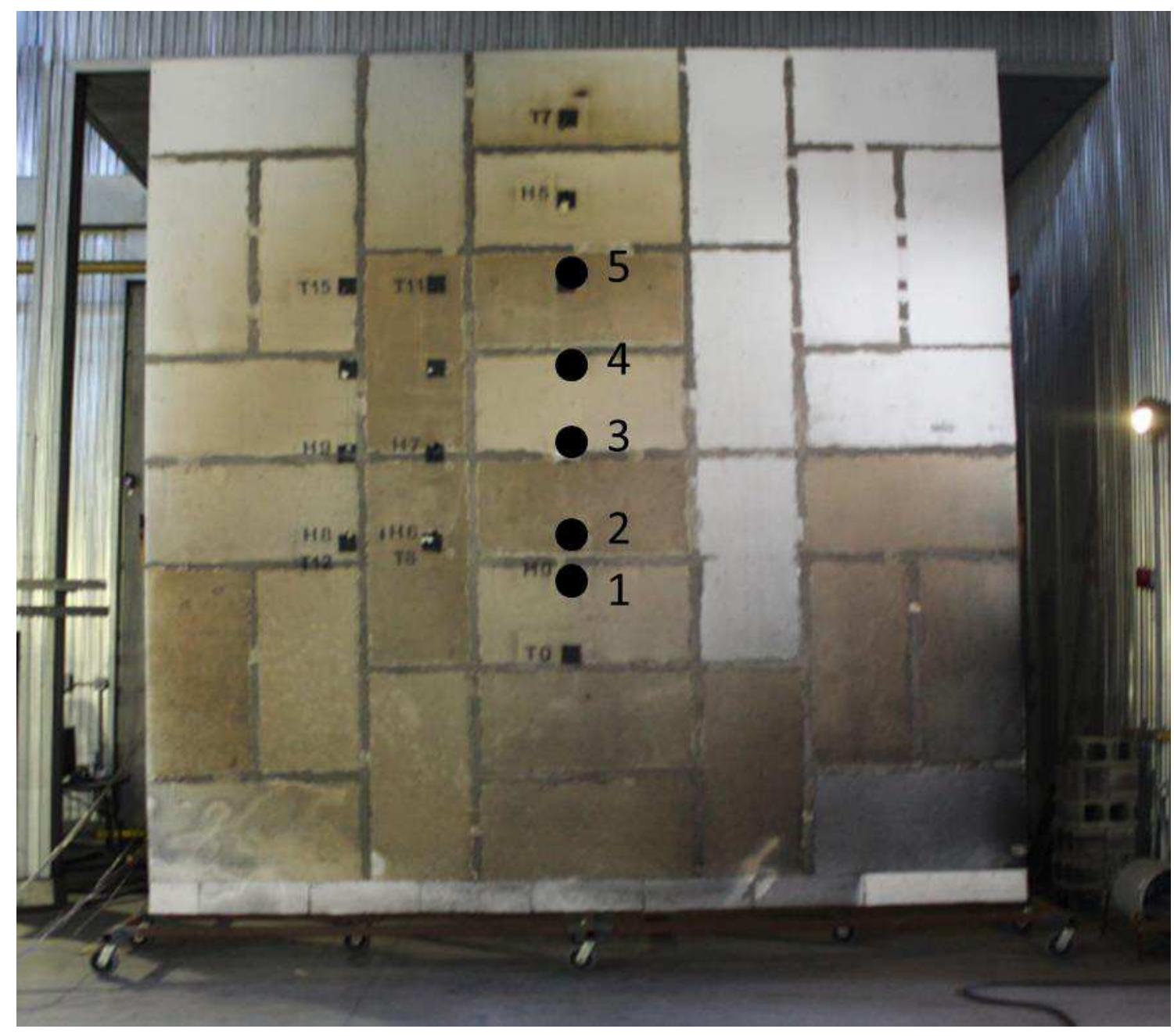

Figure 3.8 - Built target wall with sensor locations 


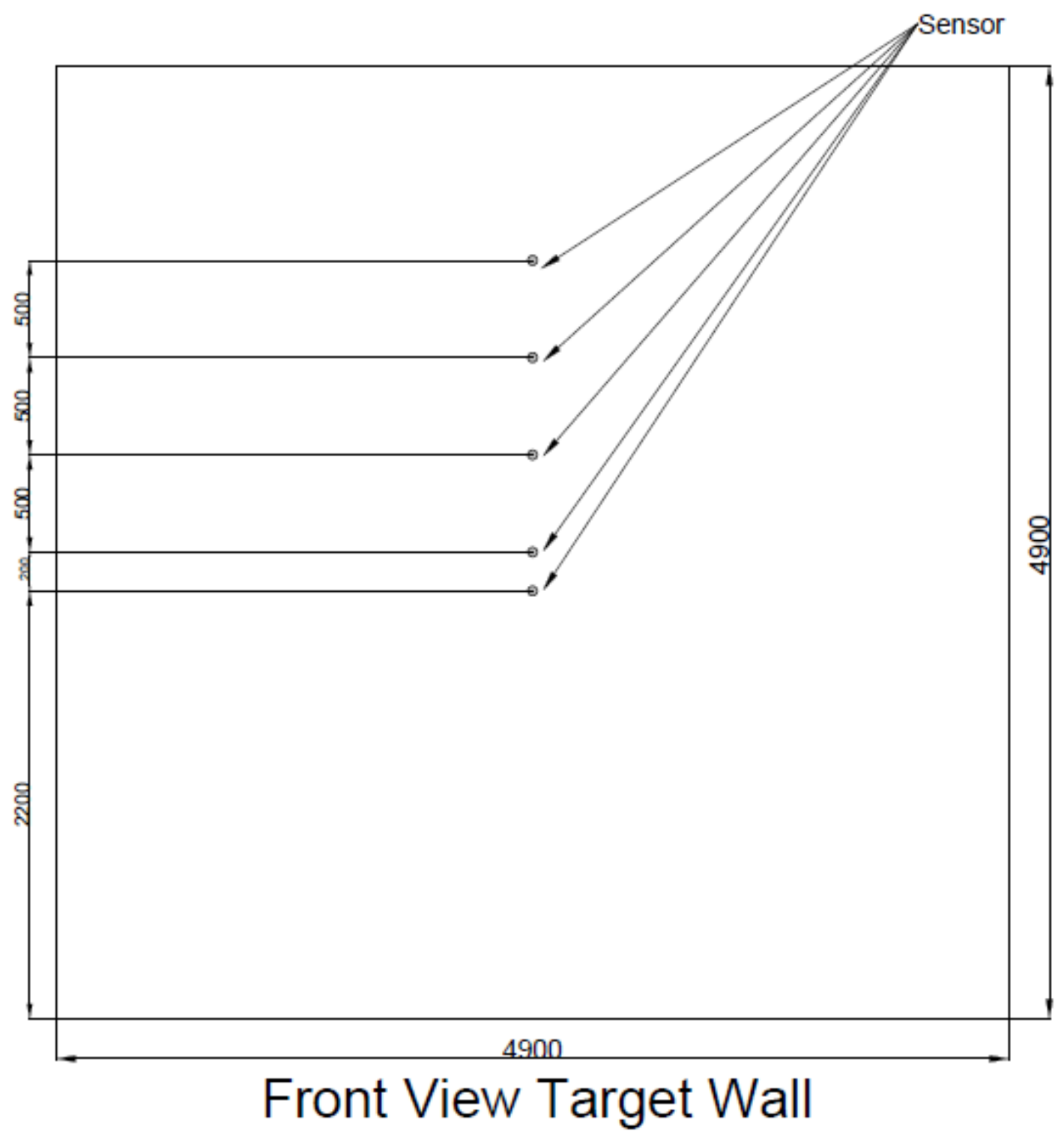

Figure 3.9 - Front View of the designed target wall with sensor locations

\subsection{Instrumentation}

Each sensor location shown in Figure 3.3 and Figure 3.9 contained a heat flux gauge and a thermocouple. Heat flux gauges and thermocouples were placed in a vertical line opposite the vertical centre line of the compartment opening in order to find the position of maximum radiation heat flux and surface temperature on the target wall. Five heat flux gauges and five thermocouples were placed along 
the target wall beginning $2.2 \mathrm{~m}$ above the floor in line with the centre of the opening. The next sensor was $0.2 \mathrm{~m}$ above the first and subsequent sensors were spaced at $0.5 \mathrm{~m}$. Three heat flux gauges and thermocouples were placed on the front façade wall extending above the opening to the compartment. The first sensor on the extension wall was $0.55 \mathrm{~m}$ above the opening and subsequent sensors were spaced at $0.5 \mathrm{~m}$.

Recordings of the test data was acquired using a data acquisition system in conjunction with the National Instruments LabVIEW software. To record the data during the test series a LabVIEW Virtual Instrument (VI) was developed to record and output the data from the experiments. Readings were taken every tenth of a second and then it was put through a low pass filter in order to minimize the amount of noise that was being encountered by the heat flux gauges. The LabVIEW program output the filtered data for both the heat fluxes and the temperatures into Excel spreadsheets that could be easily analyzed.

The heat flux gauges used are Gardon Gauges accurate to within $+/-3 \%$. The heat flux gauges were calibrated by the Medtherm Corporation in compliance with ISO/IEC 17025, ANSI/NCSL Z540-1 and MIL-STD-45662A to Medtherm PI-20 with traceability to the National Institute of Standards and Technology. The thermocouples used at the Carleton Fire Research Lab are standard K-type thermocouples, shown in Figure 2.4, accurate to within $+/-0.75 \%$. The K-Type thermocouples have a measurement range from $-200^{\circ} \mathrm{C}$ to $1250^{\circ} \mathrm{C}$.

\subsection{Cameras}

During testing two camcorders were used to record the experiments. Two infrared cameras were placed to record the infrared images of the target wall as well as the front face of the compartment. A handheld camera was used to take individual pictures during the experiments. 


\subsection{Preliminary Calculations}

Some calculations were carried out prior to the tests to try to estimate the, pressure requirements, and minimum limiting distances. These are included in Appendix A. 


\section{Experimental Results and Discussion}

The test series consisting of 24 experiments was run in the Carleton University Fire Research Lab. The experiments are differentiated by the separation distances, fire size, and sprinkler flow rates. The first series of tests was run at a separation distance of $3 \mathrm{~m}$ followed by the second test series at a separation distance of $4 \mathrm{~m}$. Following the $4 \mathrm{~m}$ separation distance test series it was decided that the planned test series at a separation distance of $5 \mathrm{~m}$ was unnecessary.

Data on the heat fluxes and temperatures was gathered using heat flux gauges and thermocouples installed at various locations along the target wall and above the compartment opening is presented below based on test series.

\subsection{First Test Series: 3 m Separation Distance}

For the first series of tests the target wall was placed $3 \mathrm{~m}$ from the room. Tests were run for 2$\mathrm{MW}, 3-\mathrm{MW}$, and 4-MW fires.

\subsubsection{2-MW Fire Tests Results}

The heat flux results, Table 4.1, for the 2-MW fire on both the target wall and the façade wall are shown graphically in Figure 4.1 and Figure 4.2, respectively. The initial average heat flux experienced by the target wall when no sprinklers were active was $7.44 \mathrm{~kW} / \mathrm{m}^{2}$, which is below the threshold for piloted ignition of wood products. The point of highest heat flux was between HF3 and HF4 located across from the top of the compartment opening with a reading of $8.2 \mathrm{~kW} / \mathrm{m}^{2}$ at $\mathrm{HF} 3$ for the baseline test. The introduction of the water curtain decreased the heat flux readings on the target wall for all flow rates to below $4.6 \mathrm{~kW} / \mathrm{m}^{2}$. The average heat flux reduction when compared to the baseline heat fluxes was $47 \%$ for the 15 gpm flow rate, $49 \%$ for the 20 gpm flow rate, and $43 \%$ for the 24 gpm flow rate. At points HF3 and HF4 the reductions were, $45 \%$ and $40 \%$, across all flow rates. With the sprinklers activated the heat flux readings along the target wall dropped by an average value of $46 \%$ for the three sprinkler flow rates. 
Table 4.1- Heat flux $\left(\mathrm{kW} / \mathrm{m}^{2}\right)$ results for the 2-MW fire tests at a separation distance of $3 \mathrm{~m}$

\begin{tabular}{cccccccc}
\hline $\begin{array}{c}\text { Sensor } \\
\text { Location }\end{array}$ & $\mathbf{0 ~ g p m}$ & $\mathbf{1 5} \mathbf{~ g p m}$ & Reduction & $\mathbf{2 0} \mathbf{~ g p m}$ & Reduction & $\mathbf{2 4} \mathbf{g p m}$ & Reduction \\
\hline $\mathbf{1}$ & 8.20 & 3.20 & 0.61 & 3.40 & 0.59 & 4.10 & 0.50 \\
$\mathbf{2}$ & 8.20 & 3.90 & 0.52 & 3.30 & 0.60 & 3.80 & 0.54 \\
$\mathbf{3}$ & 8.20 & 4.60 & 0.44 & 4.40 & 0.46 & 4.40 & 0.46 \\
$\mathbf{4}$ & 7.50 & 4.60 & 0.39 & 4.50 & 0.40 & 4.50 & 0.40 \\
$\mathbf{5}$ & 5.10 & 3.10 & 0.39 & 3.00 & 0.41 & 3.80 & 0.25 \\
Target Wall & & & & & & & \\
Average & 7.44 & 3.88 & 0.47 & 3.72 & 0.49 & 4.12 & 0.43 \\
$\mathbf{6}$ & 13.30 & 3.40 & 0.74 & 3.10 & 0.77 & 2.80 & 0.79 \\
$\mathbf{7}$ & 9.30 & 2.90 & 0.69 & 2.70 & 0.71 & 2.10 & 0.77 \\
$\mathbf{8}$ & 6.30 & 3.30 & 0.48 & 2.90 & 0.54 & 2.20 & 0.65 \\
Façade Wall & & & & & & & \\
Average & 9.63 & 3.20 & 0.64 & 2.90 & 0.67 & 2.37 & 0.74 \\
\hline
\end{tabular}

On the façade wall the heat flux was initially between $6.3 \mathrm{~kW} / \mathrm{m}^{2}$ and $13.3 \mathrm{~kW} / \mathrm{m}^{2}$. Use of the sprinklers at all flow rates caused the average heat flux to drop to below $3.2 \mathrm{~kW} / \mathrm{m}^{2}$, substantially lower than the initial values as well as the critical heat flux for piloted ignition of wood products. The heat flux reading on the façade wall dropped by $64 \%$ up to $74 \%$ as the sprinkler flow rates increased. Increase in the flow rates for the sprinklers had a minimal impact on the average heat flux impinged on the façade wall. The readings just above the opening at HF6 displayed the largest decrease with an average reduction of $76.6 \%$ while the highest sensor, $\mathrm{H} 8$, displayed the lowest decrease, reducing by only $55.6 \%$. 


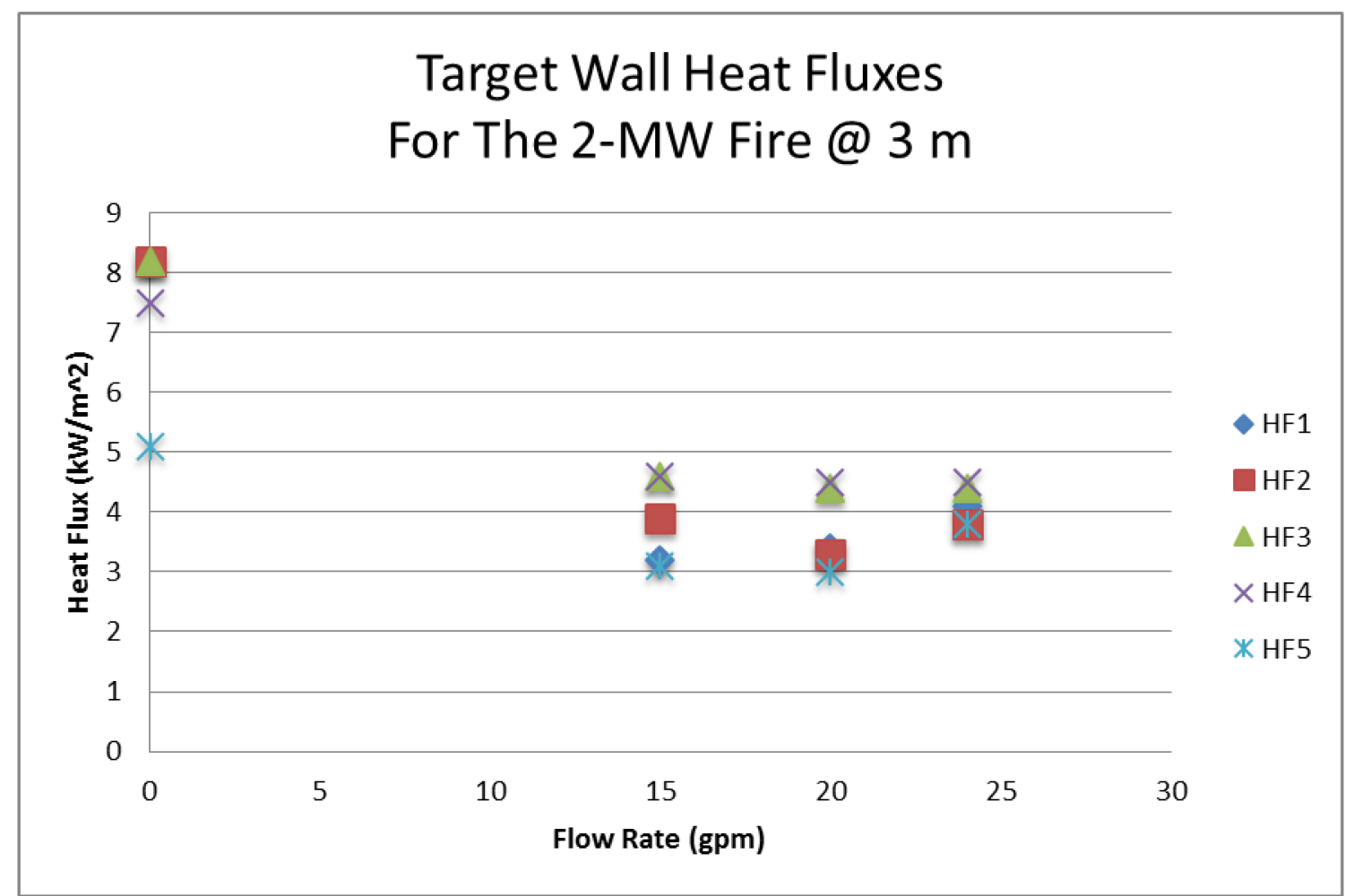

Figure 4.1 - Target wall heat flux results for the 2-MW fire at a separation distance of $3 \mathrm{~m}$

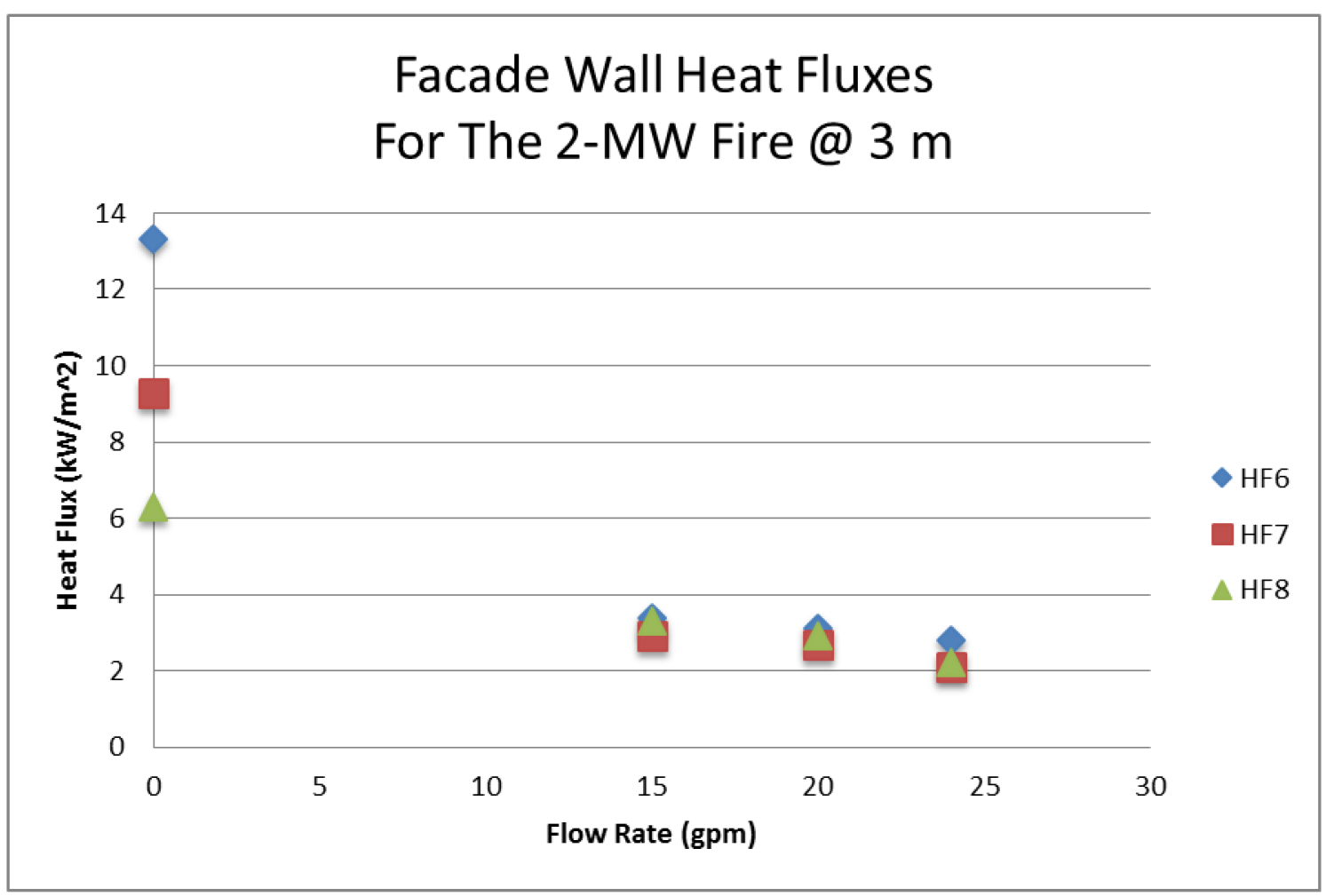

Figure 4.2 - Façade wall heat flux results for the 2-MW fire at a separation distance of $3 \mathrm{~m}$ 
The temperatures, Table 4.2, along the target wall and façade wall for the 2-MW fire are presented graphically in Figure 4.3 and Figure 4.4, respectively. Initial temperatures along the target wall were between $61^{\circ} \mathrm{C}$ and $87^{\circ} \mathrm{C}$ prior to sprinkler activation with an average temperature of $73.5^{\circ} \mathrm{C}$. The highest temperatures were found between T4 and T5 near the top of the target wall. Temperatures decreased to between $36^{\circ} \mathrm{C}$ and $64^{\circ} \mathrm{C}, 33^{\circ} \mathrm{C}$ and $55^{\circ} \mathrm{C}$, and $33^{\circ} \mathrm{C}$ and $39^{\circ} \mathrm{C}$, when the sprinklers were flowing at $15 \mathrm{gpm}, 20 \mathrm{gpm}$, and $24 \mathrm{gpm}$, each respectively. The temperature range decreased and converged as the sprinkler flow rates increased. The average temperature reduction compared to ambient temperature was $48 \%$ for the 15 gpm flow rate, $65 \%$ for the 20 gpm flow rate, and $70 \%$ for the 24 gpm flow rate.

Table 4.2 - Temperature $\left({ }^{\circ} \mathrm{C}\right)$ results for the 2-MW fire tests at a separation distance of $3 \mathrm{~m}$

\begin{tabular}{cccccccc}
\hline $\begin{array}{c}\text { Sensor } \\
\text { Location }\end{array}$ & $\mathbf{0}$ gpm & $\mathbf{1 5} \mathbf{~ g p m}$ & Reduction & $\mathbf{2 0} \mathbf{g p m}$ & Reduction & $\mathbf{2 4} \mathbf{~ g p m}$ & Reduction \\
\hline $\mathbf{1}$ & 62.3 & 36.5 & 0.61 & 33.2 & 0.69 & 33.4 & 0.68 \\
$\mathbf{2}$ & 76.4 & 39.8 & 0.65 & 33.5 & 0.76 & 35.6 & 0.72 \\
$\mathbf{3}$ & 61.5 & 40.8 & 0.50 & 33 & 0.69 & 33.6 & 0.67 \\
$\mathbf{4}$ & 86.3 & 58.1 & 0.43 & 40.3 & 0.69 & 37.3 & 0.74 \\
$\mathbf{5}$ & 81.2 & 63.4 & 0.29 & 54.5 & 0.44 & 39.1 & 0.69 \\
\hline $\begin{array}{c}\text { Target Wall } \\
\text { Average }\end{array}$ & 73.54 & 47.72 & 0.48 & 38.90 & 0.65 & 35.80 & 0.70 \\
$\mathbf{6}$ & 274.9 & 36.7 & 0.93 & 34.5 & 0.94 & 32 & 0.95 \\
$\mathbf{7}$ & 239.7 & 57.9 & 0.83 & 36.9 & 0.92 & 33.2 & 0.94 \\
$\mathbf{8}$ & 160.7 & 49.7 & 0.79 & 40.2 & 0.86 & 33.7 & 0.90 \\
\hline $\begin{array}{c}\text { Façade Wall } \\
\text { Average }\end{array}$ & 225.10 & 48.10 & 0.86 & 37.20 & 0.92 & 32.97 & 0.94 \\
\hline
\end{tabular}

Above the compartment the façade wall the temperatures were initially between $160^{\circ} \mathrm{C}$ and $275^{\circ} \mathrm{C}$, with an average temperature of $225^{\circ} \mathrm{C}$. The higher temperatures were found just above the opening due to proximity to the hot gases leaving the opening. The average temperature reduction when compared to ambient temperature caused by the introduction of the water curtain was $86 \%$ for the 15 gpm flow rate, $92 \%$ for the 20 gpm flow rate, and $94 \%$ for the 24 gpm flow rate averaging to a decrease of $91 \%$ across all the flow rates. As with the heat fluxes the temperatures at T6 saw the largest effect while T8 received the lowest effect. Sensor T6 dropped by an average of $94 \%$ while T8 dropped by $79 \%$ up to $90 \%$ as the flow rate increased. 


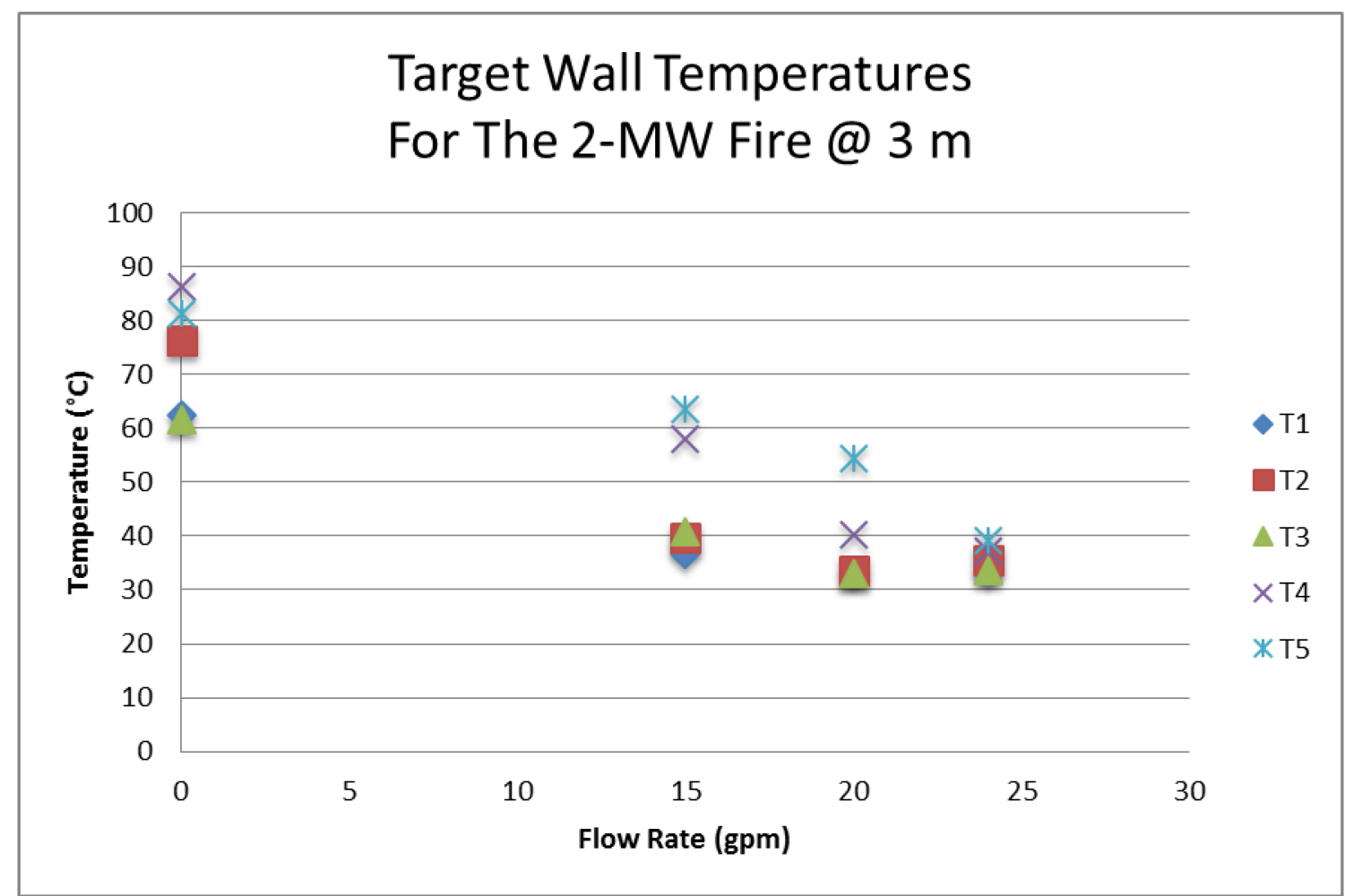

Figure 4.3 - Target wall temperature results for the 2-MW fire at a separation distance of $3 \mathrm{~m}$

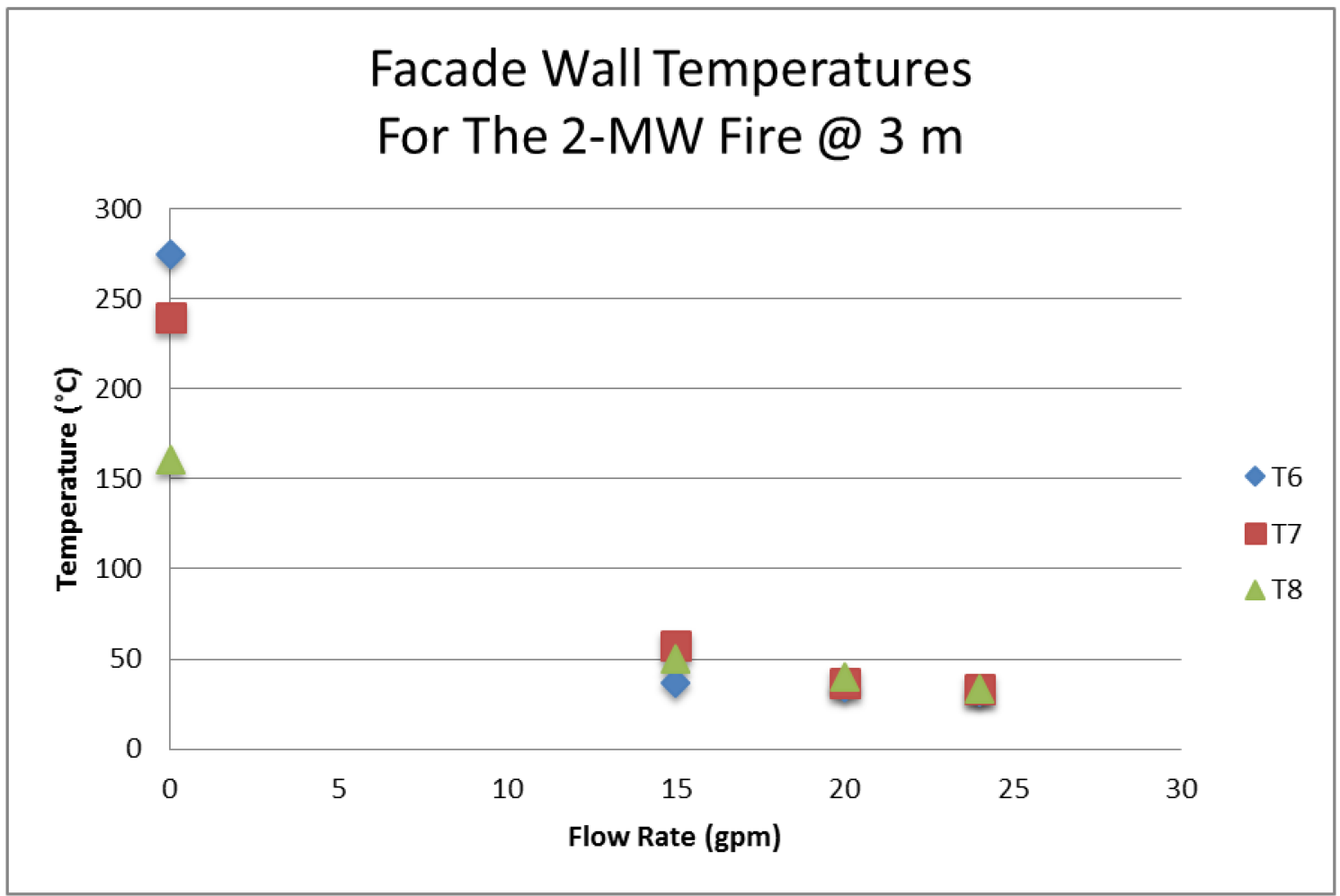

Figure 4.4 - Facade wall temperature results for the 2-MW fire at a separation distance of $3 \mathrm{~m}$ 


\subsubsection{3-MW Fire Tests Results}

The heat flux results for the 3-MW fire tests on both test walls are shown in Table 4.3 and displayed graphically in Figure 4.5 for the target wall and Figure 4.6 for the façade wall. The average heat flux along the target wall was $13.6 \mathrm{~kW} / \mathrm{m}^{2}$ initially, greater than that required for piloted ignition of wood products. As with the previous test, the highest heat flux the target wall experienced was at sensor $\mathrm{H} 3$ with a reading of $15.8 \mathrm{~kW} / \mathrm{m}^{2}$ at $\mathrm{HF} 3$. Reduction of the heat fluxes with the use of sprinklers increased with increasing sprinkler flow rate. The average reduction of the heat flux was $2 \%$ for the 15 gpm flow rate, $30 \%$ for the $20 \mathrm{gpm}$ flow rate, and $49 \%$ for the $24 \mathrm{gpm}$ flow rate. At sensor HF3 the reductions were, $3 \%, 32 \%$, and 51\%, respectively for the $15 \mathrm{gpm}, 20 \mathrm{gpm}$, and $24 \mathrm{gpm}$ flow rate per sprinkler.

Table 4.3 - Heat flux $\left(\mathrm{kW} / \mathrm{m}^{2}\right)$ results for the 3-MW fire at a separation distance of $3 \mathrm{~m}$

\begin{tabular}{cccccccc}
\hline $\begin{array}{c}\text { Sensor } \\
\text { Location }\end{array}$ & $\mathbf{0}$ GPM & $\mathbf{1 5} \mathbf{~ g p m}$ & Reduction & $\mathbf{2 0} \mathbf{g p m}$ & Reduction & $\mathbf{2 4} \mathbf{~ g p m}$ & Reduction \\
\hline $\mathbf{1}$ & 14.5 & 13 & 0.10 & 9.6 & 0.34 & 7.6 & 0.48 \\
$\mathbf{2}$ & 13.9 & 14.5 & -0.04 & 9.4 & 0.32 & 7 & 0.50 \\
$\mathbf{3}$ & 15.8 & 15.3 & 0.03 & 10.8 & 0.32 & 7.7 & 0.51 \\
$\mathbf{4}$ & 13.8 & 14.4 & -0.04 & 10.6 & 0.23 & 7.3 & 0.47 \\
$\mathbf{5}$ & 10.2 & 9.5 & 0.07 & 7.4 & 0.27 & 5.4 & 0.47 \\
Target Wall & & & & & & & \\
Average & 13.64 & 13.34 & 0.02 & 9.56 & 0.30 & 7.00 & 0.49 \\
$\mathbf{6}$ & 24.8 & 12 & 0.52 & 6.8 & 0.73 & 4.6 & 0.81 \\
$\mathbf{7}$ & 15.6 & 10.7 & 0.31 & 5.7 & 0.63 & 3.6 & 0.77 \\
$\mathbf{8}$ & 10.9 & 10.8 & 0.01 & 5.8 & 0.47 & 3.5 & 0.68 \\
Façade Wall & & & & & & & \\
Average & 17.10 & 11.17 & 0.28 & 6.10 & 0.61 & 3.90 & 0.75 \\
\hline
\end{tabular}

On the facade wall the heat flux was initially between $10 \mathrm{~kW} / \mathrm{m}^{2}$ and $25 \mathrm{~kW} / \mathrm{m}^{2}$. As with the target wall the front wall extension saw a similar decrease in the average heat flux with every increase in sprinkler flow rate. Use of the sprinklers caused the heat flux readings to drop by an average of $28 \%$ for the $15 \mathrm{gpm}$ flow rate, $61 \%$ for the $20 \mathrm{gpm}$ flow rate, and $75 \%$ for the $24 \mathrm{gpm}$ flow rate with the most prevalent reduction just above the opening at sensor HF6. The reduction at this sensor with a decrease of $52 \%, 73 \%$, and $81 \%$ for the $15 \mathrm{gpm}, 20 \mathrm{gpm}$, and $24 \mathrm{gpm}$ flow rate per sprinkler, respectively. 


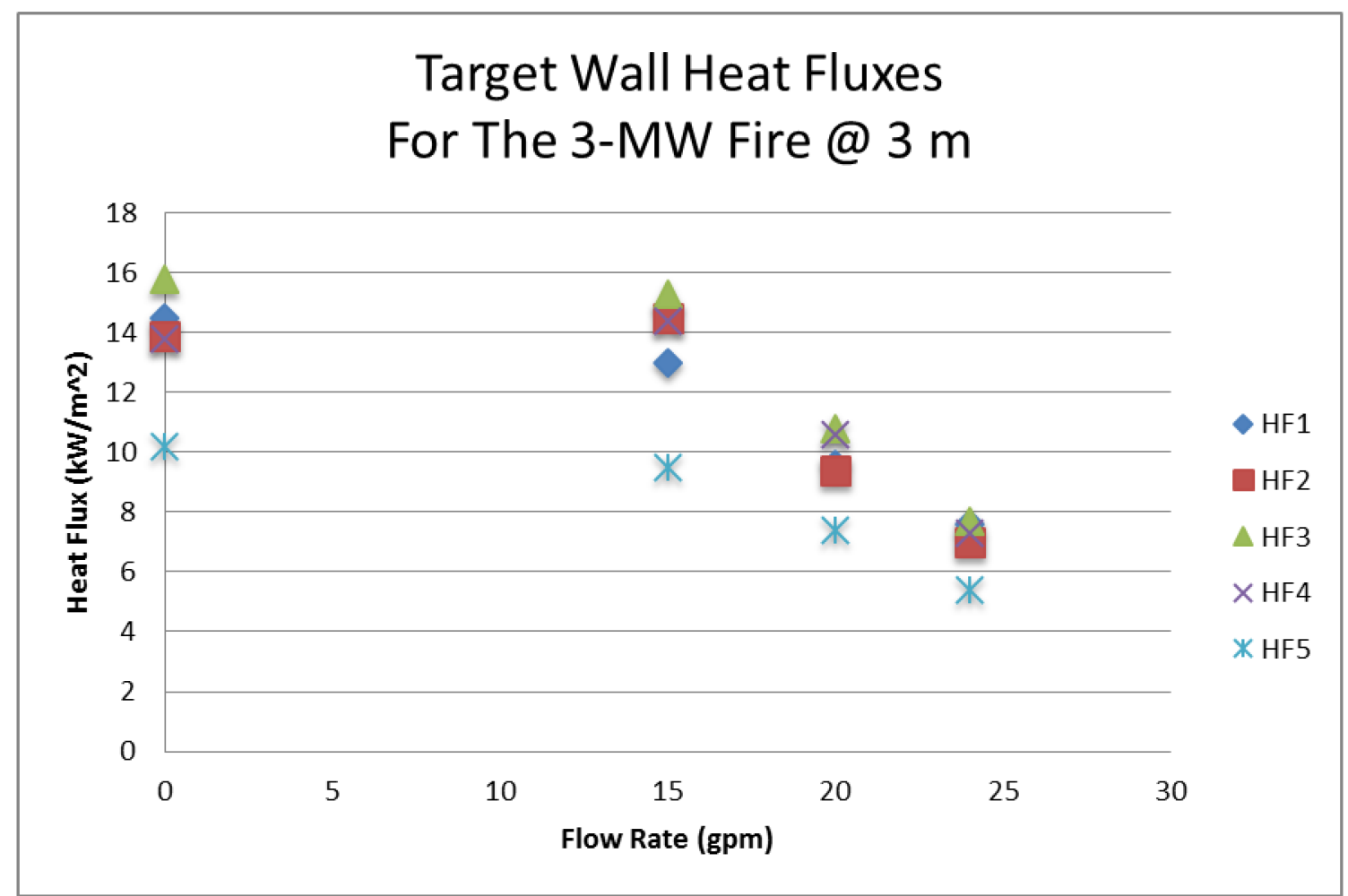

Figure 4.5 - Target wall heat flux results for the 3-MW fire at a separation distance of $3 \mathrm{~m}$

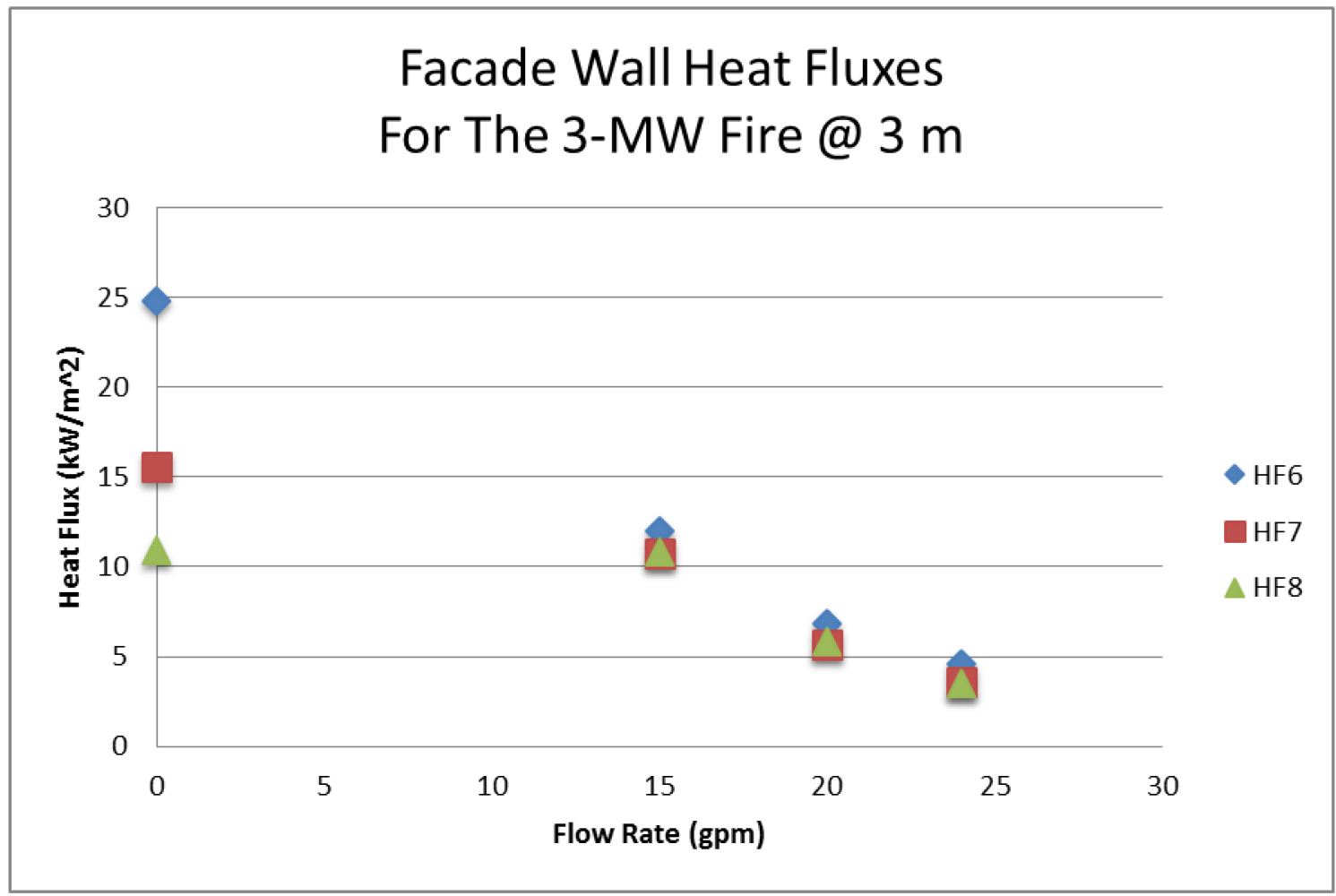

Figure 4.6 - Façade wall heat flux results for the 3-MW fire at a separation distance of $3 \mathrm{~m}$ 
The temperature data is presented in Table 4.4 and graphically displayed in Figure 4.7 for the target wall and Figure 4.8 for the façade wall. The baseline temperatures along the target wall for the 3 $\mathrm{MW}$ fire were between $99^{\circ} \mathrm{C}$ and $184^{\circ} \mathrm{C}$ with an average wall temperature of $137.8^{\circ} \mathrm{C}$. The highest temperatures recorded were at sensor T2. The temperatures decreased to an average temperature of $70.7^{\circ} \mathrm{C}$ when the sprinklers were flowing at $15 \mathrm{gpm}$ each, $53.3^{\circ} \mathrm{C}$ when the sprinklers were flowing at 20 gpm, $43.7^{\circ} \mathrm{C}$ when the sprinklers were flowing at $24 \mathrm{gpm}$. The average reduction in temperatures was $57 \%, 72 \%$ and $80 \%$ for the flow rates, $15 \mathrm{gpm}, 20 \mathrm{gpm}$, and $24 \mathrm{gpm}$, respectively.

Table 4.4 - Temperature $\left({ }^{\circ} \mathrm{C}\right)$ results for the 3-MW fire at a separation distance of $3 \mathrm{~m}$

\begin{tabular}{cccccccc}
\hline $\begin{array}{c}\text { Sensor } \\
\text { Location }\end{array}$ & $\mathbf{0 ~ g p m}$ & $\mathbf{1 5} \mathbf{~ g p m}$ & Reduction & $\mathbf{2 0} \mathbf{g p m}$ & Reduction & $\mathbf{2 4} \mathbf{g p m}$ & Reduction \\
\hline $\mathbf{1}$ & 99.1 & 69.5 & 0.37 & 56.1 & 0.54 & 43 & 0.71 \\
$\mathbf{2}$ & 183.3 & 68.7 & 0.70 & 53.4 & 0.80 & 44.9 & 0.85 \\
$\mathbf{3}$ & 124.4 & 61.2 & 0.61 & 47.9 & 0.73 & 40.9 & 0.80 \\
$\mathbf{4}$ & 144.4 & 73.1 & 0.57 & 52.7 & 0.74 & 44.7 & 0.80 \\
$\mathbf{5}$ & 138 & 80.9 & 0.48 & 56.2 & 0.69 & 45 & 0.79 \\
Target Wall & & & & & & & \\
Average & 137.84 & 70.68 & 0.57 & 53.26 & 0.72 & 43.70 & 0.80 \\
$\mathbf{6}$ & 344.4 & 53.8 & 0.90 & 41.7 & 0.93 & 36.2 & 0.95 \\
$\mathbf{7}$ & 336.5 & 124 & 0.67 & 47.7 & 0.91 & 38 & 0.94 \\
$\mathbf{8}$ & 230.6 & 100.6 & 0.62 & 50.3 & 0.86 & 39 & 0.91 \\
\hline Façade Wall & & & & & & & \\
Average & 303.83 & 92.80 & 0.74 & 46.57 & 0.91 & 37.73 & 0.94 \\
\hline
\end{tabular}

Above the compartment on the façade wall the temperatures were initially between $230^{\circ} \mathrm{C}$ and $345^{\circ} \mathrm{C}$, with an average temperature of $303.8^{\circ} \mathrm{C}$. The highest temperatures were found to be just above the compartment opening at T6 and T7. With the use of sprinklers, temperatures decreased with increasing sprinkler flow rates. Temperatures decreased to between $53^{\circ} \mathrm{C}$ and $124^{\circ} \mathrm{C}$ for the $15 \mathrm{gpm}$ flow rate with an average reduction of $74 \%$. The $20 \mathrm{gpm}$ flow rate saw an average temperature of $46.6^{\circ} \mathrm{C}$ with an average reduction of $91 \%$ for the façade wall, and the $24 \mathrm{gpm}$ flow rate saw an average temperature of $37.7^{\circ} \mathrm{C}$ with an average reduction of $94 \%$. Just above the opening at $\mathrm{H} 6$, the average reduction was $93 \%$ across all flow rates. 


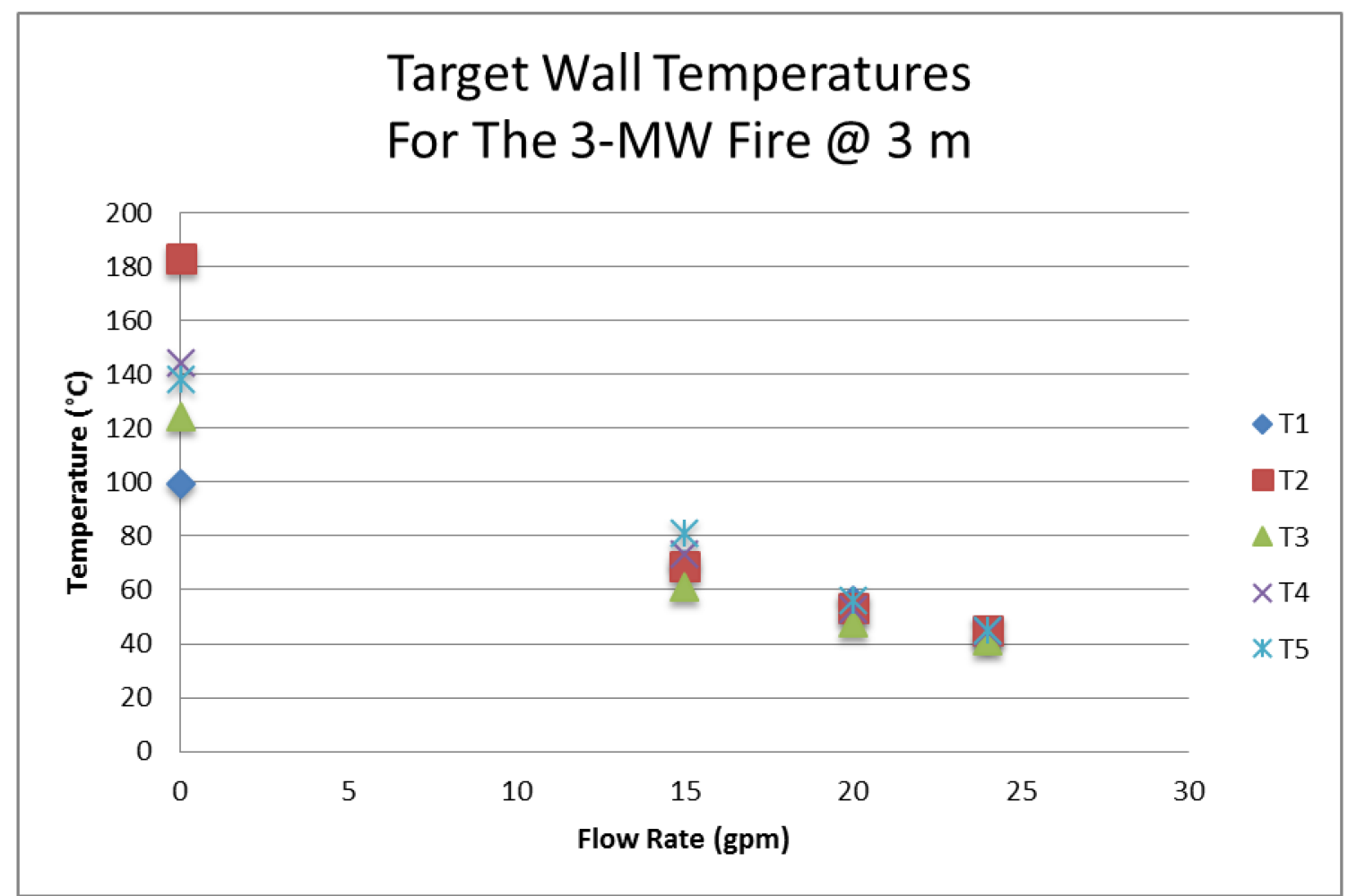

Figure 4.7 - Target wall temperature results for the 3-MW fire at a separation distance of $3 \mathrm{~m}$

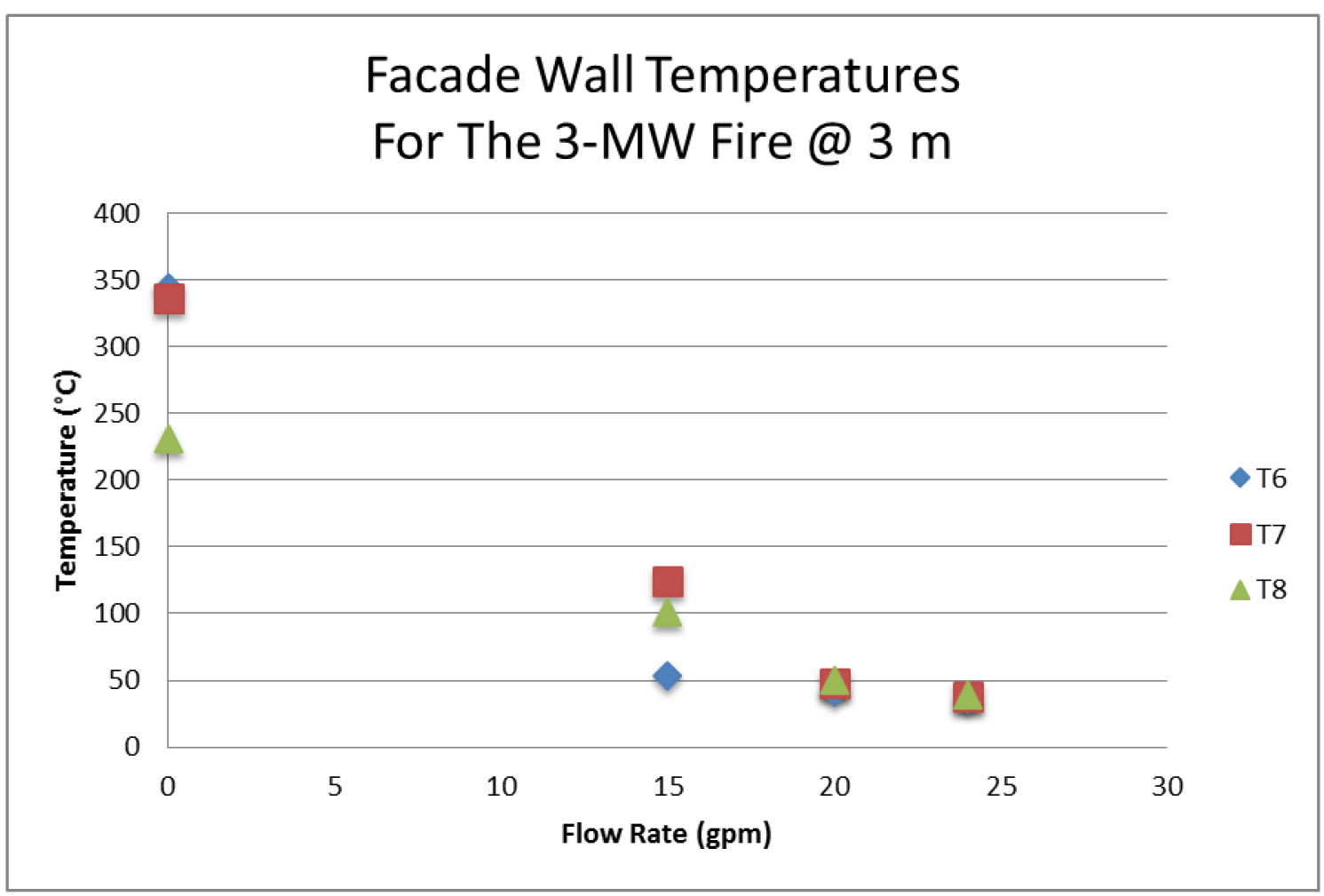

Figure 4.8 - Façade wall temperature results for the 3-MW fire at a separation distance of $3 \mathrm{~m}$ 


\subsubsection{4-MW Fire Tests Results}

Table 4.5 shows the heat flux results for the 4-MW fire on both test walls with the target wall and the façade wall of the compartment shown graphically in Figure 4.9 and Figure 4.10. The initial average heat flux experienced by the target wall was $23.3 \mathrm{~kW} / \mathrm{m}^{2}$, with the highest point heat flux being 26.6 $\mathrm{kW} / \mathrm{m}^{2}$ at HF3. The use of the water curtain showed a similar pattern to that seen for the 3-MW fire tests with each increase in flow rate having a larger impact on reducing the average heat flux. The heat flux reduction was $23 \%$ for the 15 gpm flow rate, $35 \%$ for the 20 gpm flow rate, and $46 \%$ for the 24 gpm flow rate. At HF3 the heat fluxes reduced by similar amounts. Heat fluxes were greater than the critical heat flux but it should be noted that the water curtain was wetting the target wall. During real fire events the water curtain is predicted to prevent sparks from reaching the adjacent properties.

Table 4.5 - Heat flux $\left(\mathrm{kW} / \mathrm{m}^{2}\right)$ results for the 4-MW fire at a separation distance of $3 \mathrm{~m}$

\begin{tabular}{cccccccc}
\hline $\begin{array}{c}\text { Sensor } \\
\text { Location }\end{array}$ & $\mathbf{0} \mathbf{~ g p m}$ & $\mathbf{1 5} \mathbf{~ g p m}$ & Reduction & $\mathbf{2 0} \mathbf{g p m}$ & Reduction & $\mathbf{2 4} \mathbf{~ g p m}$ & Reduction \\
\hline $\mathbf{1}$ & 25.1 & 18.8 & 0.25 & 15.5 & 0.38 & 13.8 & 0.45 \\
$\mathbf{2}$ & 23.8 & 20.8 & 0.13 & 15.7 & 0.34 & 13.2 & 0.45 \\
$\mathbf{3}$ & 26.6 & 20.1 & 0.24 & 17 & 0.36 & 14 & 0.47 \\
$\mathbf{4}$ & 23.4 & 18 & 0.23 & 15.8 & 0.32 & 13.1 & 0.44 \\
$\mathbf{5}$ & 17.4 & 12.6 & 0.28 & 11.2 & 0.36 & 9.1 & 0.48 \\
Target Wall & & & & & & & \\
Average & 23.26 & 18.06 & 0.23 & 15.04 & 0.35 & 12.64 & 0.46 \\
$\mathbf{6}$ & 41.2 & 18.3 & 0.56 & 11.2 & 0.73 & 8.6 & 0.79 \\
$\mathbf{7}$ & 22.2 & 15.7 & 0.29 & 9.2 & 0.59 & 5.7 & 0.74 \\
$\mathbf{8}$ & 16.7 & 14.8 & 0.11 & 9.8 & 0.41 & 5.4 & 0.68 \\
\hline Façade Wall & & & & & & & \\
Average & 26.70 & 16.27 & 0.32 & 10.07 & 0.58 & 6.57 & 0.74 \\
\hline
\end{tabular}

On the facade wall the heat flux was initially between $16 \mathrm{~kW} / \mathrm{m}^{2}$ and $42 \mathrm{~kW} / \mathrm{m}^{2}$. The use of the sprinklers caused greater drops in the average heat flux with increasing in sprinkler flow rates. The average decrease along the façade wall was 32\% for the $15 \mathrm{gpm}$ flow rate, $58 \%$ for the 20 gpm flow rate, and $74 \%$ for the 24 gpm flow rate. Sensor HF6 saw the largest effect with a reduction of $56 \%, 73 \%$, and $76 \%$ for each respective flow rate. 


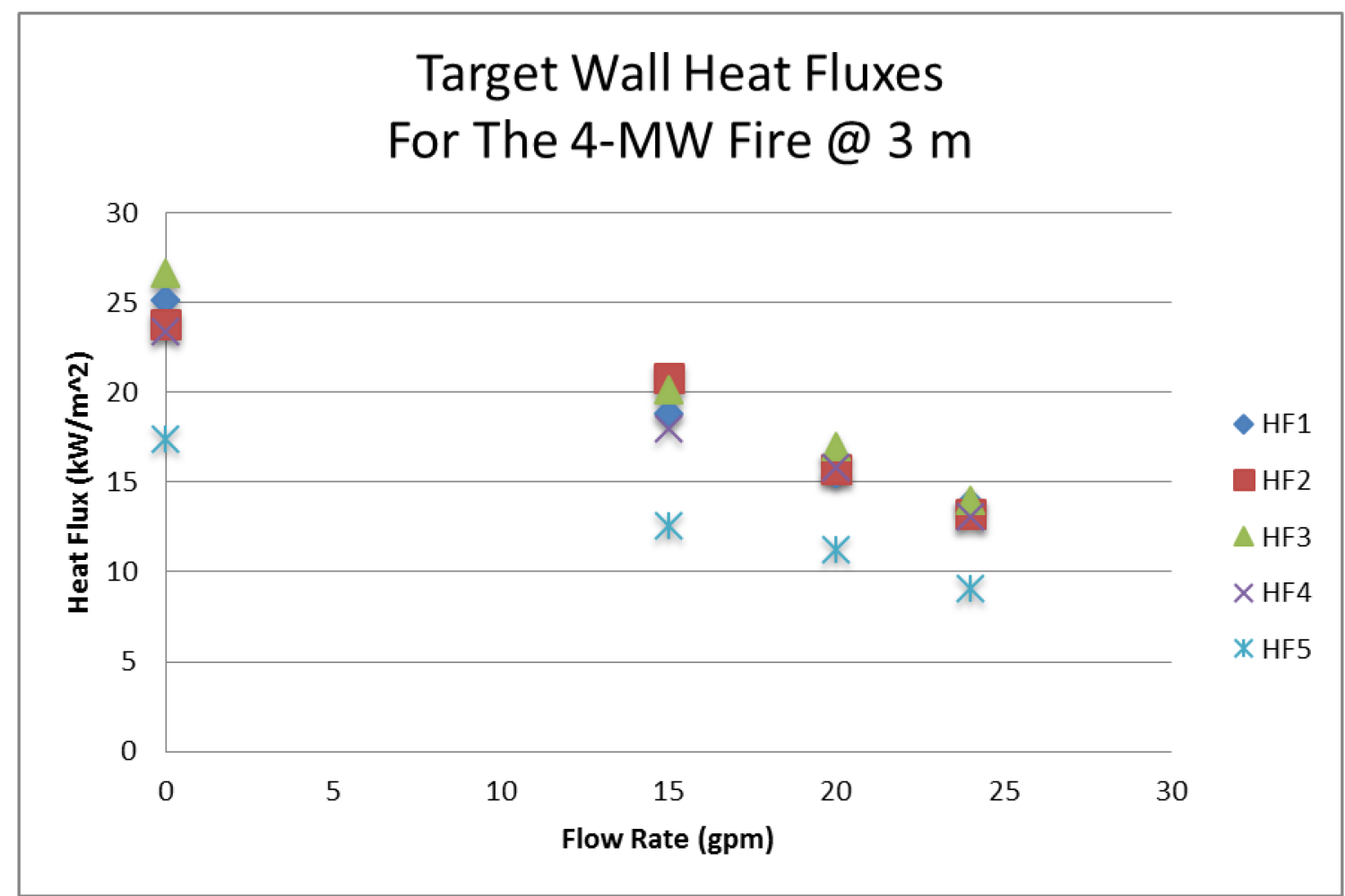

Figure 4.9- Target wall heat flux results for the 4-MW fire at a separation distance of $3 \mathrm{~m}$

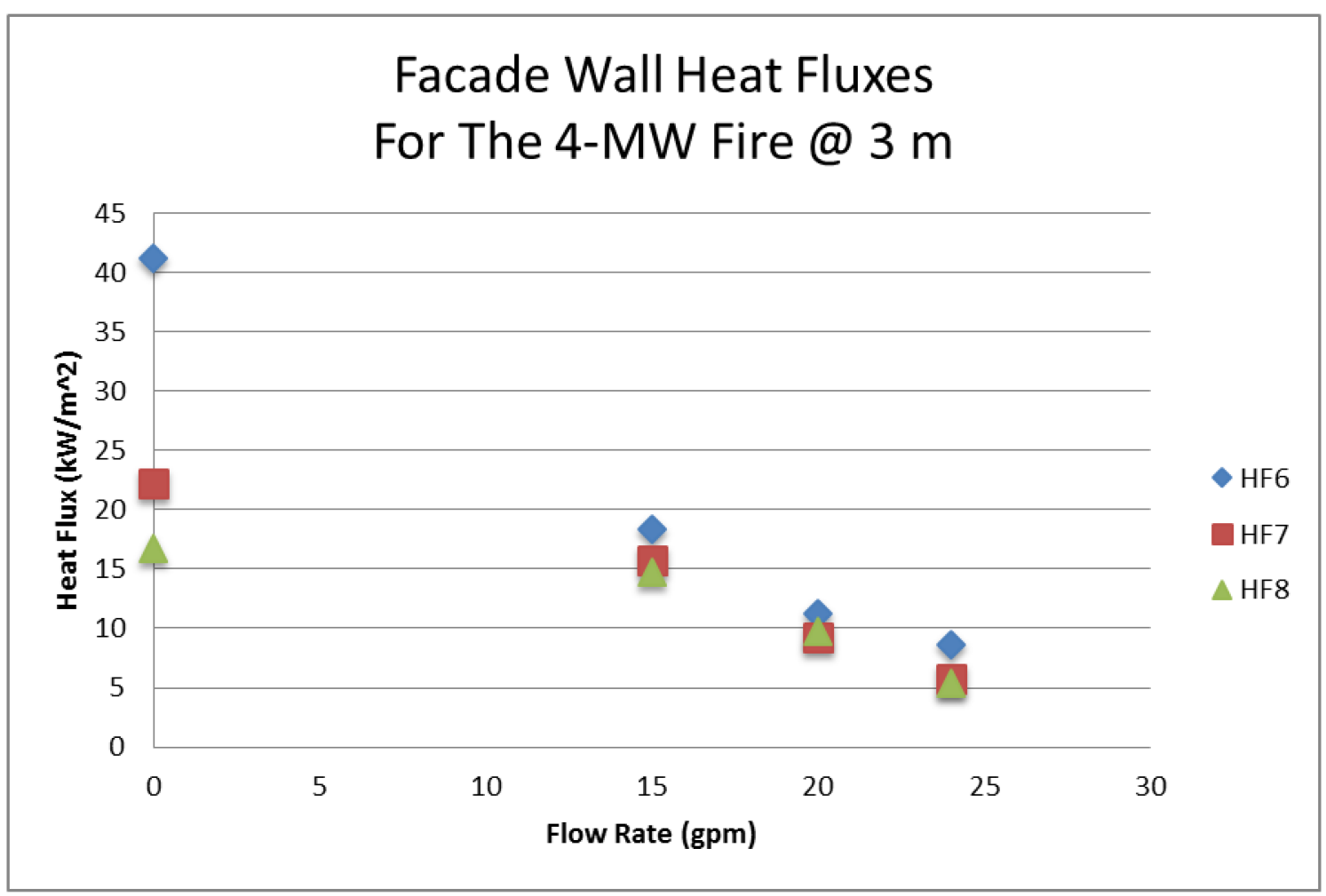

Figure 4.10 - Façade wall heat flux results for the 4-MW fire at a separation distance of $3 \mathrm{~m}$ 
The temperature data for the 4-MW fire test is shown in Table 4.6. The baseline temperatures, displayed in Figure 4.11 , along the target wall were between $145^{\circ} \mathrm{C}$ and $283^{\circ} \mathrm{C}$. The temperatures decreased to between $78^{\circ} \mathrm{C}$ and $155^{\circ} \mathrm{C}$ when each sprinkler was flowing at $15 \mathrm{gpm}$, and to between $58^{\circ} \mathrm{C}$ and $118^{\circ} \mathrm{C}$ when each sprinkler was flowing at $20 \mathrm{gpm}$. When each sprinkler was flowing at $24 \mathrm{gpm}$ the average temperature was reduced to $60.7^{\circ} \mathrm{C}$. The average reduction in temperatures was $57 \%, 69 \%$ and $79 \%$ for the flow rates, $15 \mathrm{gpm}, 20 \mathrm{gpm}$, and $24 \mathrm{gpm}$, respectively, similar to that for the 3-MW fire tests.

Table 4.6 - Temperature $\left({ }^{\circ} \mathrm{C}\right)$ results for the 4-MW fire at a separation distance of $3 \mathrm{~m}$

\begin{tabular}{cccccccc}
\hline $\begin{array}{c}\text { Sensor } \\
\text { Location }\end{array}$ & $\mathbf{0} \mathbf{~ g p m}$ & $\mathbf{1 5} \mathbf{~ g p m}$ & Reduction & $\mathbf{2 0} \mathbf{~ g p m}$ & Reduction & $\mathbf{2 4} \mathbf{g p m}$ & Reduction \\
\hline $\mathbf{1}$ & 145.7 & 80.9 & 0.52 & 73 & 0.58 & 66.8 & 0.63 \\
$\mathbf{2}$ & 282.1 & 78.2 & 0.78 & 67.6 & 0.82 & 62.9 & 0.84 \\
$\mathbf{3}$ & 195.4 & 80.5 & 0.66 & 58.1 & 0.78 & 55.6 & 0.80 \\
$\mathbf{4}$ & 219.9 & 119.4 & 0.50 & 81.4 & 0.69 & 57.9 & 0.81 \\
$\mathbf{5}$ & 207.8 & 154.4 & 0.28 & 117.7 & 0.48 & 60.5 & 0.78 \\
Target Wall & & & & & & & \\
Average & 210.18 & 102.68 & 0.57 & 79.56 & 0.69 & 60.74 & 0.79 \\
$\mathbf{6}$ & 443.6 & 73.9 & 0.87 & 50.5 & 0.93 & 43.7 & 0.94 \\
$\mathbf{7}$ & 440.3 & 210.6 & 0.55 & 78.1 & 0.86 & 46.4 & 0.94 \\
$\mathbf{8}$ & 327.2 & 159.2 & 0.55 & 91.1 & 0.77 & 51 & 0.90 \\
\hline Façade Wall & & & & & & & \\
Average & 403.70 & 147.90 & 0.67 & 73.23 & 0.86 & 47.03 & 0.93 \\
\hline
\end{tabular}

Above the compartment on the facade wall the temperatures, displayed in Figure 4.12, were initially between $327^{\circ} \mathrm{C}$ and $444^{\circ} \mathrm{C}$, with an average temperature of $403.7^{\circ} \mathrm{C}$. The highest temperatures were found to be just above the compartment opening at T6 and T7. As with the target wall the temperatures dropped as the sprinkler flow rates increased. The average temperature was $47^{\circ} \mathrm{C}$ at the 24 gpm flow rate with an average reduction of $93 \%$. As with the previous tests above the compartment at T6 saw the greatest impact due to the water curtain with an average reduction of $91 \%$ across all three flow rates similar to that of the $3-\mathrm{MW}$ tests. 


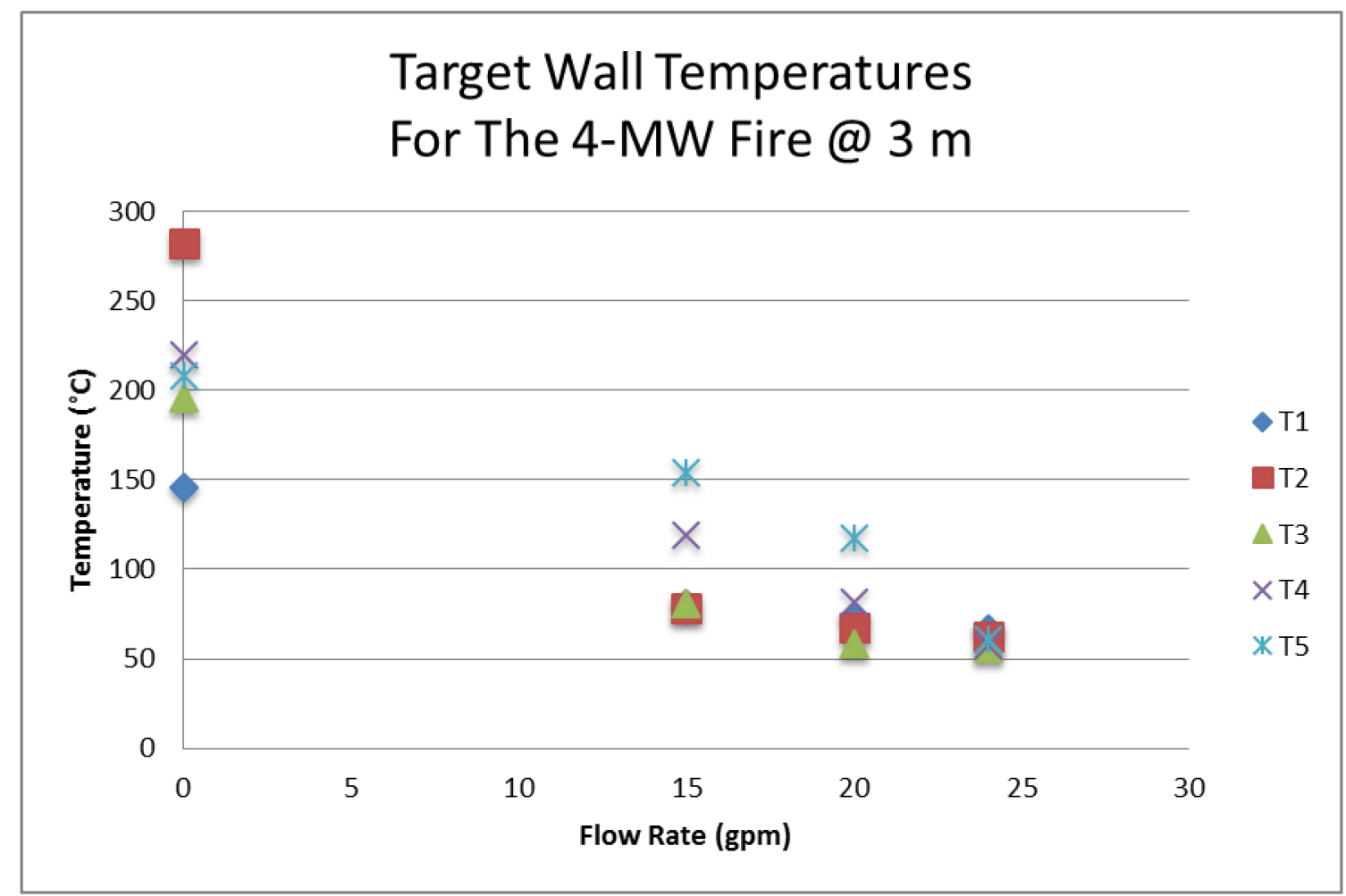

Figure 4.11 - Target wall temperature results for the 4-MW fire at a separation distance of $3 \mathrm{~m}$

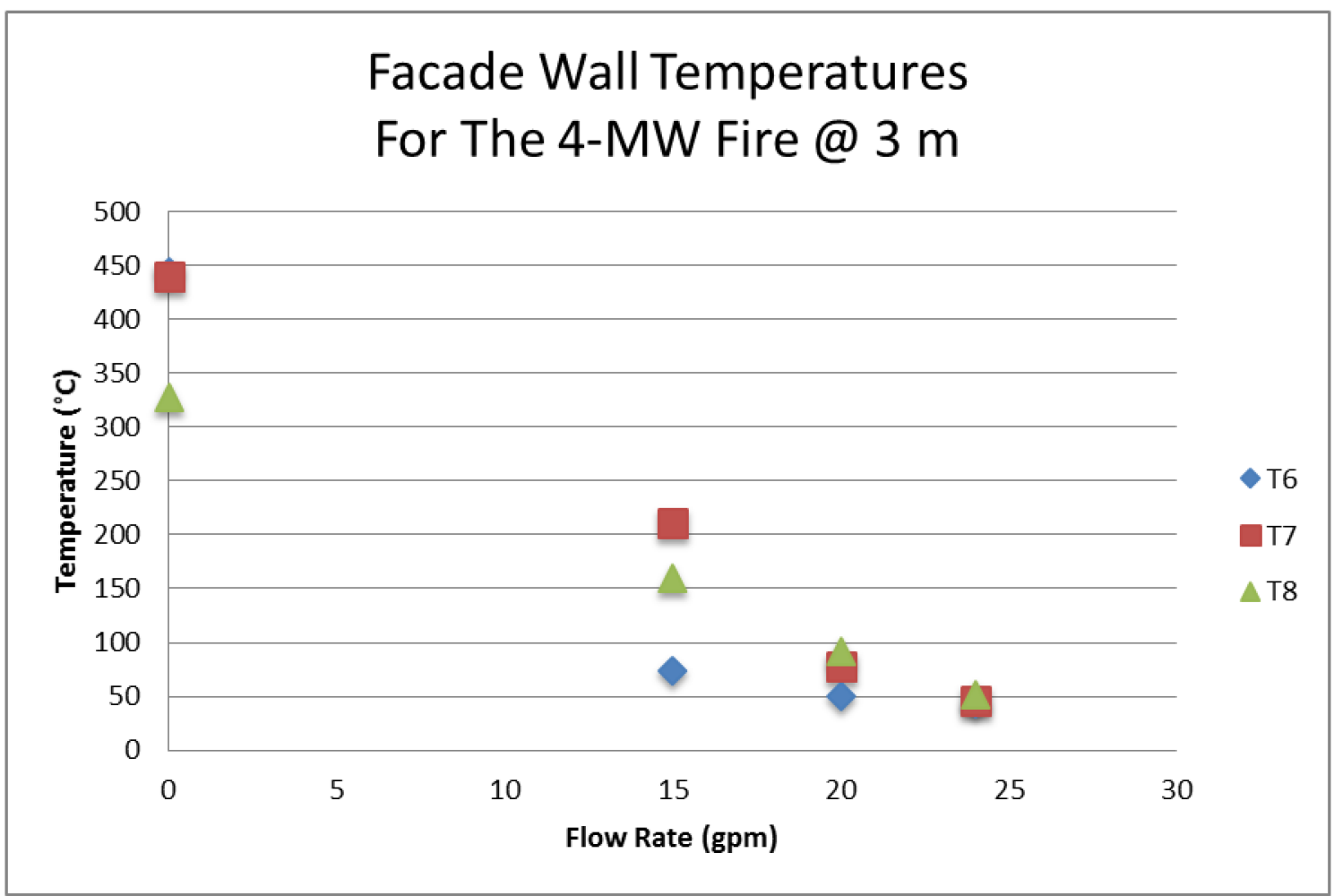

Figure 4.12 - Façade wall temperature results for the 4-MW fire at a separation distance of $3 \mathrm{~m}$ 


\subsection{Second Test Series: $4 \mathrm{~m}$ Separation Distance}

During these tests the thermocouple at T5 malfunctioned and could not to be replaced due to the protection on the thermocouple wiring for the target wall thermocouples. During the 2-MW fire test thermocouple at T7 malfunctioned during the $24 \mathrm{gpm}$ flow rate test. The thermocouple was replaced following the test. Another issue that arose was that the pressure gauge measuring the pressure in the sprinkler system was reading a value lower that the calculated value required for the system, while the flow meter was still reading correct values for the flow rates. This is believed to be caused by a damaged gauge.

\subsubsection{2-MW Fire Tests Results}

Table 4.7 shows the heat flux results for the 4-MW fire on both the target wall, shown graphically in Figure 4.13 and the façade wall, shown graphically in Figure 4.14. The initial average heat flux experienced by the target wall when no sprinklers were active was $6.4 \mathrm{~kW} / \mathrm{m}^{2}$, which is below the threshold for piloted ignition of wood products as it was for the previous 2-MW fire tests. The point of highest heat flux was HF1 located directly across from the center of the compartment opening with a reading of $7.3 \mathrm{~kW} / \mathrm{m}^{2}$ for the baseline test. The introduction of the water curtain decreased the average heat flux readings to $5.8 \mathrm{~kW} / \mathrm{m}^{2}$ reducing the readings by $10 \%$ for the $15 \mathrm{gpm}$ flow rate, $5.6 \mathrm{~kW} / \mathrm{m}^{2}$ reducing the readings by $13 \%$ for the $20 \mathrm{gpm}$ flow rate, and $5.1 \mathrm{~kW} / \mathrm{m}^{2}$ reducing the readings by $20 \%$ for the 24 gpm flow rate. At point HF1 the reductions were, 8\%, 14\%, and 19\%, respectively for the 15 gpm, $20 \mathrm{gpm}$, and $24 \mathrm{gpm}$ flow rates. With the sprinklers activated the heat flux readings along the target wall dropped by an average value of about $14.3 \%$ for the three sprinkler flow rates. 
Table 4.7 - Heat flux $\left(\mathrm{kW} / \mathrm{m}^{2}\right)$ results for the 2-MW fire at a separation distance of $4 \mathrm{~m}$

\begin{tabular}{cccccccc}
\hline $\begin{array}{c}\text { Sensor } \\
\text { Location }\end{array}$ & $\mathbf{0} \mathbf{~ g p m}$ & $\mathbf{1 5} \mathbf{~ g p m}$ & Reduction & $\mathbf{2 0} \mathbf{~ g p m}$ & Reduction & $\mathbf{2 4} \mathbf{~ g p m}$ & Reduction \\
\hline $\mathbf{1}$ & 7.3 & 6.7 & 0.08 & 6.3 & 0.14 & 5.9 & 0.19 \\
$\mathbf{2}$ & 6.7 & 6 & 0.10 & 6 & 0.10 & 5.4 & 0.19 \\
$\mathbf{3}$ & 6.8 & 6.3 & 0.07 & 6 & 0.12 & 5.5 & 0.19 \\
$\mathbf{4}$ & 6.6 & 5.5 & 0.17 & 5.4 & 0.18 & 5.1 & 0.23 \\
$\mathbf{5}$ & 4.7 & 4.3 & 0.09 & 4.1 & 0.13 & 3.8 & 0.19 \\
Target Wall & & & & & & & \\
Average & 6.42 & 5.76 & 0.10 & 5.56 & 0.13 & 5.14 & 0.20 \\
$\mathbf{6}$ & 7.7 & 4.6 & 0.40 & 4.1 & 0.47 & 2.1 & 0.73 \\
$\mathbf{7}$ & 7 & 4.9 & 0.30 & 2.3 & 0.67 & 1.2 & 0.83 \\
$\mathbf{8}$ & 6.3 & 5.1 & 0.19 & 2.5 & 0.60 & 0.24 & 0.96 \\
Façade Wall & & & & & & & \\
Average & 7.00 & 4.87 & 0.30 & 2.97 & 0.58 & 1.18 & 0.84 \\
\hline
\end{tabular}

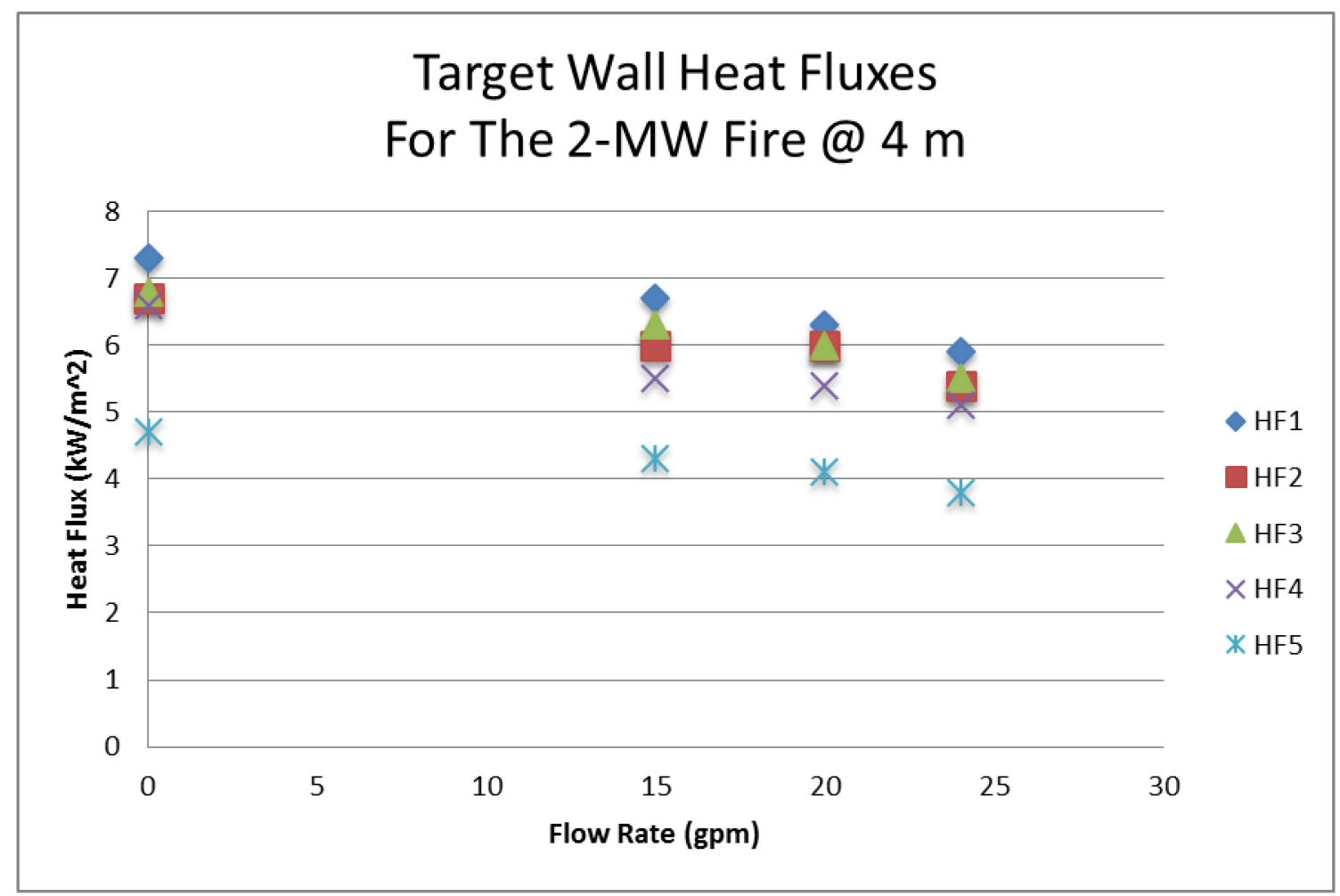

Figure 4.13 - Target wall heat flux results for the 2-MW fire at a separation distance of $4 \mathrm{~m}$

On the façade wall the heat flux was initially between $6.3 \mathrm{~kW} / \mathrm{m}^{2}$ and $7.7 \mathrm{~kW} / \mathrm{m}^{2}$. Use of the sprinklers at all flow rates caused the average heat flux to drop to below $5.1 \mathrm{~kW} / \mathrm{m}^{2}$ for the $15 \mathrm{gpm}$ flow rate, $4.1 \mathrm{~kW} / \mathrm{m}^{2}$ for the $20 \mathrm{gpm}$ flow rate, and $2.1 \mathrm{~kW} / \mathrm{m}^{2}$ for the $24 \mathrm{gpm}$ flow rate. The average heat flux reading on the façade wall dropped by between $30 \%$ and $80 \%$ as the sprinkler flow rates increased. The 
readings at HF6 just above the opening dropped by $40 \%$ at the lowest flow rate to $73 \%$ at the highest flow rate.

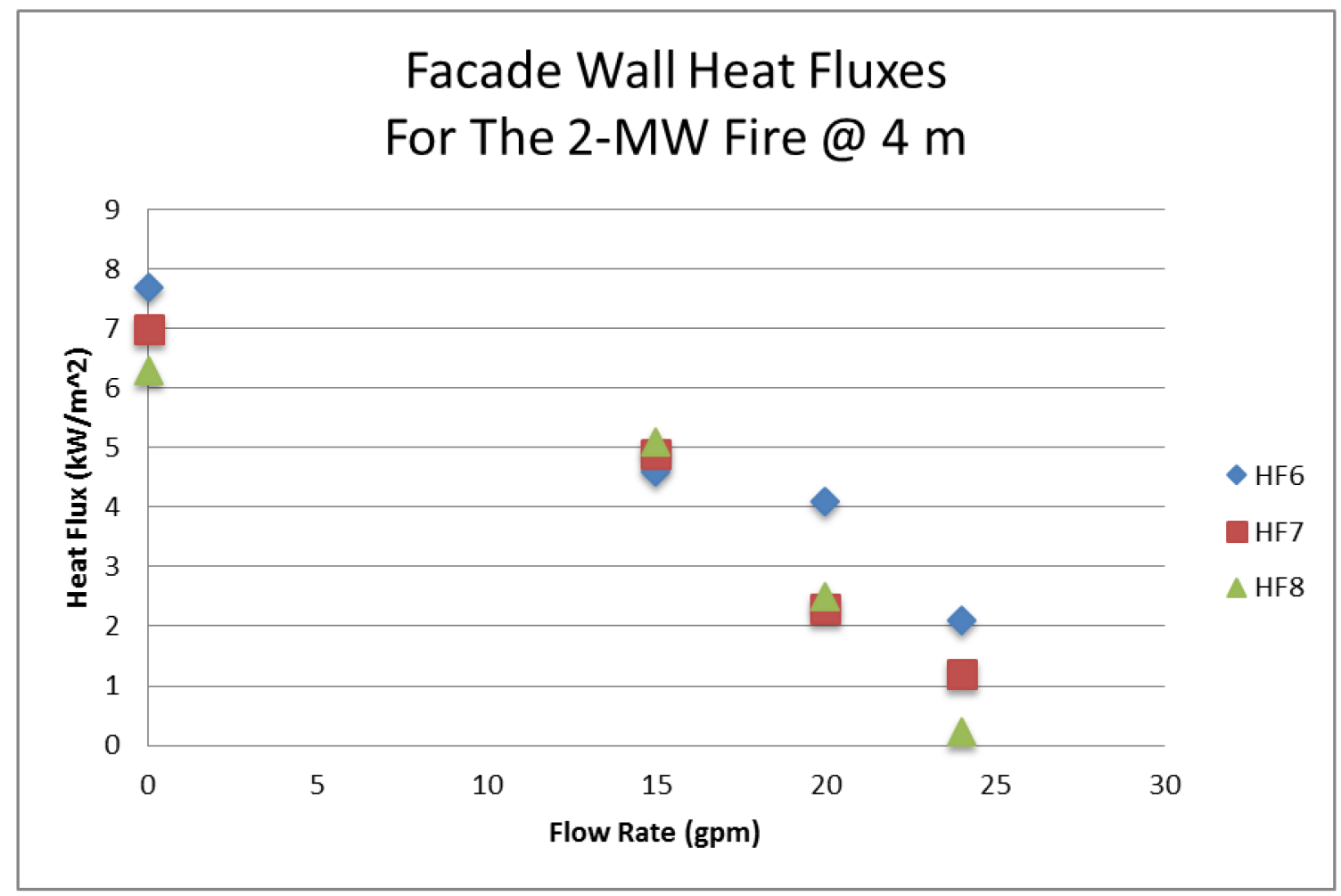

Figure 4.14 - Façade wall heat flux results for the 2-MW fire at a separation distance of $4 \mathrm{~m}$

The temperatures results, Table 4.8, along the target wall and façade wall for the 2-MW fire at a separation distance of $4 \mathrm{~m}$ is presented graphically in Figure 4.15 and Figure 4.16, respectively. Initial temperatures along the target wall were between $86^{\circ} \mathrm{C}$ and $115^{\circ} \mathrm{C}$ prior to sprinkler activation with an average temperature of $102.6^{\circ} \mathrm{C}$. The highest temperatures was initially found at $\mathrm{T} 4$. Temperatures decreased to between $62^{\circ} \mathrm{C}$ and $98^{\circ} \mathrm{C}$ when the sprinklers were running, with an average target wall temperature of $76.3^{\circ} \mathrm{C}$ and an average reduction of $32 \%$ across all the flow rates. It was found that with the sprinklers active the highest temperature location was $\mathrm{T} 2$ with an average temperature of $94.9^{\circ} \mathrm{C}$ and an average reduction of $12.7 \%$, located on the target just above the centre point of the compartment opening. 
Table 4.8 -Temperature $\left({ }^{\circ} \mathrm{C}\right)$ results for the 2-MW fire at a separation distance of $4 \mathrm{~m}$

\begin{tabular}{cccccccc}
\hline $\begin{array}{c}\text { Sensor } \\
\text { Location }\end{array}$ & $\mathbf{0} \mathbf{g p m}$ & $\mathbf{1 5} \mathbf{~ g p m}$ & Reduction & $\mathbf{2 0} \mathbf{g p m}$ & Reduction & $\mathbf{2 4} \mathbf{g p m}$ & Reduction \\
\hline $\mathbf{1}$ & 102.8 & 67.9 & 0.42 & 68 & 0.42 & 66 & 0.44 \\
$\mathbf{2}$ & 105.9 & 93.8 & 0.14 & 97.9 & 0.09 & 93 & 0.15 \\
$\mathbf{3}$ & 86.7 & 62.9 & 0.36 & 68.9 & 0.27 & 65 & 0.33 \\
$\mathbf{4}$ & 114.8 & 82.5 & 0.34 & 75.7 & 0.41 & 73.9 & 0.43 \\
Target Wall & 102.55 & 76.78 & 0.31 & 77.63 & 0.30 & 74.48 & 0.34 \\
Average & & & & & & & \\
$\mathbf{6}$ & 166.4 & 135.6 & 0.21 & 69 & 0.67 & 41.2 & 0.86 \\
$\mathbf{7}$ & 185.9 & 191.3 & -0.03 & 161.9 & 0.14 & $\mathrm{~N} / \mathrm{A}$ & N/A \\
$\mathbf{8}$ & 163 & 166 & -0.02 & 123.1 & 0.28 & 72.1 & 0.64 \\
$\begin{array}{c}\text { Façade Wall } \\
\text { Average }\end{array}$ & 171.77 & 164.30 & 0.05 & 118.00 & 0.35 & 56.65 & 0.76 \\
\hline
\end{tabular}

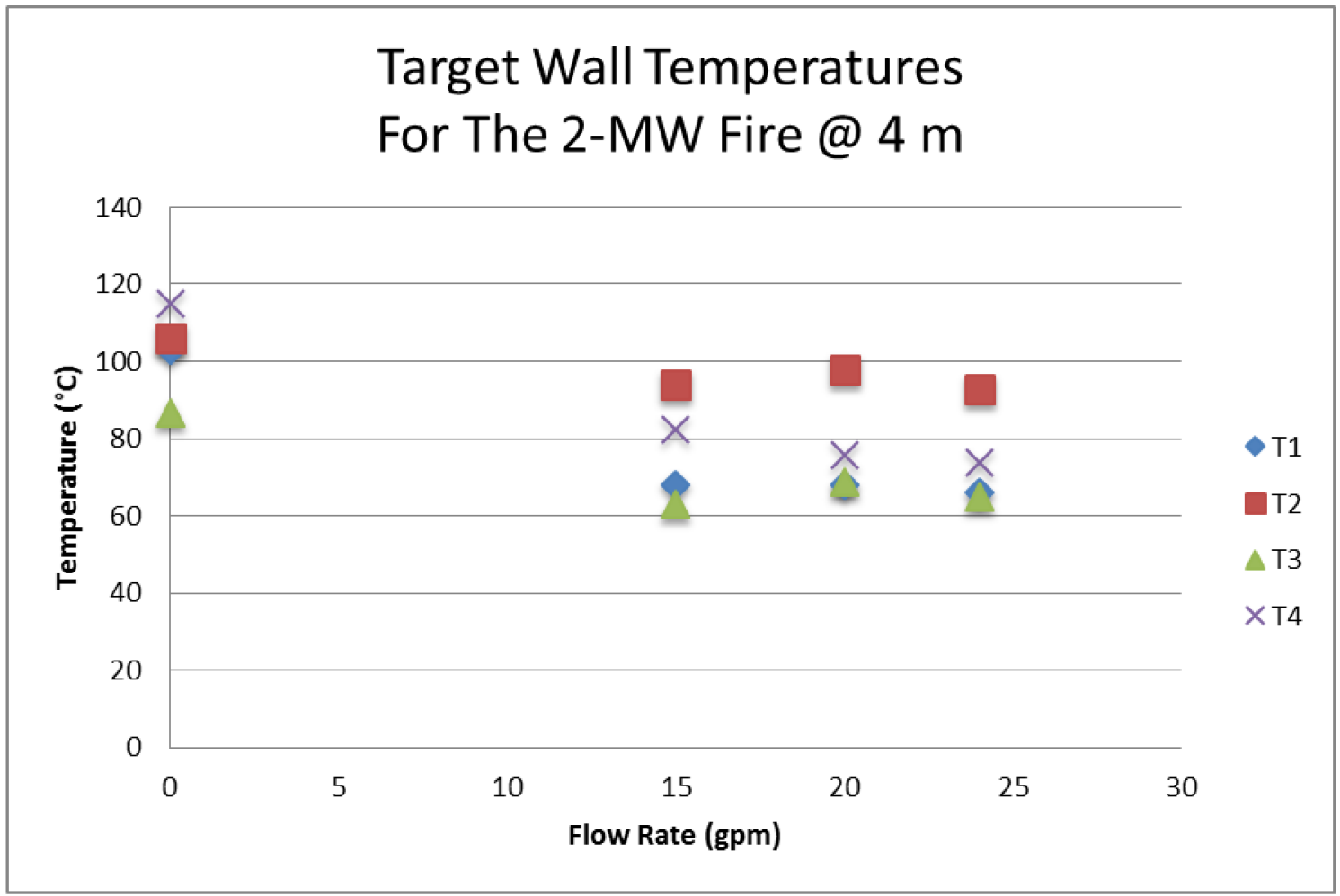

Figure 4.15 - Target wall temperature results for the 2-MW fire at a separation distance of $4 \mathrm{~m}$

Above the compartment on the front façade wall the temperatures were initially between $163^{\circ} \mathrm{C}$ and $186^{\circ} \mathrm{C}$, with an average temperature of $171.8^{\circ} \mathrm{C}$. With the sprinkler flow the $15 \mathrm{gpm}$, the only temperature location to be effected was T6 with the others having no effect. The temperatures dropped with the higher sprinkler flow rates. The average reduction caused by the introduction of the water curtain 
was $5 \%$ for the $15 \mathrm{gpm}$ flow rate, $35 \%$ for the $20 \mathrm{gpm}$ flow rate, and $76 \%$ for the $24 \mathrm{gpm}$ flow rate. As with the heat fluxes the temperatures at T6 saw the largest effect while T8 received the smallest effect. The temperature at $\mathrm{T} 6$ decreased by $21 \%, 67 \%$, and $86 \%$ across the increasing flow rates.

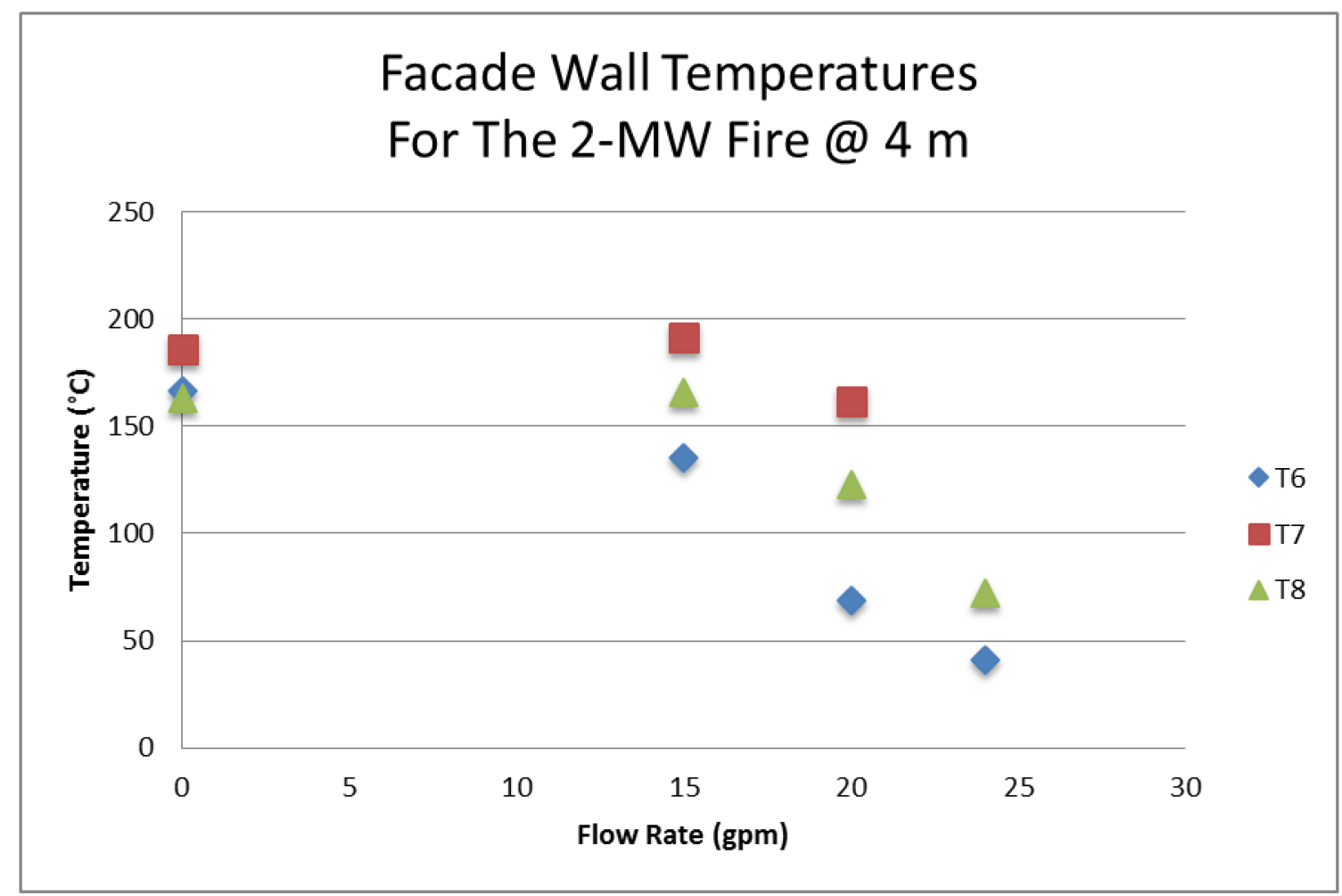

Figure 4.16 - Façade wall temperature results for the 2-MW fire at a separation distance of $4 \mathrm{~m}$

\subsubsection{3-MW Fire Tests Results}

The heat flux results for the 3-MW fire tests on both test walls are shown in Table 4.9 and displayed graphically in Figure 4.17 for the target wall and Figure 4.18 for the façade wall. The average heat flux along the target wall was $13.7 \mathrm{~kW} / \mathrm{m}^{2}$ initially, greater than that required for piloted ignition of wood products. The highest heat flux experienced along the target wall for the baseline test was at sensor HF3 with a reading of $15.3 \mathrm{~kW} / \mathrm{m}^{2}$. The average reduction of the heat flux was $34 \%$ for the $15 \mathrm{gpm}$ flow rate, $30 \%$ for the $20 \mathrm{gpm}$ flow rate, and $33 \%$ for the $24 \mathrm{gpm}$ flow rate. During testing with sprinklers the point with the highest heat flux was HF1, directly across from the centre of the compartment. The average reduction at this point was $32.3 \%$ similar to the other target wall locations. 
Table 4.9 - Heat flux $\left(\mathrm{kW} / \mathrm{m}^{2}\right)$ results for the 3-MW fire at a separation distance of $4 \mathrm{~m}$

\begin{tabular}{cccccccc}
\hline $\begin{array}{c}\text { Sensor } \\
\text { Location }\end{array}$ & $\mathbf{0} \mathbf{~ g p m}$ & $\mathbf{1 5} \mathbf{~ g p m}$ & Reduction & $\mathbf{2 0} \mathbf{~ g p m}$ & Reduction & $\mathbf{2 4} \mathbf{~ g p m}$ & Reduction \\
\hline $\mathbf{1}$ & 14.8 & 9.8 & 0.34 & 10.3 & 0.30 & 9.9 & 0.33 \\
$\mathbf{2}$ & 14 & 9 & 0.36 & 9.6 & 0.31 & 9.2 & 0.34 \\
$\mathbf{3}$ & 15.3 & 9.8 & 0.36 & 10.2 & 0.33 & 9.6 & 0.37 \\
$\mathbf{4}$ & 14.2 & 9.1 & 0.36 & 9.9 & 0.30 & 9.6 & 0.32 \\
$\mathbf{5}$ & 10.3 & 7.1 & 0.31 & 7.6 & 0.26 & 7.4 & 0.28 \\
Target Wall & & & & & & & \\
Average & 13.72 & 8.96 & 0.34 & 9.52 & 0.30 & 9.14 & 0.33 \\
$\mathbf{6}$ & 18.4 & 6.9 & 0.63 & 5 & 0.73 & 3.9 & 0.79 \\
$\mathbf{7}$ & 16.7 & 7.9 & 0.53 & 5.1 & 0.69 & 4.3 & 0.74 \\
$\mathbf{8}$ & 13.1 & 7.8 & 0.40 & 4 & 0.69 & 3.2 & 0.76 \\
\hline Façade Wall & & & & & & & \\
Average & 16.07 & 7.53 & 0.52 & 4.70 & 0.71 & 3.80 & 0.76 \\
\hline
\end{tabular}

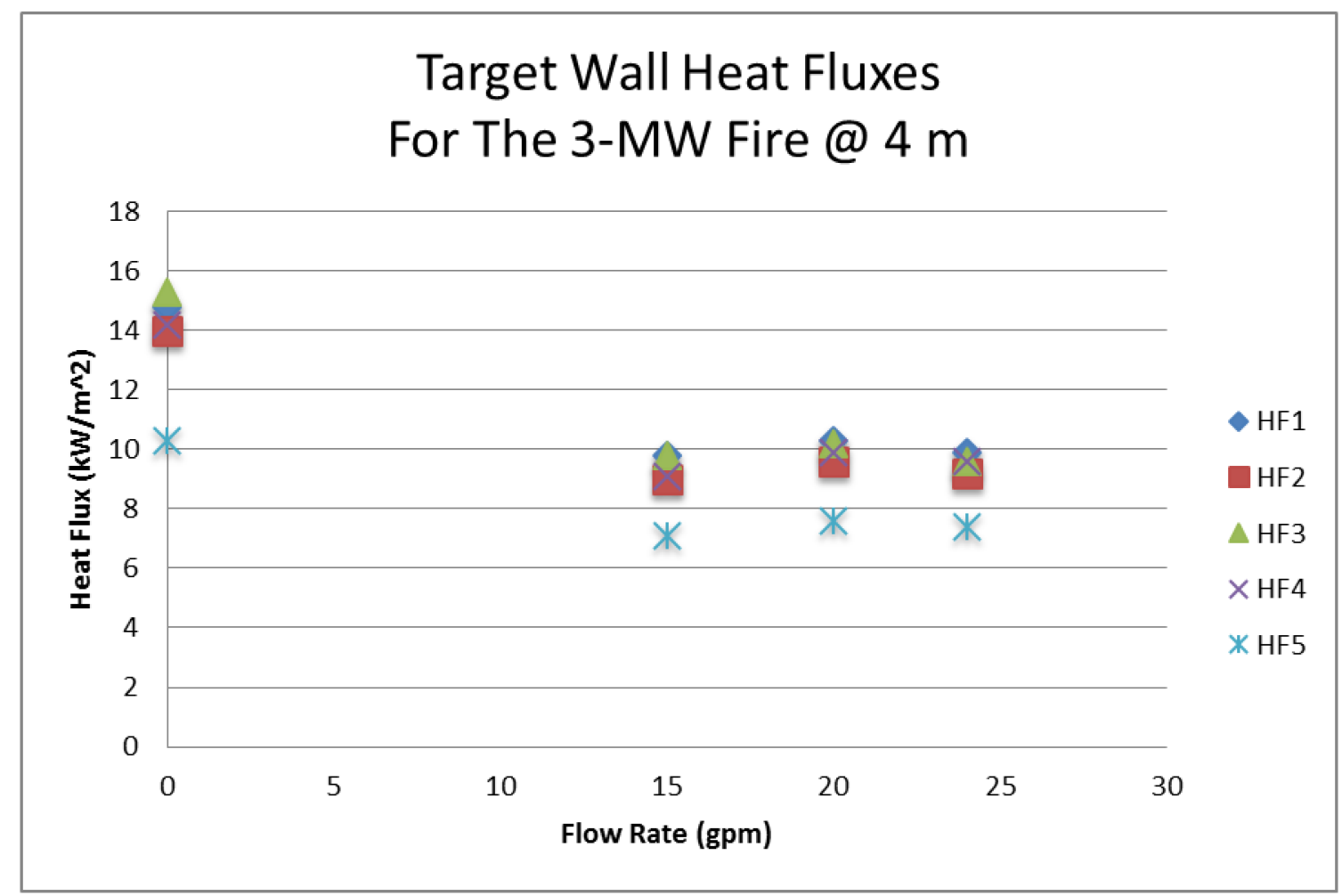

Figure 4.17 - Target wall heat flux results for the 3-MW fire at a separation distance of $4 \mathrm{~m}$

On the facade wall the heat flux was initially between $13 \mathrm{~kW} / \mathrm{m}^{2}$ and $19 \mathrm{~kW} / \mathrm{m}^{2}$. Use of the sprinklers caused the heat flux readings to drop by an average of $52 \%$ for the $15 \mathrm{gpm}$ flow rate, $71 \%$ for the $20 \mathrm{gpm}$ flow rate, and $76 \%$ for the $24 \mathrm{gpm}$ flow rate. The reduction was most prevalent just above 
the opening at $\mathrm{HF} 6$ with a decrease of $63 \%, 73 \%$, and $79 \%$ for the $15 \mathrm{gpm}, 20 \mathrm{gpm}$, and $24 \mathrm{gpm}$ flow rates, respectively.

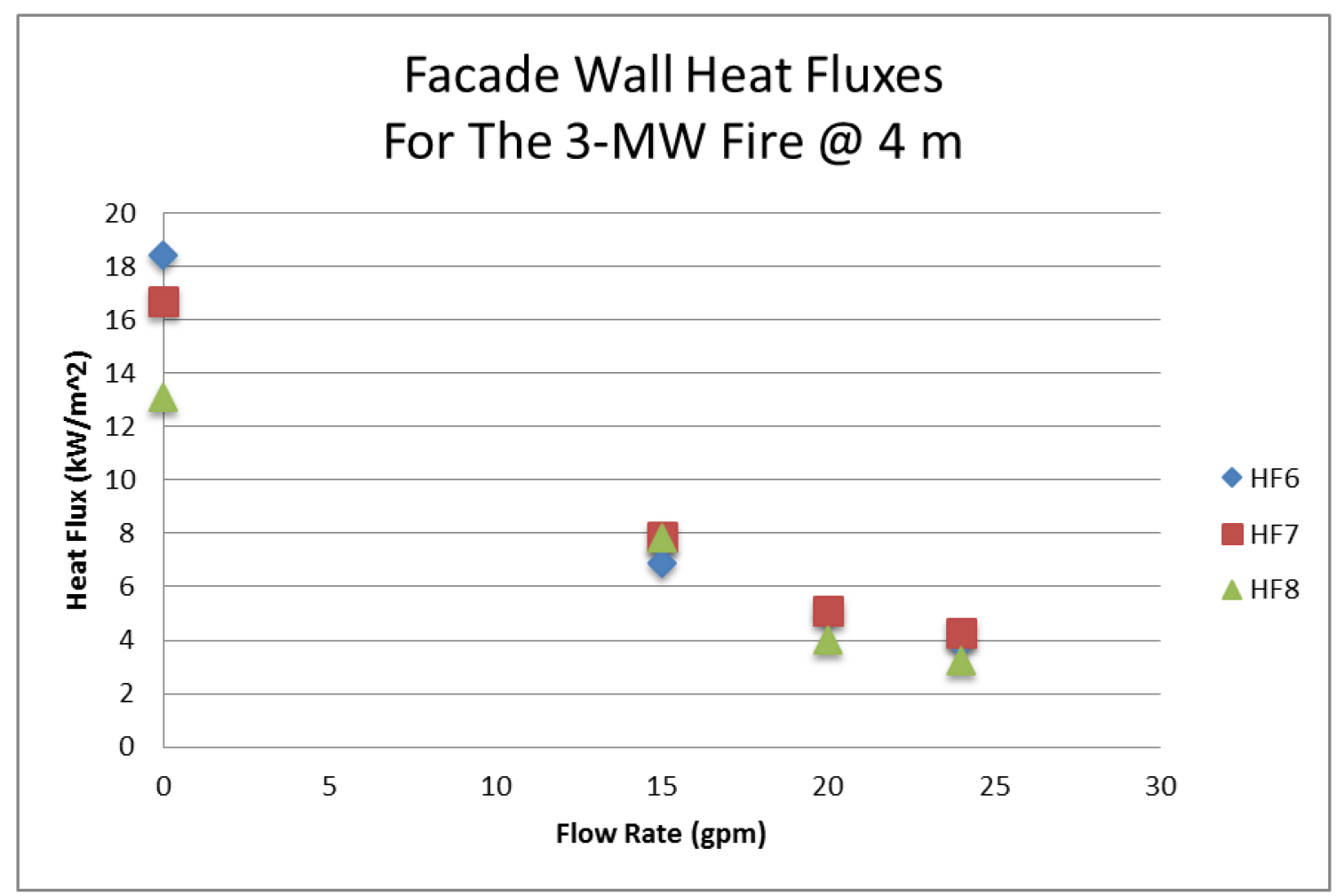

Figure 4.18 - Façade wall heat flux results for the 3-MW fire at a separation distance of $4 \mathrm{~m}$

The temperature data, Table 4.10, is presented graphically in Figure 4.19 for the target wall and Figure 4.20 for the façade wall. The baseline temperatures along the target wall for the 3-MW fire were between $141^{\circ} \mathrm{C}$ and $182^{\circ} \mathrm{C}$ with an average wall temperature of $165.7^{\circ} \mathrm{C}$. The temperatures decreased to an average temperature of $100.6^{\circ} \mathrm{C}$ when the sprinklers were flowing at $15 \mathrm{gpm}, 115.1^{\circ} \mathrm{C}$ when the sprinklers were flowing at $20 \mathrm{gpm}, 115.5^{\circ} \mathrm{C}$ when the sprinklers were flowing at $24 \mathrm{gpm}$. The average reduction in temperatures was $45 \%, 35 \%$ and $34 \%$ for the flow rates, $15 \mathrm{gpm}, 20 \mathrm{gpm}$, and $24 \mathrm{gpm}$, respectively. Increasing the sprinklers flow rates beyond the initial $15 \mathrm{gpm}$ flow rate did not make a large impact on the temperatures along the target wall. 
Table 4.10 - Temperature $\left({ }^{\circ} \mathrm{C}\right)$ results for the 3-MW fire at a separation distance of $4 \mathrm{~m}$

\begin{tabular}{cccccccc}
\hline $\begin{array}{c}\text { Sensor } \\
\text { Location }\end{array}$ & $\mathbf{0 ~} \mathbf{~ p p m}$ & $\mathbf{1 5} \mathbf{~ g p m}$ & Reduction & $\mathbf{2 0} \mathbf{~ g p m}$ & Reduction & $\mathbf{2 4} \mathbf{~ g p m}$ & Reduction \\
\hline $\mathbf{1}$ & 167.9 & 85.9 & 0.55 & 96.9 & 0.48 & 92.6 & 0.51 \\
$\mathbf{2}$ & 181.5 & 121.2 & 0.37 & 137.6 & 0.27 & 136.1 & 0.28 \\
$\mathbf{3}$ & 141.6 & 86.2 & 0.46 & 106.1 & 0.29 & 107.1 & 0.28 \\
$\mathbf{4}$ & 171.7 & 109.1 & 0.41 & 119.7 & 0.34 & 126 & 0.30 \\
Target Wall & & & & & & & \\
Average & 165.68 & 100.60 & 0.45 & 115.08 & 0.35 & 115.45 & 0.34 \\
$\mathbf{6}$ & 322.9 & 152 & 0.56 & 61.4 & 0.86 & 38.3 & 0.94 \\
$\mathbf{7}$ & 338.6 & 238.7 & 0.31 & 121.8 & 0.68 & 110.2 & 0.72 \\
$\mathbf{8}$ & 283.6 & 193.1 & 0.34 & 119.6 & 0.62 & 95.4 & 0.71 \\
$\begin{array}{c}\text { Façade Wall } \\
\text { Average }\end{array}$ & 315.03 & 194.60 & 0.41 & 100.93 & 0.73 & 81.30 & 0.79 \\
\hline
\end{tabular}

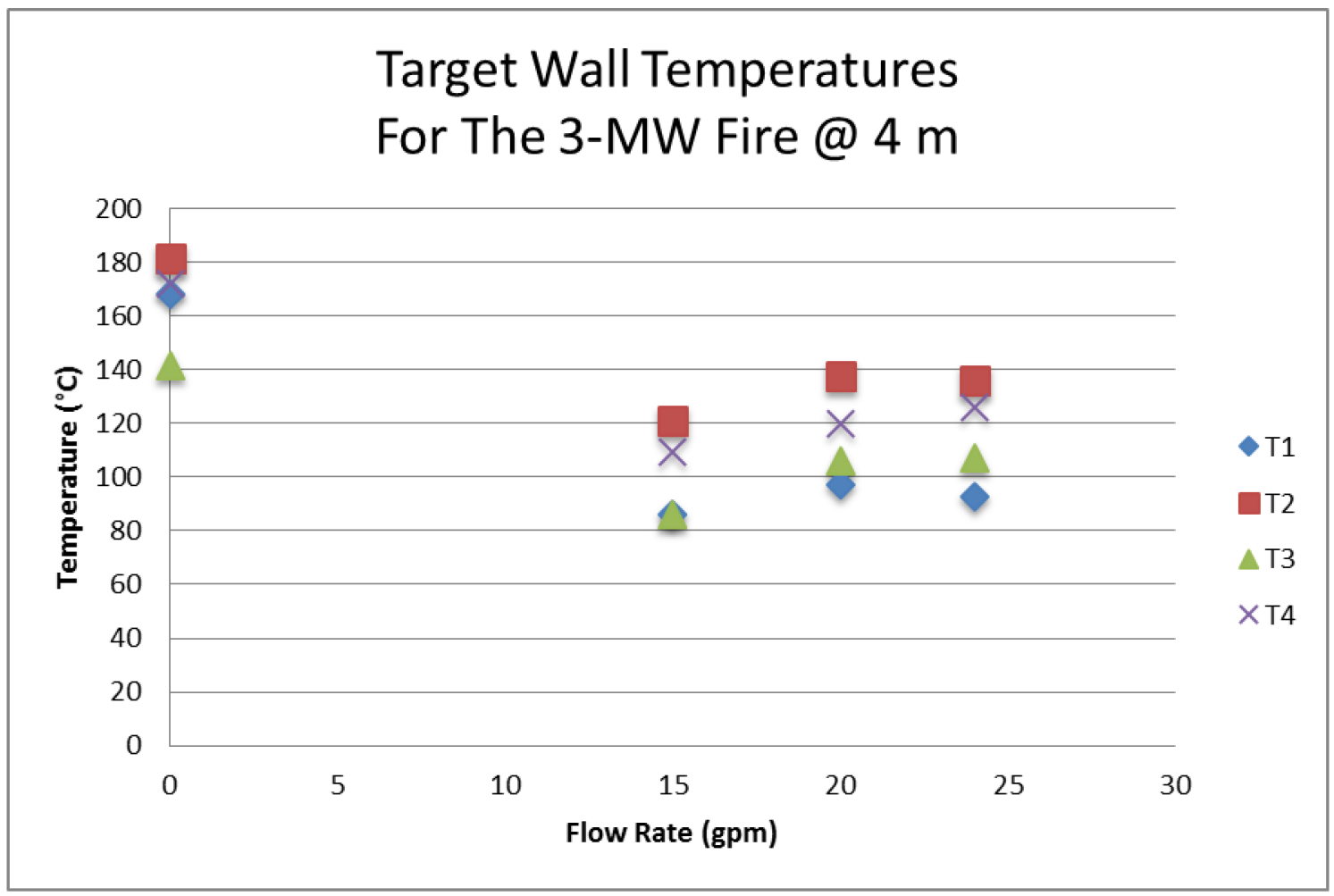

Figure 4.19 - Target wall temperature results for the 3-MW fire at a separation distance of $4 \mathrm{~m}$

Above the compartment on the façade wall the temperatures were initially between $283^{\circ} \mathrm{C}$ and $339^{\circ} \mathrm{C}$, with an average temperature of $315^{\circ} \mathrm{C}$. The highest temperatures were found to be just above the compartment opening at $\mathrm{H} 6$ and $\mathrm{H7}$. With the introduction of sprinklers the temperatures decreased with increasing sprinkler flow rates. Temperatures decreased to between, $152^{\circ} \mathrm{C}$ and $239^{\circ} \mathrm{C}$ for the $15 \mathrm{gpm}$ flow 
rate with an average reduction of $41 \%, 61^{\circ} \mathrm{C}$ and $122^{\circ} \mathrm{C}$ for the $20 \mathrm{gpm}$ flow rate with an average reduction of $73 \%, 38^{\circ} \mathrm{C}$ and $111^{\circ} \mathrm{C}$ for the $24 \mathrm{gpm}$ flow rate with an average reduction of $79 \%$. Just above the compartment at T6 saw the greatest impact due to the water curtain with an average reduction of, 56\%, $86 \%$, and, $94 \%$ as the flow rates increased.

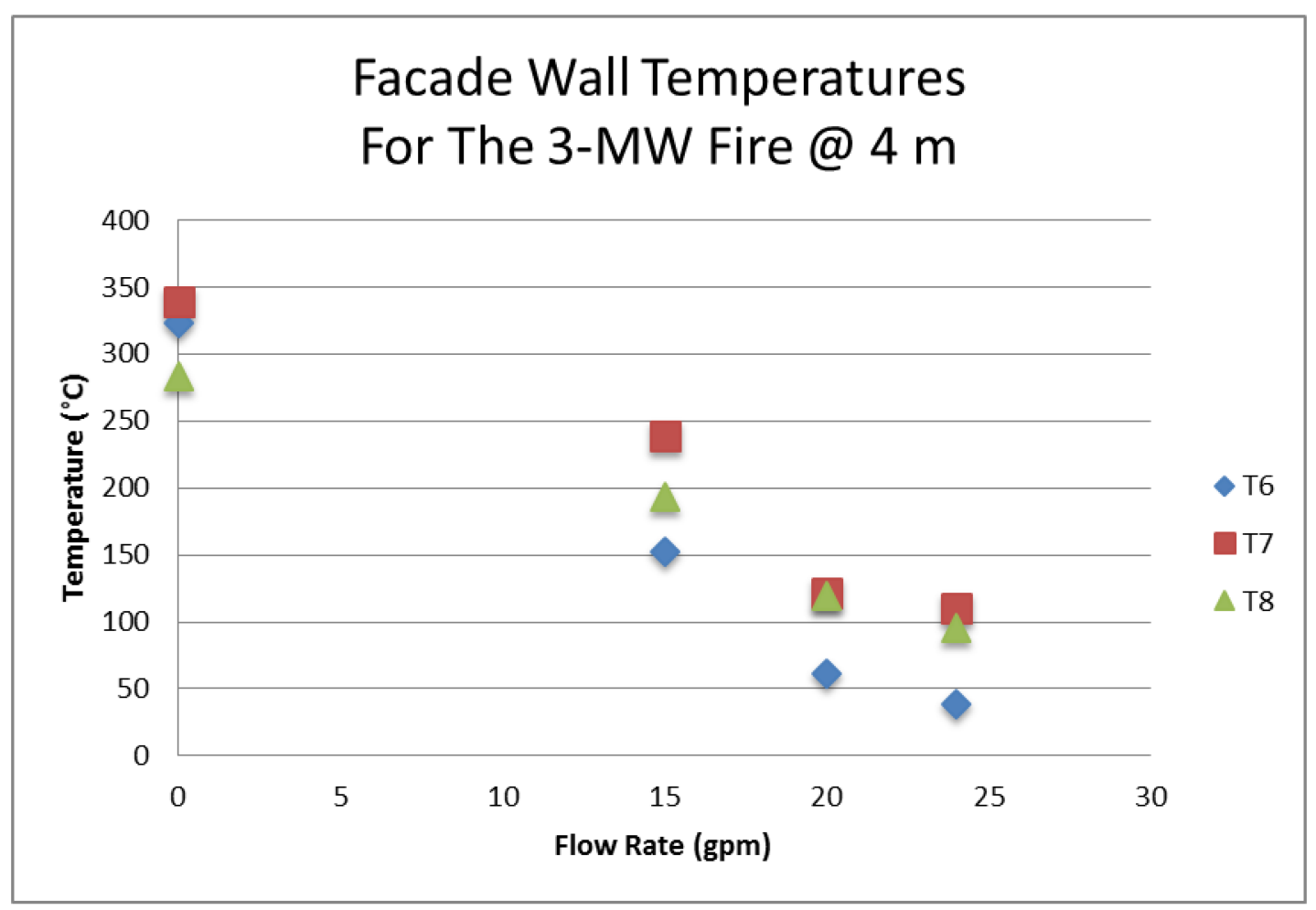

Figure 4.20 - Façade wall temperature results for the 3-MW fire at a separation distance of $4 \mathrm{~m}$

\subsubsection{4-MW Fire Tests Results}

Table 4.11 shows the heat flux results for the 4-MW fire on both the target wall and the façade wall, displayed graphically in Figure 4.21 and Figure 4.22. The initial average heat flux experienced by the target wall was $19.2 \mathrm{~kW} / \mathrm{m}^{2}$, with the highest point heat flux being $21.2 \mathrm{~kW} / \mathrm{m}^{2}$ at $\mathrm{H} 3$. The heat flux reduction was $24 \%$ for the 15 gpm flow rate, $24 \%$ for the 20 gpm flow rate, and $32 \%$ for the 24 gpm flow rate. The baseline heat flux was highest at point HF3, but during testing with sprinklers the heat flux at HF1 was found to be the largest. The average reduction at HF1 was $25 \%$ across all three sprinkler flow 
rates. Similar to the 3-MW fire test the heat fluxes were greater than the critical heat flux but no sparks were getting through the water curtain.

Table 4.11 - Heat flux $\left(\mathrm{kW} / \mathrm{m}^{2}\right)$ results for the 4-MW fire at a separation distance of $4 \mathrm{~m}$

\begin{tabular}{cccccccc}
\hline $\begin{array}{c}\text { Sensor } \\
\text { Location }\end{array}$ & $\mathbf{0} \mathbf{~ g p m}$ & $\mathbf{1 5} \mathbf{~ g p m}$ & Reduction & $\mathbf{2 0} \mathbf{~ g p m}$ & Reduction & $\mathbf{2 4} \mathbf{g p m}$ & Reduction \\
\hline $\mathbf{1}$ & 20.9 & 16.7 & 0.20 & 15.9 & 0.24 & 14.4 & 0.31 \\
$\mathbf{2}$ & 19.9 & 14.8 & 0.26 & 15.2 & 0.24 & 13.6 & 0.32 \\
$\mathbf{3}$ & 21.2 & 15.6 & 0.26 & 15.7 & 0.26 & 14.2 & 0.33 \\
$\mathbf{4}$ & 19.8 & 14.8 & 0.25 & 14.6 & 0.26 & 13.4 & 0.32 \\
$\mathbf{5}$ & 14.4 & 11.4 & 0.21 & 11.2 & 0.22 & 10.1 & 0.30 \\
\hline $\begin{array}{c}\text { Target Wall } \\
\text { Average }\end{array}$ & 19.24 & 14.66 & 0.24 & 14.52 & 0.24 & 13.14 & 0.32 \\
$\mathbf{6}$ & 39.4 & 13.9 & 0.65 & 10.7 & 0.73 & 7.6 & 0.81 \\
$\mathbf{7}$ & 33.2 & 12 & 0.64 & 10.3 & 0.69 & 7.9 & 0.76 \\
$\mathbf{8}$ & 22.9 & 9.6 & 0.58 & 7.6 & 0.67 & 6 & 0.74 \\
\hline $\begin{array}{c}\text { Façade Wall } \\
\text { Average }\end{array}$ & 31.83 & 11.83 & 0.62 & 9.53 & 0.70 & 7.17 & 0.77 \\
\hline
\end{tabular}

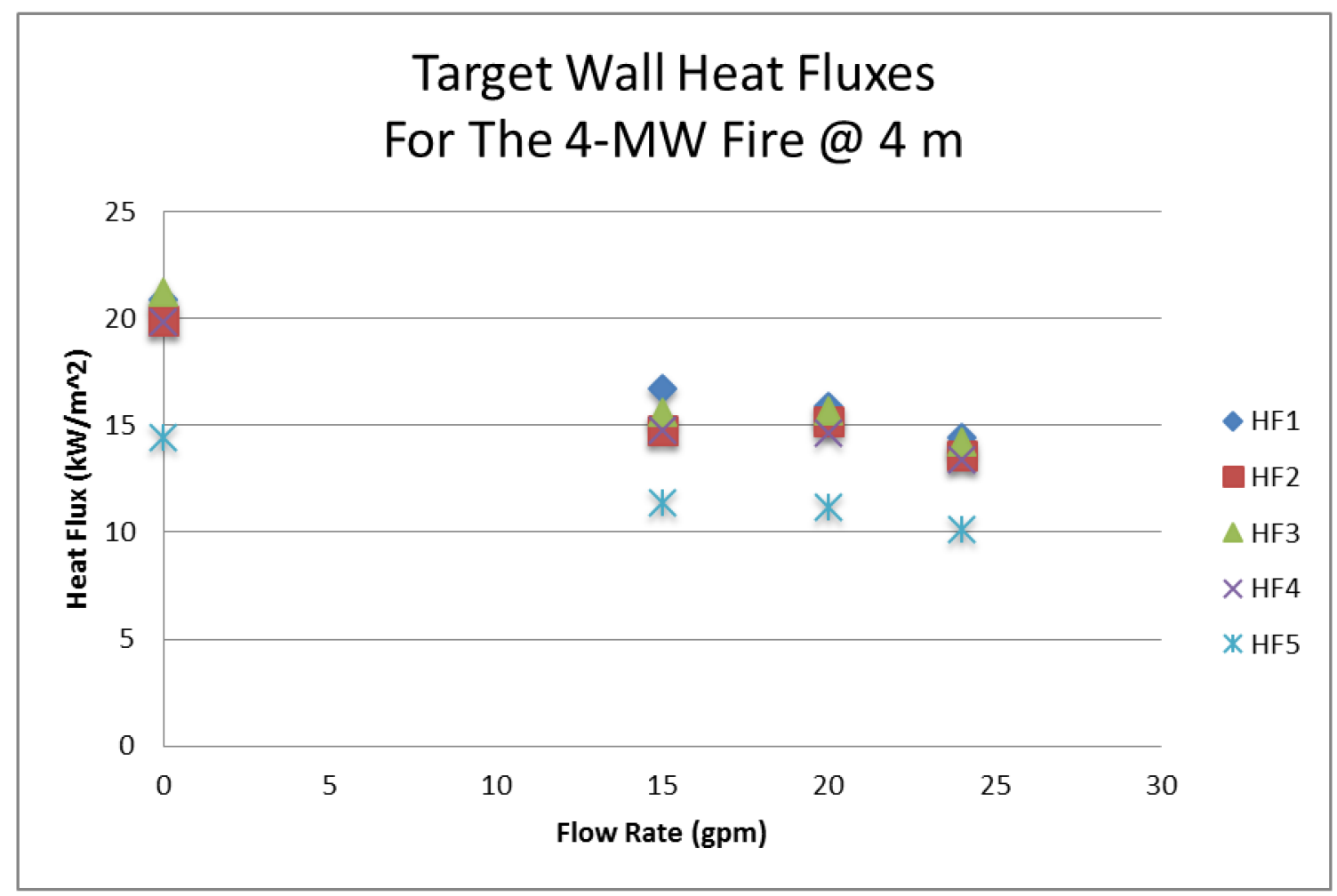

Figure 4.21 - Target wall heat flux results for the 4-MW fire at a separation distance of $4 \mathrm{~m}$

On the facade wall the heat flux was initially between $22 \mathrm{~kW} / \mathrm{m}^{2}$ and $40 \mathrm{~kW} / \mathrm{m}^{2}$. The use of the sprinklers caused the average heat flux to drop by $62 \%$ for the 15 gpm flow rate, $70 \%$ for the 20 gpm flow 
rate, and $77 \%$ for the 24 gpm flow rate. Sensor HF6 saw the largest effect with a reduction of $65 \%, 73 \%$, and $81 \%$ for each respective flow rate.

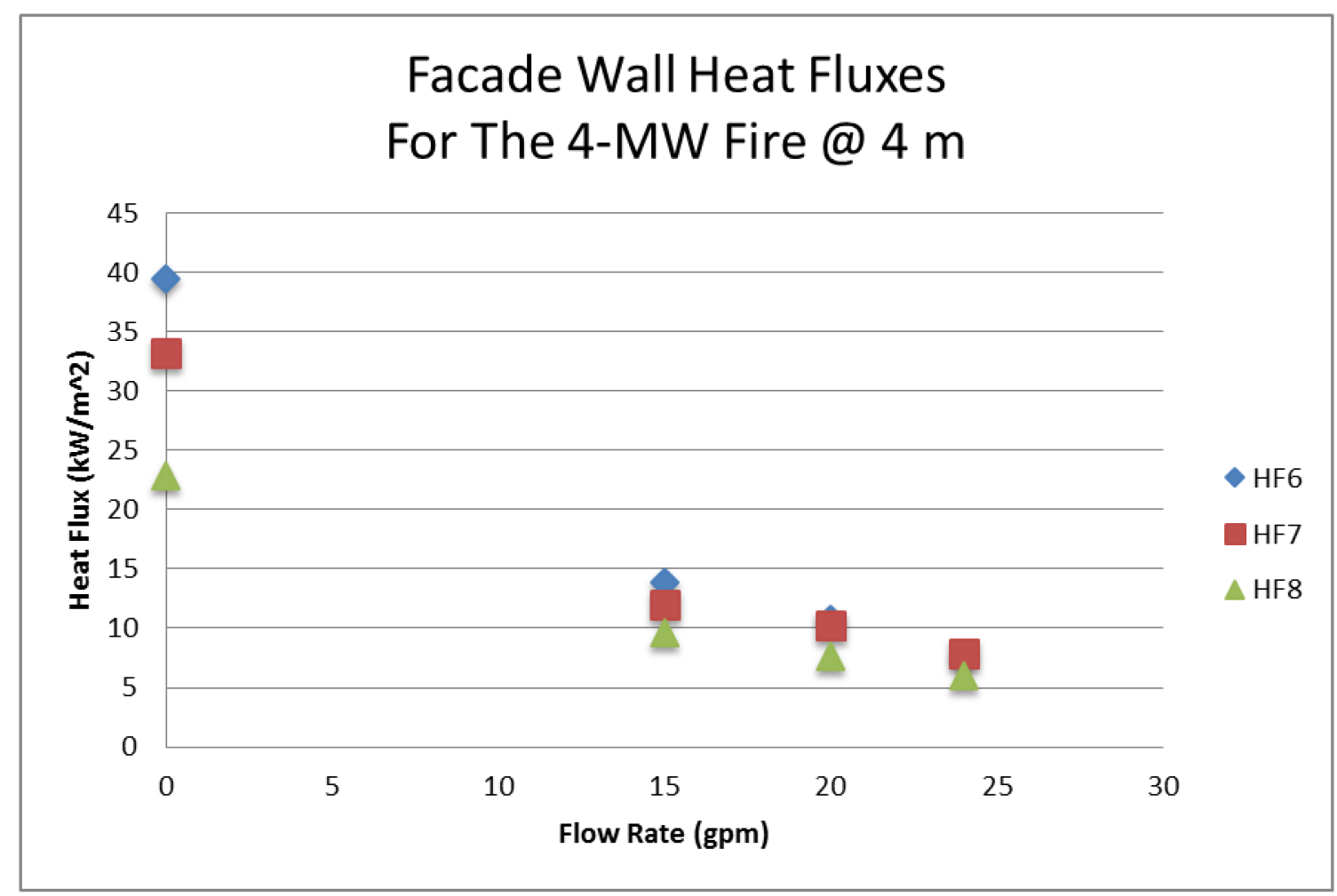

Figure 4.22 - Façade wall heat flux results for the 4-MW fire at a separation distance of $4 \mathrm{~m}$

The temperature data for the 4-MW fire test is shown in Table 4.12. The baseline temperatures, shown in Figure 4.23 , along the target wall were between $177^{\circ} \mathrm{C}$ and $224^{\circ} \mathrm{C}$. The temperatures decreased to between $125^{\circ} \mathrm{C}$ and $175^{\circ} \mathrm{C}$ when each sprinkler was flowing at $15 \mathrm{gpm}$, and to between $134^{\circ} \mathrm{C}$ and $188^{\circ} \mathrm{C}$ when each sprinkler was flowing at $20 \mathrm{gpm}$, and to between $121^{\circ} \mathrm{C}$ and $175^{\circ} \mathrm{C}$ when each sprinkler was flowing at $24 \mathrm{gpm}$. The average reduction in temperatures was $32 \%, 23 \%$ and $33 \%$ for the flow rates, 15 gpm, $20 \mathrm{gpm}$, and $24 \mathrm{gpm}$, respectively. The highest temperatures were found at sensor location T2 with reductions of $23 \%$ for the 15 gpm flow rate, $18 \%$ for the $20 \mathrm{gpm}$ flow rate, and $24 \%$ for the 24 gpm flow rate. 
Table 4.12 - Temperature $\left({ }^{\circ} \mathrm{C}\right)$ results for the 4-MW fire at a separation distance of $4 \mathrm{~m}$

\begin{tabular}{cccccccc}
\hline $\begin{array}{c}\text { Sensor } \\
\text { Location }\end{array}$ & $\mathbf{0 ~} \mathbf{~ g p m}$ & $\mathbf{1 5} \mathbf{~ g p m}$ & Reduction & $\mathbf{2 0} \mathbf{~ g p m}$ & Reduction & $\mathbf{2 4} \mathbf{~ g p m}$ & Reduction \\
\hline $\mathbf{1}$ & 208.5 & 124.7 & 0.44 & 133.9 & 0.40 & 121.2 & 0.46 \\
$\mathbf{2}$ & 223.7 & 177.4 & 0.23 & 186.8 & 0.18 & 174.3 & 0.24 \\
$\mathbf{3}$ & 177.4 & 137.6 & 0.25 & 149.5 & 0.18 & 134.9 & 0.27 \\
$\mathbf{4}$ & 222.5 & 153 & 0.34 & 187.4 & 0.17 & 152.5 & 0.35 \\
Target Wall & & & & & & & \\
Average & 208.03 & 148.18 & 0.32 & 164.40 & 0.23 & 145.73 & 0.33 \\
$\mathbf{6}$ & 453.3 & 159.5 & 0.68 & 106.3 & 0.80 & 63 & 0.90 \\
$\mathbf{7}$ & 468 & 182 & 0.64 & 155.4 & 0.70 & 143.8 & 0.72 \\
$\mathbf{8}$ & 387.8 & 175.8 & 0.58 & 154.6 & 0.63 & 142.7 & 0.67 \\
\hline $\begin{array}{c}\text { Façade Wall } \\
\text { Average }\end{array}$ & 436.37 & 172.43 & 0.63 & 138.77 & 0.71 & 116.50 & 0.77 \\
\hline
\end{tabular}

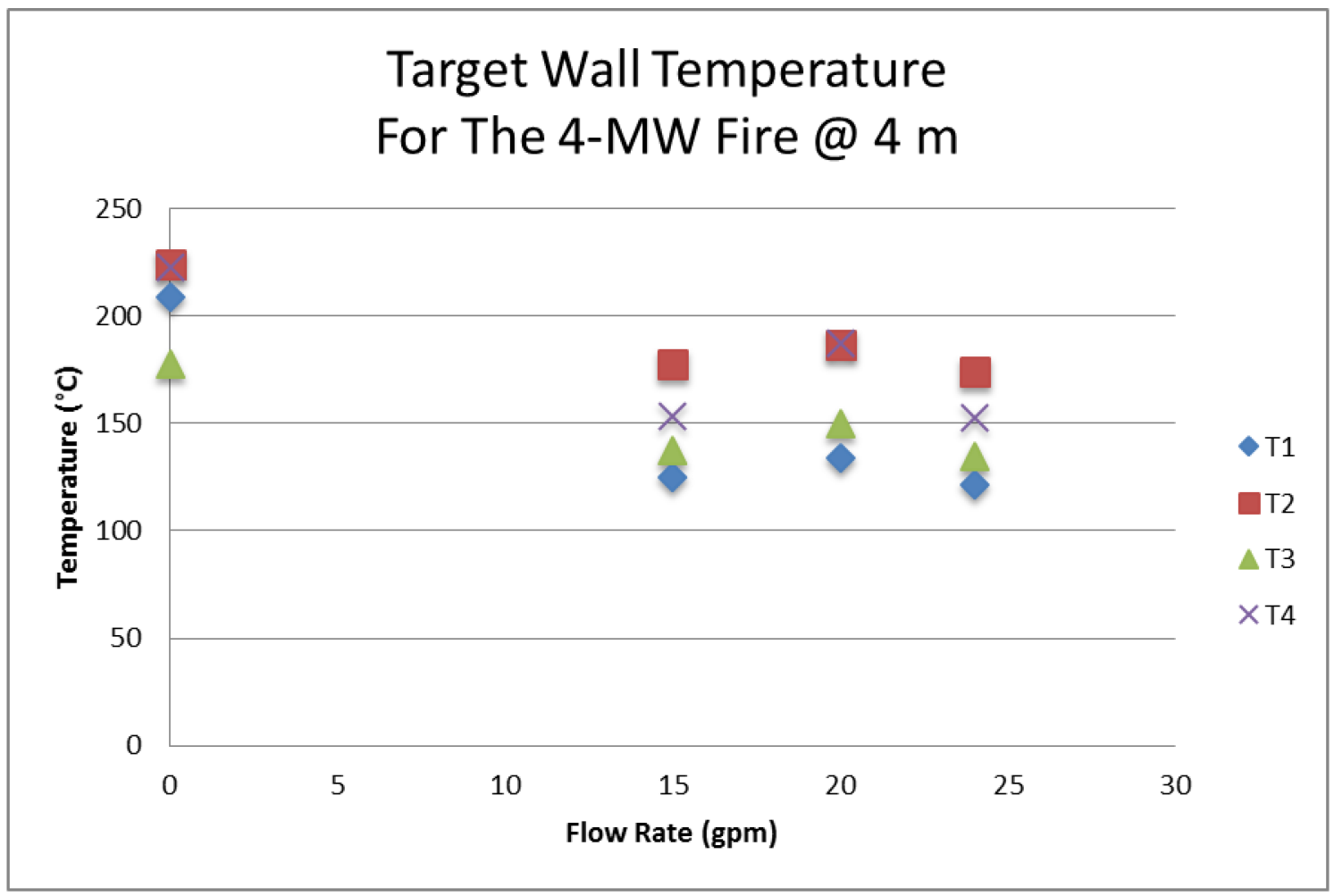

Figure 4.23 - Target wall temperature results for the 4-MW fire at a separation distance of $4 \mathrm{~m}$

Above the compartment on the facade wall the temperatures, shown in Figure 4.12, were initially between $387^{\circ} \mathrm{C}$ and $468^{\circ} \mathrm{C}$, with an average temperature of $436.4^{\circ} \mathrm{C}$. The highest temperatures were found to be just above the compartment opening at T6 and T7. Temperatures dropped with increasing reductions as the sprinkler flow rates increased. As with the previous tests above the compartment at T6 
saw the greatest impact due to the water curtain with an average reduction of $68 \%, 80 \%$, and $90 \%$ as the flow rates increased.

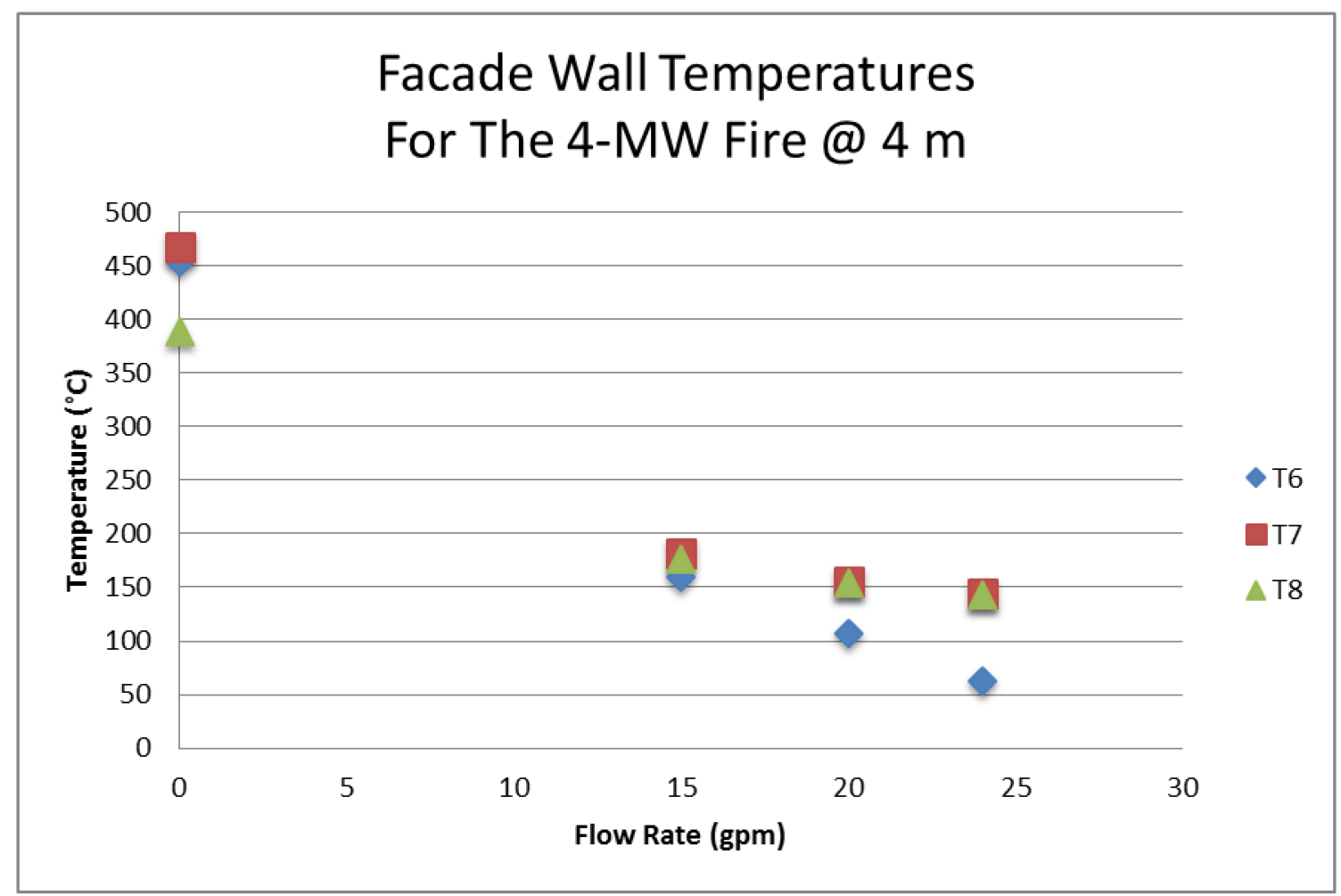

Figure 4.24 - Façade wall temperature results for the 4-MW fire at a separation distance of $4 \mathrm{~m}$

\subsection{Discussion on Experimental Findings}

\subsubsection{2-MW Fire Tests Discussion}

Based on the 2-MW fire tests for both separation distances, $3 \mathrm{~m}$ and $4 \mathrm{~m}$, the initial heat fluxes along the target wall were found to be below the critical heat flux required for piloted ignition of wood products. With the sprinkler flow the heat flux reductions for both distances were found to be similar for all flow rates meaning that increasing the water flow rates had minimal impact of the attenuation after the minimum flow rate test. The results of the tests at the $3 \mathrm{~m}$ separation distanced showed larger reductions on the lower sensors than on the higher sensors. 
The results from the façade wall sensors showed that the heat fluxes above the opening were varied due to the hot gases exiting the compartment causing turbulence. The 3-m separation distance test found that the sensor closest to the opening received a heat flux greater than the critical heat flux, but this was not the case for the 4-m separation distance test. With the introduction of the sprinklers all heat fluxes dropped to well below the critical heat flux. During the 3-m separation distance tests the reductions along the façade were similar across all the flow rates, while during the 4-m separation distance test the attenuation amount increased as the flow rate increased.

The highest temperatures along the target wall were initially located at the highest sensors. During testing for the 3-m separation distance, temperatures decreased and converged to a uniform temperature as well as increased attenuation with increasing flow rates, but this was not the case for the 4-m separation distance tests in which the temperatures decreased slightly with the introduction of the water curtain. Higher flow rates for the 3-m separation tests showed better attenuation for the temperatures than they did for the heat fluxes.

Along the façade wall the temperatures showed a similar attenuation pattern to that of the heat fluxes for the 3-m separation distance tests. For the 4-m separation distance tests the temperature attenuation showed minimal impact during the lowest flow rate test but increased substantially with the increasing flow rate.

\subsubsection{3-MW Fire Tests Discussion}

Based on the 3-MW fire tests the initial heat fluxes were greater than the critical heat flux for piloted ignition of wood products. With the sprinkler flow all heat fluxes fell below the critical heat flux for the 4-m tests but required a larger flow rate to bring the 3-m separation distance tests to below the critical heat flux. For the 3-m separation distance test the increasing flow rates improved the attenuation while the attenuation was similar across all flow rates for the 4-m separation distance. 
Along the façade wall initial heat fluxes were greater than the critical heat flux but all fell below the critical heat flux with the sprinkler water flow. A significant increase in attenuation was seen with the increase in the sprinkler flow rates for both separation distances.

The temperatures on the target wall were initially the highest near the point opposite the centre of the compartment opening. During the 3-m separation distance tests the use of sprinklers caused the location of the highest temperatures to rise to near the top of the target wall while the location of highest temperature did not change during the 4-m separation distance tests with sprinklers in use. Temperature attenuation increased with the increasing sprinkler flow rates for the 3-m separation distance tests but did not increase for the 4-m separation distance tests.

Temperatures along the façade wall were initially very high but dropped substantially with the use of the water curtain. Increasing the sprinkler flow rate increased the attenuation of the temperatures for both separation distances.

\subsubsection{4-MW Fire Tests Discussion}

The initial heat flux results of the 4-MW fire tests were much greater than the critical heat flux for piloted ignition of wood products. The sprinkler water flow failed to bring the heat fluxes below the critical heat flux but they were brought low enough to avoid spontaneous combustion. Even though the heat fluxes were above the critical value, the critical value is a conservative and requires a spark or flame to be in close proximity to the target wall. With the use of the sprinklers, sparks and flames were unable to penetrate the water curtain and during the 3-m separation tests the water curtain was wetting the wall. The use of sprinklers caused uniform reductions to the heat fluxes for both separation distances.

Along the façade wall initial heat fluxes were greater than the critical heat flux but fell below the critical heat flux with the larger flow rate sprinklers. A significant increase in attenuation was seen with 
the increase in the sprinkler flow rates for the 3-m separation distance with a smaller increase for the 4m separation distance.

The temperatures along the target wall were initially the highest near the point opposite the centre of the compartment opening. During the 3-m separation distance tests the use of sprinklers required larger flow rates to be more effective while reductions during the 4-m separation distance tests with sprinklers were similar for all flow rates.

Temperatures along the façade wall were initially very high but dropped substantially with the use of the water curtain. Increasing the sprinkler flow rate increased the attenuation of the temperatures for both separation distances.

\subsubsection{Overall Discussion on Experiments}

The attenuation along the target was found to be less effective for the larger separation distance. The heat fluxes for all the experiments were lowered to acceptable ranges such that flame spread could be avoided, protecting adjacent property. The largest reductions were generally seen during the sprinklers tests with the highest flow rate. It was found that the baseline heat fluxes for the 4-m separation tests were similar to or even higher than the 3-m separation tests with the exception of the 2-MW tests. For the 2-MW fire the 3-m separation tests had clearly higher heat fluxes. This is believed to be caused by one or more reasons. The reasons include; the 4- $\mathrm{m}$ separation tests having better insulation resulting in more heat exiting from the opening as opposed to the compartment boundaries, the separation distance between the compartment and the target wall affecting the amount of air available to be entrained into the compartment, and variations in the propane flow rate.

Temperatures along the target wall were initially the highest near the top of the wall during the 2-MW fire tests when no flames were seen exiting the compartment but during the larger fire tests flames 
were seen exiting the compartment which resulted in the highest temperatures being closer to the compartment opening. During the tests with the use of sprinklers the location of highest temperature was near the point opposite the centre of the compartment opening. As with the heat fluxes it was found that the temperatures on the target wall for all tests (including the 2-MW test) were similar or higher for the 4-m separation tests than for the 3-m separation tests. It is believed to be due to the same reasons as the heat fluxes.

The façade wall heat fluxes were all initially varied due to the hot gases and flames escaping the compartment causing a turbulent effect. The heat fluxes were found to be greater than the critical heat flux required for piloted ignition but were brought to acceptable levels with the introduction of the water curtain with the larger fires requiring larger flow rates to bring the heat fluxes down to acceptable level. The use of sprinklers helped reduce the turbulence caused by the hot gases and flames resulting in a reduction that can help prevent upward flame spread from a lower compartment to a higher one through an opening. The sensors closest to the opening were impacted more than the higher sensors due to being in closer proximity to the hot gases and flames that were exiting the compartment.

Temperatures along the façade wall showed similar results to the heat fluxes in that the larger fires required larger flow rates to be effective at reducing the temperatures. The sensors closest to the opening had the most attenuation while the sensors further from the opening showed less attenuation.

\subsubsection{Comparison with National Building Code of Canada}

Fire protection design falls under Division B Part 3 of the National Building Code of Canada [1]. Within the section 3.2.3 are the requirements for spatial separation and exposure protection. This section is intended to prevent fire spread from thermal radiation assuming there is adequate firefighting available. The requirements state that spatial separation should prove adequate to inhibit the ignition of an exposed building face or the interior of an adjacent building by radiation. Preliminary calculations performed in 
Appendix A determined that the minimum separation distance allowed by the National Building Code is $2.37 \mathrm{~m}$. Distances of $3 \mathrm{~m}$ and $4 \mathrm{~m}$ was used during testing.

The requirements of the National Building Code of Canada state that the percentage area of the unprotected openings of an exposing building face is based on the limiting distance for a building. The unprotected area of the compartment in these experiments as a percentage of the total exposing face was $25 \%$ and the length to height ratio of the compartment is 1.33 . The compartment being tested falls between the 10 to $15 \mathrm{~m}$ max area (compartment exposing area $=12 \mathrm{~m}$ ). Therefore, Table 3.2.3.1.B. states that the maximum allowable area of unprotected openings as a percentage for a building is between $33 \%$ and $46 \%$ for a building with a limiting distance of $3 \mathrm{~m}$ and a building with a limiting distance of $4 \mathrm{~m}$ has a maximum allowable area of unprotected openings between $63 \%$ and $91 \%$. These values are for Group A, C, D, and F, Division 3 Occupancies that do not have sprinklers. Table 3.2.3.1.C., which is for Group E, and F, Division 1 and 2 Occupancy buildings without sprinklers, states that the maximum allowable area of unprotected openings as a percentage for a building is between $16 \%$ and $23 \%$ for a building with a limiting distance of $3 \mathrm{~m}$ and a building with a limiting distance of $4 \mathrm{~m}$ has a maximum allowable area of unprotected openings between $32 \%$ and $46 \%$. Table 3.2.3.1.D., which is for buildings in Group A, C, D, and F, Division 3 Occupancies with sprinklers, states that the maximum allowable area of unprotected openings as a percentage for a building is between $74 \%$ and $100 \%$ for a building with a limiting distance of $3 \mathrm{~m}$ and a building with a limiting distance of $4 \mathrm{~m}$ has a maximum allowable area of unprotected openings $100 \%$. Finally, Table $3 \cdot 2 \cdot 3.1$. E. states that the maximum allowable area of unprotected openings as a percentage for a building is between $36 \%$ and $50 \%$ for a building with a limiting distance of $3 \mathrm{~m}$ and a building with a limiting distance of $4 \mathrm{~m}$ has a maximum allowable area of unprotected openings between $68 \%$ and $96 \%$, for Group E, and F, Division 1 and 2 Occupancy buildings with sprinklers. 
Based on these requirements the compartment tested in these experiments is allowed for all occupancies with the exception of Group E, and F, Division 1 and 2 Occupancy buildings without sprinklers at a separation distance of $3 \mathrm{~m}$. From the baseline tests it was found that for fires above 3-MW the target wall was exposed to heat fluxes that would allow flame spread to adjacent buildings. This shows that the spatial separation requirements for the National Building Code of Canada may not prevent fire spread to adjacent buildings. 


\section{Effect of the Water Curtain and Discussion}

In order to study the effect the water curtain had on attenuating radiation the individual fire tests were broken down and analyzed.

\subsection{Configuration Factor}

For each test the configuration factor was determined using the height of the flames exiting the compartment as well as the sensors along the target wall that fell with the boundaries of the radiator area. The radiator was assumed to be rectangular and to be in plane with the window such that the window and flames exiting the compartment were a single rectangular radiator. The average flame height for each of the fire sizes was determined by taking individual flame heights during the baseline tests and taking the average height of the flames. For the 2-MW fire there were no flames exiting the compartment, so only the window height of $1.5 \mathrm{~m}$ was considered to determine the configuration factor. For the 3-MW and 4-MW fires the flames rose to an average height from the window sill of $2.37 \mathrm{~m}$ and $2.73 \mathrm{~m}$, respectively.

The radiators for each test were broken down into quadrants and each configuration factor for the quadrants was determined. Using the individual quadrant configuration factors the total configuration factor for each test and sensor was determined using the equations presented in Chapter 2.1.4.

\subsection{Compartment Temperature}

Once the configuration factors were determined the compartment temperatures for each test series was determined by solving Equation 2.1. The temperature within the compartment during each test could be calculated using; the heat flux readings along the wall as the target wall during the baseline test, the configuration factor for the test, total emissivity, Stefan Boltzmann constant of $5.67 \times 10^{-8} \mathrm{~W} / \mathrm{m}^{2} \mathrm{~K}^{4}$, and temperature at the thermocouples along the target wall. The emissivity for both surfaces was assumed to be 0.9 , resulting in a total emissivity for each test being 0.82 . 
Based on each sensor within the radiator area the compartment temperatures were calculated for each heat flux sensor and thermocouple location. The average compartment temperature was calculated using the individual compartment temperatures calculated for each sensor during each test series. The average compartment temperatures calculated for each test are presented in Table 5.1. The average compartment temperature for all 4-m separation distance tests was found to be higher than the 3-m separation distance tests. This is believe to be caused by; the 4-m separation tests having better insulation resulting in more heat exiting from the opening as opposed to the compartment boundaries, the separation distance between the compartment and the target wall affecting the amount of air available to be entrained into the compartment, and variations in the propane flow rate.

Table 5.1 - Average calculated compartment temperatures based on the baseline test results

\begin{tabular}{|cc}
\hline Test Series & $\begin{array}{c}\text { Average Compartment } \\
\text { Temperature }\left(\mathrm{K} /{ }^{\circ} \mathrm{C}\right)\end{array}$ \\
\hline 2-MW @ 3-m & $1175(902)$ \\
\hline 2-MW @ 4-m & $1281(1008)$ \\
\hline 3-MW @ 3-m & $1223(950)$ \\
\hline 3-MW @ 4-m & $1389(1116)$ \\
\hline 4-MW @ 3-m & $1349(1076)$ \\
\hline 4-MW @ 4-m & $1463(1190)$ \\
\hline
\end{tabular}

\subsection{Reduction Factor}

The average compartment temperature were then used to determine the theoretical reduction factor for each sensor using the following equation:

$$
\begin{aligned}
& q_{\text {red }}^{\prime \prime}=\left(1-f_{t}\right) \varphi \varepsilon \sigma\left(T_{c}{ }^{4}-T_{a}{ }^{4}\right) \\
& f_{t}=1-\left(\frac{q^{\prime \prime}{ }_{r}}{\varphi \varepsilon \sigma\left(T_{c}{ }^{4}-T_{a}{ }^{4}\right)}\right)
\end{aligned}
$$




$$
\begin{aligned}
& q_{\text {red }}^{\prime \prime}=\text { Experimental Reduced Heat Flux } \\
& f_{t}=\text { Theoretical Reduction Factor } \\
& \varphi=\text { Configuration Factor } \\
& \sigma=\text { Stefan Boltzmann constant, } 5.67 \times 10^{-8} \mathrm{~W} / \mathrm{m}^{2} \mathrm{~K}^{4} \\
& T_{e}=\text { Average Compartment Temperature, } \mathrm{K} \\
& T_{a}=\text { Ambient Temperature, } \mathrm{K} \\
& \varepsilon=\text { emissivity, } \varepsilon=\left(\frac{1}{\varepsilon_{e}}+\frac{1}{\varepsilon_{r}}-1\right)^{-1}
\end{aligned}
$$

Using Equation 5.1 the reduction factor was solved for all sensors, fires, and flow rates. This theoretical reduction, Equation 5.2, was then compared to the actual experimental reduction, Equation 5.3, of the experimental heat fluxes with the water curtain to the baseline heat fluxes without the water curtain. Comparison of the calculated theoretical heat flux reductions and the actual experimental heat flux reductions found that the theoretical reductions were within $-8 \%$ to $4 \%$ of the actual experimental heat flux reductions.

$$
\begin{aligned}
& f_{e}=1-\frac{q^{\prime \prime} \text { red }}{q^{\prime \prime}{ }_{\text {base }}} \\
& q_{\text {red }}^{\prime \prime}=\text { Experimental Reduced Heat Flux } \\
& q_{\text {base }}^{\prime \prime}=\text { Experimental Baseline Heat Flux } \\
& f_{e}=\text { Experimental Reduction Factor }
\end{aligned}
$$

The reductions were then averaged for each flow rate for both theoretical and experimental to determine the reduction factor for each particular flow rate. The reduction factors were averaged with all experiments as well as without the outliers (i.e. the minimum and maximum experiments omitted) to determine the average reduction factor for each flow rate. The reduction factors omitting the outliers, theoretical and experimental, were determined to be between $21.9 \%$ and $23.3 \%$ for the $15 \mathrm{gpm}$ flow rate, $29 \%$ and $30.3 \%$ for the 20 gpm flow rate, and $39 \%$ and $40.1 \%$ for the 24 gpm flow rate. The difference between the theoretical reduction factors and the experimental reduction factors is reasonably accurate with a difference less than $1.5 \%$, which can be attributed to the use of ambient temperature instead of 
the actual temperature of the receiving surface. The individual reduction factors as well as the average reduction factor for each flow rate are presented in Table 5.2.

Table 5.2 - Calculated theoretical and experimental reduction factors at sensors within the configuration factor

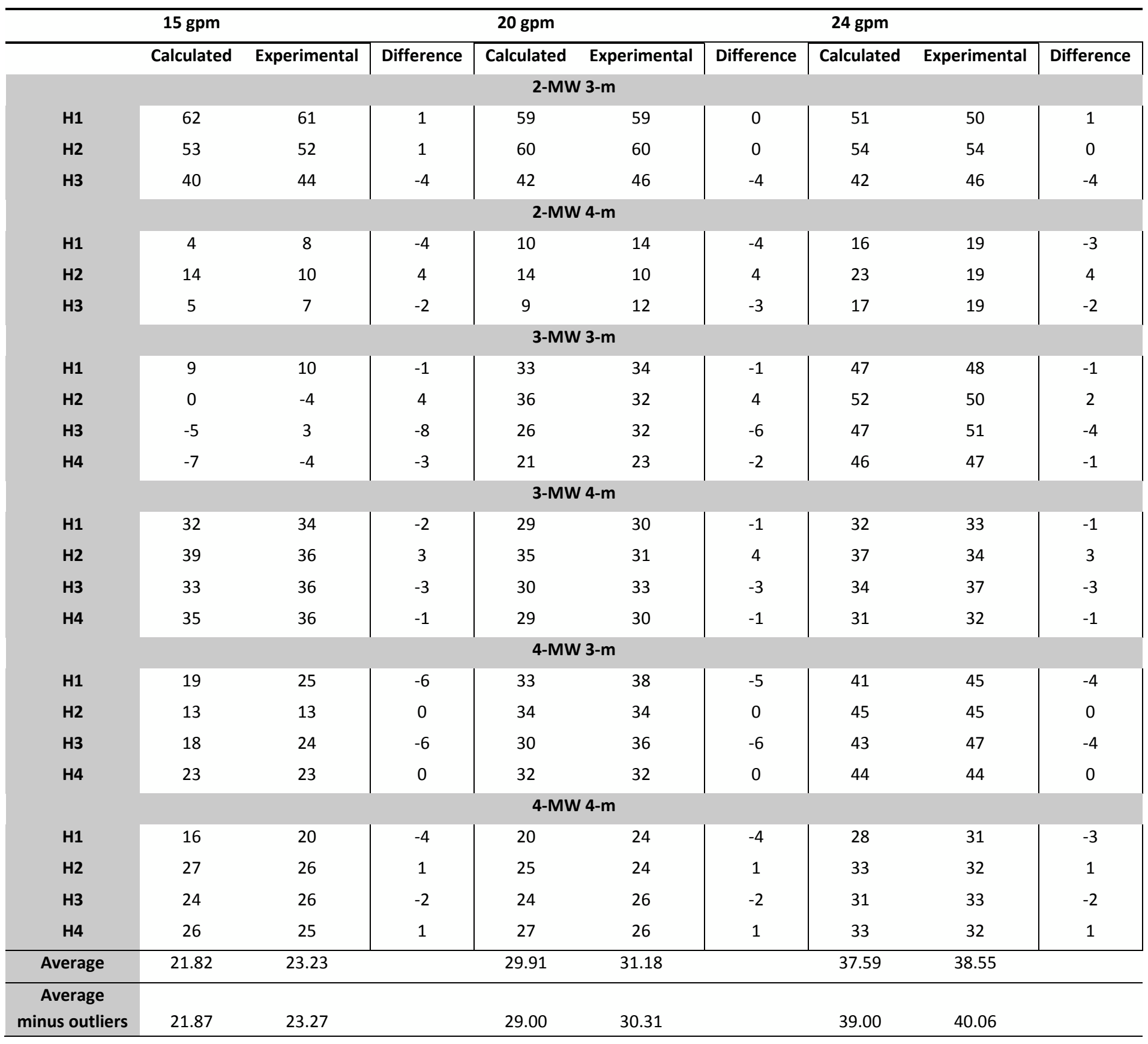




\subsection{Theoretical Heat Flux Calculations}

Using the average theoretical heat flux reductions the theoretical heat flux based on the reductions was calculated, using Equation 5.4.

$$
\begin{aligned}
& q_{t}^{\prime \prime}=\left(1-f_{t}\right) \varphi \varepsilon \sigma\left(T_{c}{ }^{4}-T_{a}{ }^{4}\right) \\
& q^{\prime \prime}{ }_{t}=\text { Theoretical Reduced Heat Flux } \\
& f_{t}=\text { Theoretical Reduction Factor } \\
& \varphi=\text { Configuration Factor } \\
& \sigma=\text { Stefan Boltzmann constant, } 5.67 \times 10^{-8} \mathrm{~W} / \mathrm{m}^{2} \mathrm{~K}^{4} \\
& T_{e}=\text { Average Compartment Temperature, } \mathrm{K} \\
& T_{a}=\text { Ambient Temperature, } \mathrm{K} \\
& \varepsilon=\text { emissivity, } \varepsilon=\left(\frac{1}{\varepsilon_{e}}+\frac{1}{\varepsilon_{r}}-1\right)^{-1}
\end{aligned}
$$

The theoretical reduced heat flux was calculated using a reduction factor of $21.9 \%$ for the $15 \mathrm{gpm}$ flow rate, $29 \%$ for the 20 gpm flow rate, and $39 \%$ for the 24 gpm flow rate. The theoretical heat fluxes were then compared with the actual experimental heat fluxes for all sensors, fires, and flow rates. All the individual heat fluxes were compared and the average of the absolute differences was calculated. The average accuracy of the absolute differences was found to be within $18 \%$ for the 15 gpm flow rate, $12 \%$ for the $20 \mathrm{gpm}$ flow rate, and $15 \%$ for the $24 \mathrm{gpm}$ flow rate. If the outliers are omitted the average absolute differences becomes accurate to within $11 \%$ for the 15 GPM flow rate, $9 \%$ for the 20 GPM flow rate, and $14 \%$ for the 24 GPM flow rate. The individual differences were to some extent accurate with a few tests showing large inaccuracies but the overall accuracy is reasonable, Figure 5.1. The heat flux comparisons can be found in Table 5.3. 


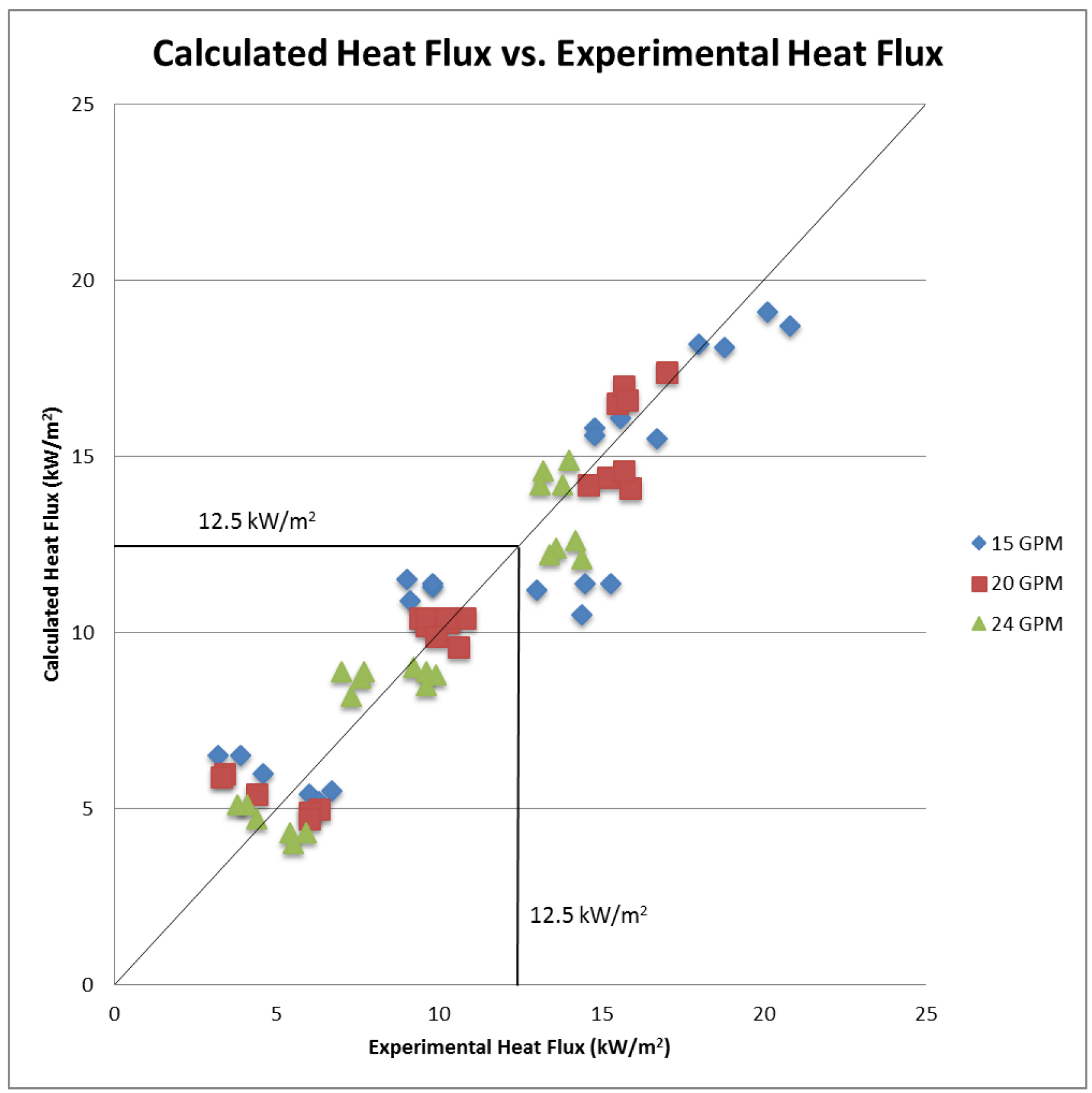

Figure 5.1 - Calculated and experimental heat flux differences with critical heat flux displayed 
Table 5.3 - Calculated theoretical and experimental heat fluxes at sensors with the configuration factor for each fire size and flow rate

\begin{tabular}{|c|c|c|c|c|c|c|c|c|c|}
\hline & 15 gpm & & & 20 gpm & & & $24 \mathrm{gpm}$ & & \\
\hline & Calculated & Experimental & Difference & Calculated & Experimental & Difference & Calculated & Experimental & Difference \\
\hline \multicolumn{10}{|c|}{ 2-MW 3-m } \\
\hline H1 & 6.5 & 3.2 & 0.51 & 6 & 3.4 & 0.43 & 5.1 & 4.1 & 0.20 \\
\hline $\mathrm{H} 2$ & 6.5 & 3.9 & 0.40 & 5.9 & 3.3 & 0.44 & 5.1 & 3.8 & 0.25 \\
\hline H3 & 6 & 4.6 & 0.23 & 5.4 & 4.4 & 0.19 & 4.7 & 4.4 & 0.06 \\
\hline \multicolumn{10}{|c|}{ 2-MW 4-m } \\
\hline H1 & 5.5 & 6.7 & -0.22 & 5 & 6.3 & -0.26 & 4.3 & 5.9 & -0.37 \\
\hline $\mathrm{H} 2$ & 5.4 & 6 & -0.11 & 4.9 & 6 & -0.22 & 4.3 & 5.4 & -0.26 \\
\hline H3 & 5.2 & 6.3 & -0.21 & 4.7 & 6 & -0.28 & 4 & 5.5 & -0.38 \\
\hline \multicolumn{10}{|c|}{ 3-MW 3-m } \\
\hline H1 & 11.2 & 13 & -0.16 & 10.2 & 9.6 & 0.06 & 8.7 & 7.6 & 0.13 \\
\hline $\mathrm{H} 2$ & 11.4 & 14.5 & -0.27 & 10.4 & 9.4 & 0.10 & 8.9 & 7 & 0.21 \\
\hline H3 & 11.4 & 15.3 & -0.34 & 10.4 & 10.8 & -0.04 & 8.9 & 7.7 & 0.13 \\
\hline $\mathrm{H} 4$ & 10.5 & 14.4 & -0.37 & 9.6 & 10.6 & -0.10 & 8.2 & 7.3 & 0.11 \\
\hline \multicolumn{10}{|c|}{ 3-MW 4-m } \\
\hline H1 & 11.3 & 9.8 & 0.13 & 10.3 & 10.3 & 0.00 & 8.8 & 9.9 & -0.13 \\
\hline $\mathrm{H} 2$ & 11.5 & 9 & 0.22 & 10.4 & 9.6 & 0.08 & 9 & 9.2 & -0.02 \\
\hline H3 & 11.4 & 9.8 & 0.14 & 10.4 & 10.2 & 0.02 & 8.9 & 9.6 & -0.08 \\
\hline H4 & 10.9 & 9.1 & 0.17 & 9.9 & 9.9 & 0.00 & 8.5 & 9.6 & -0.13 \\
\hline \multicolumn{10}{|c|}{ 4-MW 3-m } \\
\hline H1 & 18.1 & 18.8 & -0.04 & 16.5 & 15.5 & 0.06 & 14.2 & 13.8 & 0.03 \\
\hline $\mathrm{H} 2$ & 18.7 & 20.8 & -0.11 & 17 & 15.7 & 0.08 & 14.6 & 13.2 & 0.10 \\
\hline H3 & 19.1 & 20.1 & -0.05 & 17.4 & 17 & 0.02 & 14.9 & 14 & 0.06 \\
\hline $\mathrm{H} 4$ & 18.2 & 18 & 0.01 & 16.6 & 15.8 & 0.05 & 14.2 & 13.1 & 0.08 \\
\hline \multicolumn{10}{|c|}{ 4-MW 4-m } \\
\hline H1 & 15.5 & 16.7 & -0.08 & 14.1 & 15.9 & -0.13 & 12.1 & 14.4 & -0.19 \\
\hline $\mathrm{H} 2$ & 15.8 & 14.8 & 0.06 & 14.4 & 15.2 & -0.06 & 12.4 & 13.6 & -0.10 \\
\hline H3 & 16.1 & 15.6 & 0.03 & 14.6 & 15.7 & -0.08 & 12.6 & 14.2 & -0.13 \\
\hline H4 & 15.6 & 14.8 & 0.05 & 14.2 & 14.6 & -0.03 & 12.2 & 13.4 & -0.10 \\
\hline
\end{tabular}

\subsection{Discussion}

The results of the theoretical heat flux calculations based on the configuration factor, total emissivity, Stefan Boltzmann constant, average theoretical reduction factor, average compartment temperature, and ambient temperature, showed a good correlation with the experimental findings. It was found that the average reduction factor increased with flow rate increase which was expected. The 
discrepancies between the theoretical heat fluxes and the experimental heat fluxes can be attributed to the use of the ambient temperature instead of the actual temperature of the receiving surface.

It was found that the reduction effect of the water curtain could be determined with reasonable accuracy such that it can be applied to the radiation equation to determine the reduced heat flux. In order to verify the results the average reductions were compared to the experimental results with and without the outliers, resulting in a difference of less than $1.5 \%$ across all flow rates. When comparing the results of the theoretical and experimental reduced heat fluxes the average difference was less than $18 \%$ for the 2-MW tests and less than $12 \%$ for the $3-\mathrm{MW}$ tests and $15 \%$ for the $4-\mathrm{MW}$ tests.

These finding can help establish guidelines for determining safe separation distances with the inclusion of a water curtain. With further study into the effectiveness of the water curtain the reduction factor can be modelled more effectively such that the reduction can be calculated using the flow rate and density of the water curtain. 


\section{Conclusions and Recommendations}

\subsection{Conclusions}

The objective of this research was to conduct full scale experiments on compartment fires to study the contribution of a water curtain to the attenuation of radiation leaving a compartment and the spatial requirements within the National Building Code of Canada. This research contributes to the knowledge on the effect of water curtains for radiation attenuation for compartment fires. The results can be used to develop guidelines for spatial separations in construction and develop fire modelling tools to predict fire performance.

24 full scale fire tests were conducted between May 2014 and October 2015 at the Carleton University Fire Research Laboratory using a target wall and a compartment of non-combustible construction with propane as the fuel. Tests were conducted for three fire sizes, three flow rates, and two separation distances.

Data was collected on heat fluxes and temperatures at five locations on the target wall and three locations on the façade wall above the compartment. LabVIEW software was used to record and display the information. Estimated attenuation reductions were $21.9 \%, 29 \%$ and $39 \%$ for the three flow rates studied while the experimental reductions were $23.3 \%, 30.3 \%$ and $40.1 \%$, respectively. Based on the results, the inclusion of a water curtain reduced the radiant heat flux leaving a compartment allowing for reduced spatial separation. This reduction is able to be calculated to within a reasonable accuracy.

Based on the experiments and research conducted in this thesis the following conclusions can be drawn:

1. For all tests the use of a water curtain was able to reduce the heat fluxes along the target wall to minimize the ignition of combustibles in adjacent properties. 
2. For tests in which the heat fluxes were above the heat flux required for piloted ignition of wood the water curtain was wetting the target wall and preventing sparks from getting through to the target wall. This means that flame spread would not be possible without another flame source.

3. The water curtain was able to prevent upward flame spread by reducing the heat fluxes on the façade wall to within acceptable levels. The water curtain helps stabilize the turbulent flames and hot gases that were exiting the compartment and preventing the heat flux on the façade wall above the opening from reaching critical levels.

4. The piloted ignition of wood products criteria for the tests performed is a conservative value as the water curtain was preventing sparks from reaching the target wall. The water curtain was also wetting the target wall at close distances.

5. Heat flux and temperature reductions caused by the water curtain were found to be less effective as the separation distance increased.

6. With the use of a water curtain heat fluxes were low enough to allow for a reduction of spatial separation requirements.

7. The effect of the water curtain on the attenuation of radiation can be modelled to within a reasonable accuracy based on the flow rate of the water curtain.

\subsection{Recommendations for Future Work}

This research studied the ability of a water curtain placed over a compartment opening to attenuate radiation in order to protect adjacent property. The experiments conducted were on a single compartment with a single fixed opening. The factors that were tested included the flow rate of the water curtain, the fire sizes, and the separation distance. To ensure that the results of this research are used practically for assessing the performance of water curtains placed over compartment openings, further tests should be conducted using different compartment sizes and openings, as well as varying types of 
water curtains made with different sprinkler systems. In a building environment there are many possible parameters that could require different configurations that need to be studied.

Other research could perform experiments with different window sizes, model experiments using computational fluid dynamics models such as FDS, consider the use of water mist systems, and consider the effect of wind on the heat fluxes on the target wall.

In other areas of the world common construction materials may have different critical heat flux requirements. This research can be adjusted in order to compare reduced heat fluxes with critical heat fluxes of common construction materials, such as plastic cladding, in order to determine if a water curtain can be used as an effective fire protection system for other materials in those regions of the world. Comparison with building code requirements in those regions may allow for the installation of a water curtain to protect those materials.

In future research it would be beneficial to fully understand the effects of the water droplet contribution to radiation attenuation in order to better adapt their effect to the radiation equations commonly used in practice. 


\section{References}

[1] Canadian Commission on Building and Fire Codes, National Building Code of Canada (2010), National Research Council of Canada, 2010.

[2] Drysdale, Dougal. An introduction to fire dynamics. John Wiley \& Sons, 2011.

[3] Babrauskas, Vytenis, and Richard D. Peacock. "Heat release rate: the single most important variable in fire hazard." Fire safety journal 18.3 (1992): 255-272.

[4] Babrauskas, V. "Heat release rates. In 'The SFPE handbook of fire protection and engineering'." National Fire Protection Association, Quincy, MA (2002).

[5] Karlsson, Bjorn, and James Quintiere. Enclosure fire dynamics. CRC press, 1999.

[6] Gardon, Robert. "An instrument for the direct measurement of intense thermal radiation." Review of Scientific Instruments 24.5 (1953): 366-370.

[7] Kidd, C. T., and C. G. Nelson. How the Schmidt-Boelter gage really works. No. CONF-9505201--. Instrument Society of America, Research Triangle Park, NC (United States), 1995.

[8] Shannon, K. S., and B. W. Butler. "A review of error associated with thermocouple temperature measurement in fire environments." Second international wildland fire ecology an fire management congress and fifth symposium on fire and forest meteorology. American Meteorological Society, Orlando, FL. 2003.

[9] Quintiere, James. Fundamentals of fire phenomena. Wiley, 2006.

[10] Buchanan, Andrew Hamilton. Structural design for fire safety. Vol. 273. New York: Wiley, 2001.

[11] Walton, William D., and Philip H. Thomas. "Estimating temperatures in compartment fires." SFPE handbook of fire protection engineering 3 (1995): 3-188.

[12] Bwalya, Alex. "An overview of design fires for building compartments." Fire technology 44.2 (2008): 167-184.

[13] Heskestad, Gunnar. "Engineering relations for fire plumes." Fire Safety Journal7.1 (1984): 25-32.

[14] NFPA, NFPA. "204M-Guide for Smoke and Heat Venting." National Fire Protection Association (1995).

[15] Bwalya, Alex C., Noureddine Benichou, and M. A. Sultan. "Literature review on design fires." (2003).

[16] Waterman, T. E. "Room flashover-criteria and synthesis." Fire Technology 4.1 (1968): 25-31.

[17] Francis, Jonathan, and A. P. Chen. "Observable characteristics of flashover." Fire Safety Journal 51 (2012): 42-52. 
[18] McCaffrey, B. J., J. G. Quintiere, and M. F. Harkleroad. "Estimating room temperatures and the likelihood of flashover using fire test data correlations." Fire Technology 17.2 (1981): 98-119.

[19] Artim, Nick. "An introduction to fire detection, alarm, and automatic fire sprinklers." Northeast Document Conservation Center Preservation Leaflets (1999).

[20] National Fire Protection Association. "NFPA 13: Automatic Sprinkler Systems Handbook." (2010).

[21] Ndubizu, C. C., et al. "On water mist fire suppression mechanisms in a gaseous diffusion flame." Fire Safety Journal 31.3 (1998): 253-276.

[22] Keramida, E., A. Boudouvis Souris, and N. Markatos. "AN EULER-LAGRANGE METHOD FOR THE SIMULATION OF RADIANT ATTENUATION BY WATER MIST."

[23] Shorter, G. W., et al. The St. Lawrence Burns. Division of Building Research, National Research Council, 1960.

[24] Law, Margaret. Heat radiation from fires and building separation. London: HM Stationery Office, 1963.

[25] Law, Margaret. Radiation from Fires in a Compartment. HM Stationery Office, 1968.

[26] Lin, Ching-Yuan. "Study of exposure fire spread between buildings by radiation." Journal of the Chinese institute of engineers 23.4 (2000): 493-504.

[27] Chen, A., and J. Francis. "Radiant heat flux to external surfaces from escaping and extrusive flashover flames." Proceedings of the Institution of Mechanical Engineers, Part C: Journal of Mechanical Engineering Science 217.2 (2003): 247-256.

[28] Cheng, Hao, and George V. Hadjisophocleous. "Experimental study and modeling of radiation from compartment fires to adjacent buildings." Fire Safety Journal 53 (2012): 43-62.

[29] Keramida, E. P., et al. "Numerical modeling of radiant heat attenuation through water mist." Combustion science and technology 159.1 (2000): 351-371.

[30] Coppalle, A., D. Nedelka, and B. Bauer. "Fire protection: water curtains." Fire Safety Journal 20.3 (1993): 241-255.

[31] Parent, Gilles, et al. "Experimental investigation of radiation transmission through a water spray." Journal of Quantitative Spectroscopy and Radiative Transfer 97.1 (2006): 126-141.

[32] Hostikka, Simo, and Kevin McGrattan. "Numerical modeling of radiative heat transfer in water sprays." Fire Safety Journal 41.1 (2006): 76-86.

[33] Yang, Wenhua, et al. "The interaction of thermal radiation and water mist in fire suppression." Fire Safety Journal 39.1 (2004): 41-66. 
[34] Boulet, Pascal, Anthony Collin, and Gilles Parent. "Heat transfer through a water spray curtain under the effect of a strong radiative source." Fire Safety Journal 41.1 (2006): 15-30.

[35] Chow, Wan Ki, and Elaine YL Ma. "Experimental studies on thermal and smoke blockage by water curtains." 9th AIAA/ASME Joint Thermophysics and Heat Transfer Conference. 2006.

[36] Grant, G., J. Brenton, and D. Drysdale. "Fire suppression by water sprays." Progress in energy and combustion science 26.2 (2000): 79-130.

[37] Buchlin, Jean-Marie. "Thermal shielding by water spray curtain." Journal of loss prevention in the process industries 18.4 (2005): 423-432.

[38] Choi, C.L. "RADIATION BLOCKAGE EFFECTS BY WATER CURTAIN." International Journal on Engineering Performance-Based Fire Codes, Volume 6, 4 (2004): P.248-254.

[39] Wen, J. X., et al. "Numerical investigation on the effectiveness of water spray deluge in providing cooling, smoke dilution and radiation attenuation in fires." Fire Safety Science 9 (2008): 639-650.

[40] Ravigururajan, T. S., and M. R. Beltran. "A model for attenuation of fire radiation through water droplets." Fire Safety Journal 15.2 (1989): 171-181.

[41] Downie, Bruce, Constantine Polymeropoulos, and George Gogos. "Interaction of a water mist with a buoyant methane diffusion flame." Fire Safety Journal 24.4 (1995): 359-381.

[42] McCaffrey, Bernard J. Purely buoyant diffusion flames: some experimental results. NBSIR7919IO, National Bureau of Standards, Gaithersburg, USA, 1979. 


\section{Appendix}

\section{Appendix A}

\section{Pressure Requirements}

The water curtain pipe was designed such that the pressure could be determined and maintained for the system so the system would have the same flow rate at each sprinkler. The chosen flow rates for the tests were $15 \mathrm{gpm}, 20 \mathrm{gpm}$, and $24 \mathrm{gpm}$ at each sprinkler.

In order to create these flow rates the pressure at each sprinkler head as well as the pressure loss along the pipe needed to be determined. The required pressure was calculated using Equation A.1, which solved for the required pressure using the flow rate in GPM and the k factor for the sprinkler. The initial flow rate of $15 \mathrm{gpm}$ was chosen because it is the minimum flow rate that allows for operation of the sprinkler (sprinklers used in testing have a k factor of 5.6.

$$
P=(Q / k)^{2}
$$

The total length of pipe is $54.9 \mathrm{ft}$. with the first sprinkler being located at $42.9 \mathrm{ft}$. along the pipe. This length includes the total length of pipe and the equivalent lengths added for the four elbow joints. The length of pipe between each sprinkler is $6 \mathrm{ft}$. The Hazen-Williams roughness constant (C) is 120 for the $2 \mathrm{in}$. steel pipe. The total elevation of the system is $9.8 \mathrm{ft}$. The pressure required for the elevation is 4.234 psi. Equation A.2, The Hazen-Williams Equation, was used to calculate the pressure loss due to friction along the pipe at each sprinkler head.

$$
\begin{aligned}
& P_{L}=\frac{4.52 Q^{1.85}}{C^{1.85} d^{4.87}} L \\
& P_{L}=\text { Pressure Loss due to friction, psi } \\
& Q=\text { Flow Rate, GPM }
\end{aligned}
$$




$$
\begin{aligned}
& C=\text { Hazen-Williams roughness constant, } 120 \\
& d=\text { Internal diameter }, \text { in } \\
& L=\text { Length of pipe }, \mathrm{ft}
\end{aligned}
$$

The results of the pressure calculations are presented in Table A-1.

Table A.1 - Pressure requirements for the water curtain system

\begin{tabular}{cccccc|c|}
\hline $\begin{array}{c}\text { Flow Rate } \\
\text { Required per } \\
\text { Sprinkler } \\
\text { (Q) }\end{array}$ & $\begin{array}{c}\text { Pressure } \\
\text { required at } \\
\text { Sprinkler 3 } \\
\text { (psi) }\end{array}$ & $\begin{array}{c}\text { Pressure } \\
\text { Loss } \\
\text { Sprinkler 3 } \\
\text { (psi) }\end{array}$ & $\begin{array}{c}\text { Pressure } \\
\text { Loss } \\
\text { Sprinkler 2 } \\
\text { (psi) }\end{array}$ & $\begin{array}{c}\text { Pressure } \\
\text { Loss } \\
\text { Sprinkler 1 } \\
\text { (psi) }\end{array}$ & $\begin{array}{c}\text { Elevation } \\
\text { Pressure } \\
\text { (psi) }\end{array}$ & $\begin{array}{c}\text { Pressure } \\
\text { Total } \\
\text { (psi) }\end{array}$ \\
\hline 15 & 7.17 & 0.0169 & 0.0608 & 0.9201 & 4.24 & 12.42 \\
\hline 20 & 12.76 & 0.0287 & 0.1035 & 1.5667 & 4.24 & 18.70 \\
\hline 24 & 18.37 & 0.0402 & 0.1450 & 2.1952 & 4.24 & $\mathbf{2 4 . 9 9}$ \\
\hline
\end{tabular}

\section{Distance Requirements}

The National Building Code of Canada [1] Clause 3.2.3.1 Sentence 5 states: Except for buildings that are sprinklered, where the limiting distance is $2 \mathrm{~m}$ or less, individual unprotected openings in an exposing building face shall be no greater than

a) The area stated in Table 3.2.3.1.A., or

b) Where the limiting distance is equal to or greater than $1.2 \mathrm{~m}$, the area calculated by

$$
\text { Area }=0.24(2 * L D-1.2)^{2}
$$

Table A.2 - Table 3.2.3.1.A. From the National Building Code of Canada [1]

\begin{tabular}{cc}
\hline $\begin{array}{c}\text { Limiting Distance } \\
(\mathrm{m})\end{array}$ & $\begin{array}{c}\text { Maximum Area of Individual Unprotected Openings } \\
\left(\mathbf{m}^{\mathbf{2}}\right)\end{array}$ \\
\hline $\mathbf{1 . 2}$ & 0.35 \\
$\mathbf{1 . 5}$ & 0.78 \\
$\mathbf{2}$ & 1.88
\end{tabular}

The maximum area of the compartment opening is $3 \mathrm{~m}^{2}$ which means that the compartment being testing would fall under part b) of the aforementioned clause. The minimum limiting distance of the compartment being tested can be calculated by substituting the maximum area of $3 \mathrm{~m}^{2}$ into 
Equation A.3. The resulting limiting distance must therefore be greater than $2.37 \mathrm{~m}$. Therefore during testing the limiting distance was set to $3 \mathrm{~m}$, and $4 \mathrm{~m}$. 